Old Dominion University

ODU Digital Commons

Fall 2017

\title{
An Exploration of Career Decision-Making Among Domestic and International Instructional Design Students
}

\author{
Erin L. Mills \\ Old Dominion University, em1202@yahoo.com
}

Follow this and additional works at: https://digitalcommons.odu.edu/stemps_etds

Part of the Educational Psychology Commons, Higher Education Commons, and the Instructional Media Design Commons

\section{Recommended Citation}

Mills, Erin L.. "An Exploration of Career Decision-Making Among Domestic and International Instructional Design Students" (2017). Doctor of Philosophy (PhD), Dissertation, STEM Education \& Professional Studies, Old Dominion University, DOI: 10.25777/yn7g-tz44 https://digitalcommons.odu.edu/stemps_etds/26

This Dissertation is brought to you for free and open access by the STEM Education \& Professional Studies at ODU Digital Commons. It has been accepted for inclusion in STEMPS Theses \& Dissertations by an authorized administrator of ODU Digital Commons. For more information, please contact digitalcommons@odu.edu. 
AN EXPLORATION OF CAREER DECISION-MAKING AMONG DOMESTIC AND

INTERNATIONAL INSTRUCTIONAL DESIGN STUDENTS

By

Erin L. Mills

B.A. December 2003, Longwood University

MSEd. December 2008, Old Dominion University

A Dissertation Submitted to the Faculty of

Old Dominion University in Partial Fulfillment of the

Requirements for the Degree of

DOCTOR OF PHILOSOPHY

INSTRUCTIONAL DESIGN \& TECHNOLOGY

OLD DOMINION UNIVERSITY

December 2017

Approved by:

Jill E. Stefaniak (Director)

Tian Luo (Member)

Christopher Glass (Member) 


\begin{abstract}
AN EXPLORATION OF CAREER DECISION-MAKING AMONG DOMESTIC AND INTERNATIONAL INSTRUCTIONAL DESIGN STUDENTS
\end{abstract}

\author{
Erin Mills \\ Old Dominion University \\ Director: Dr. Jill Stefaniak
}

Graduate students encounter specific career difficulties in making career decisions, and turn to various sources of assistance, help-seeking resources and guidance (Gati, Gadasi \& Shemesh, 2005). Previous research into graduate student career needs have not sought to better understand the specific differences between international and domestic graduate students in instructional design. As a result, the factors that influence and impact graduate students in the context of their career decision making within an instructional design graduate program remain unexplored.

This mixed methods study captured actual career related difficulties of graduate instructional design students through a conceptual framework based on Bandura (1986) and Lent's (1994) social cognitive career theory, emphasizing the importance of interactions with key factors such as career readiness, access to career information and consistent and reliable career information. Participants recorded their levels of career decision-making difficulty through an online survey, the Career Decision Making Questionnaire (CDDQ), (Gati, Kraus \& Osipow, 1996). The CDDQ was used to measure: 1) lack of readiness, 2) lack of information and 3) inconsistent information. Independent t-tests compared mean scores per question in each category among the domestic and international student groups, indicating statistical significance. A demographic questionnaire added to the CDDQ captured participant's demographic 
information and resources utilized. A sample $(n=20)$ of the participants completed semistructured follow up interviews.

This study indicates that the current level of support for graduate students in instructional design may not be robust enough to support their needs. It also demonstrates the value of mixed method approaches toward better understanding instructional design students, their avenues for accessing career information, and the benefit of assisting students with career decision-making. The results demonstrate that graduate students have specific career needs and experience career decision-making difficulty regardless of country of origin, primarily in the pre-decision making phase and in working through internal and external sources of conflict. The psychosocial mechanisms revealed by this study can help educators (including professional organizations, university practitioners and academic advisors) better understand both domestic and international student's challenges, and eventually facilitate their academic and career success. 
Copyright, 2017, by Erin Mills, All Rights Reserved 


\section{DEDICATION}

This thesis is dedicated to Alexander Quinn. You have been my strongest source of motivation. I hope that when you think back over your childhood, during this time when I was in graduate school, you remember that your Mom gave it her all. I worried too much, failed at times and did not always get it right, but I tried hard to teach you about God's love, the importance of working diligently, and to put others first. I aspired to set an example of the value in obtaining an education in order to go as far in life as God and determination would allow. You and I have experienced firsthand His faithfulness and blessings in our lives, a testimony that far outlasts a degree program or its humble accomplishments! I love you - everyday no matter what - don't ever forget that! 


\section{ACKNOWLEDGEMENTS}

It takes a village! A large community of people supported me as I have pursued this dream and I owe them more thanks than I can ever possibly provide! Dr. Stefaniak, thank you for your time, guidance, and advising without which I would not have been able to turn my career aspirations into a reality! To my family and friends, thank you for the millions of ways you have supported and encouraged me over the years. I am incredibly grateful for your patience and love throughout this journey. Extra special thanks to Mom and Dad! I cannot even put into words my gratitude for your unwavering support, love and encouragement. You have always been my firm foundation - even when life took me by surprise - you were (and still are) by my side helping to see me through some of life's most difficult challenges. Beyond the support you have provided, your leap of faith as missionaries is a testimony that God wastes nothing. The fruit of that labor is evidenced in part by this research project. Following God's direction has had a ripple effect of blessings that have gone far beyond your time in the field - extending to me and all the international students I have interacted with as a result. Hundreds of us owe it to you both to say thank you! 
TABLE OF CONTENTS

A COMPARATIVE ANALYSIS BETWEEN THE CAREER NEEDS OF DOMESTIC AND INTERNATIONAL INSTRUCTIONAL DESIGN STUDENTS ....................... i

LIST OF TABLES $\quad$.................................................................. vii

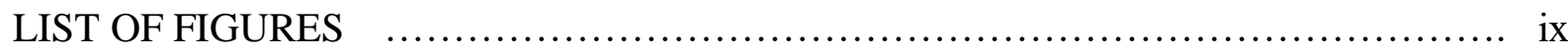

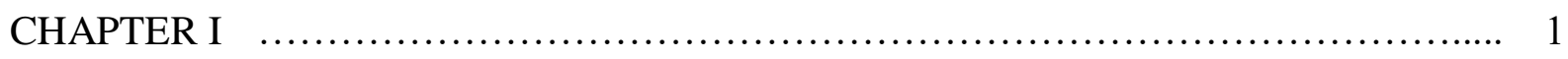

INTRODUCTION AND LITERATURE REVIEW …......................... 1

Literature Review ...................................................... 16

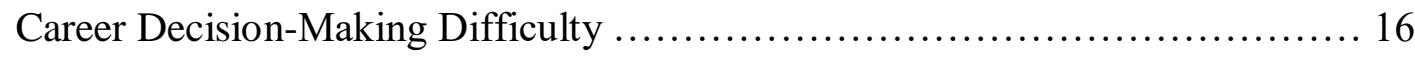

Self-Efficacy and Help Seeking in Career Development ........................ 18

Specific Career Needs of International Students ............................ 21

Help-Seeking Behavior Among International Students ....................... 22

Barriers to Help-Seeking within Social Cognitive Career Theory ............... 25

Resources Through Professional Organizations ............................ 28

Professional Development .............................................. 29

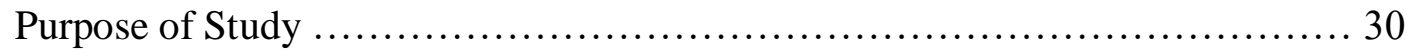

Research Questions .................................................. 31

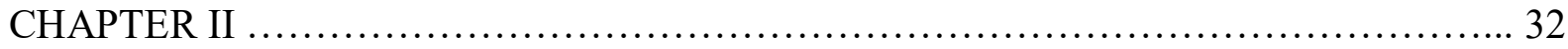

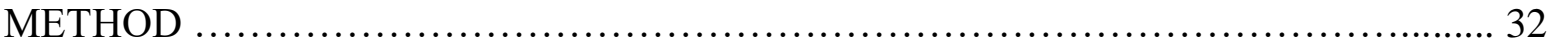

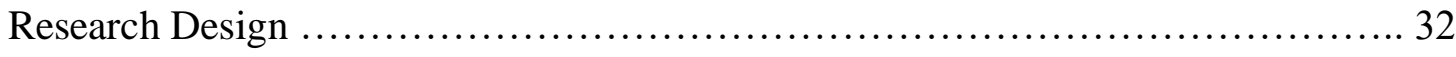

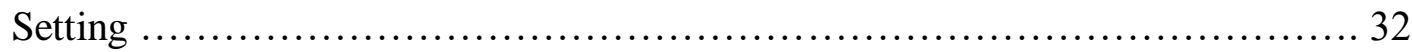

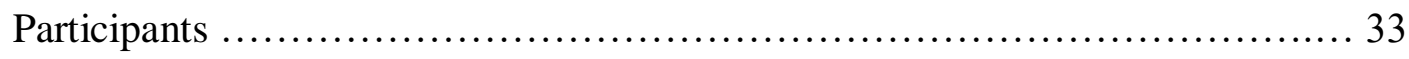




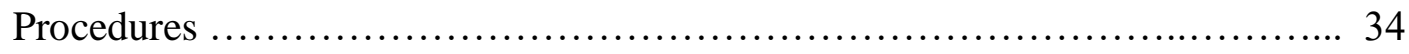

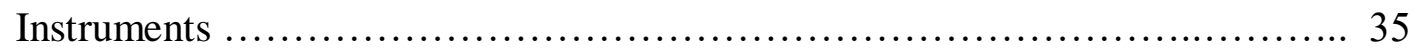

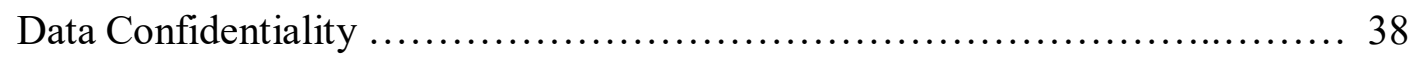

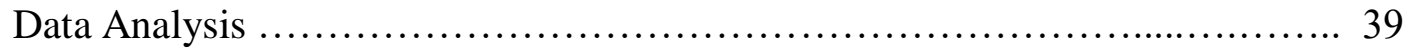

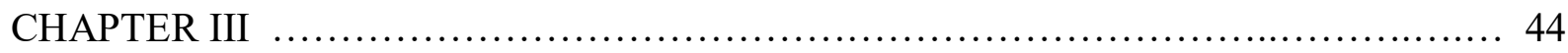

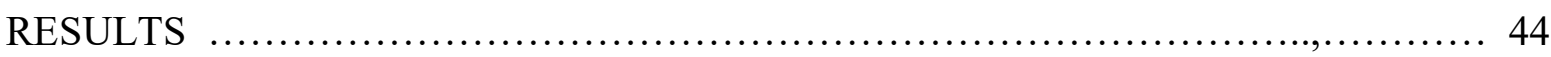

Career Needs of International and Domestic Instructional Design Students ........ 46

Career Decision-Making Difficulties Students Encounter $\ldots \ldots \ldots \ldots \ldots \ldots \ldots \ldots \ldots . \ldots 1$

Help-Seeking Resources Students Utilize ............................... 54

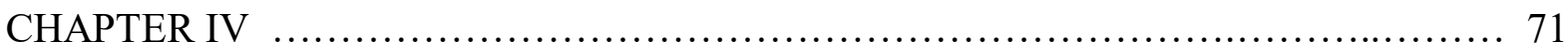

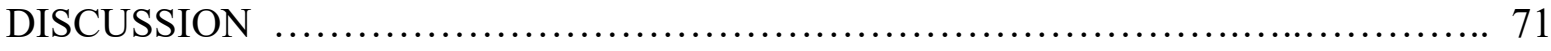

Implications for Academic Advisors . .................................... 73

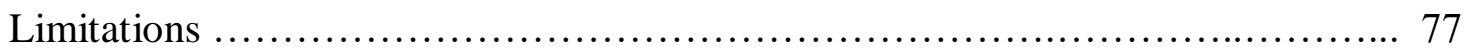

Future Research .......................................................... 79

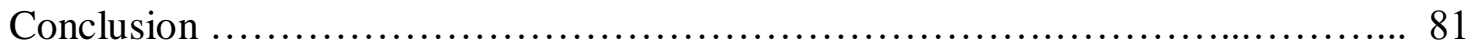

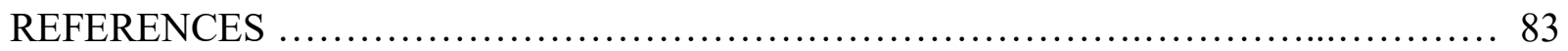

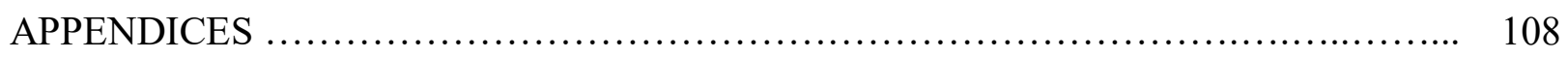

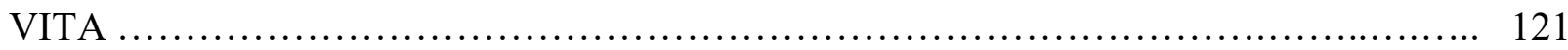




\section{LIST OF TABLES}

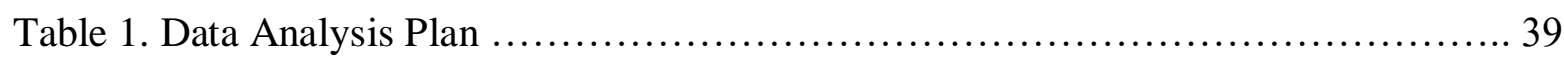

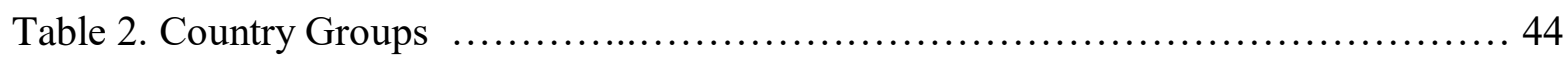

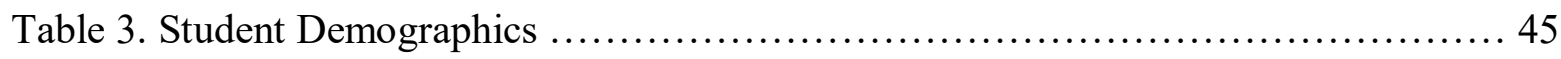

Table 4. Readiness Results Q1-Q12 ........................................ 48

Table 5. Lack of Information Q13-Q24 ..................................... 52

Table 6. Inconsistent Information Q25-Q35 .................................. 56

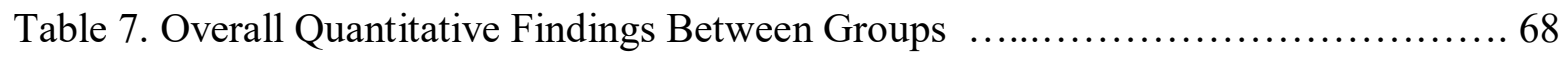

Table 8. Overall Qualitative Findings Between Groups $\ldots \ldots \ldots \ldots \ldots \ldots \ldots \ldots \ldots \ldots \ldots 69$ 


\section{LIST OF FIGURES}

Figure 1. Readiness ........................................................ 47

Figure 2. Lack of Information ............................................... 52

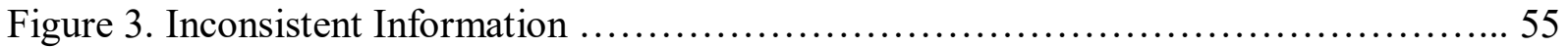




\section{CHAPTER I \\ INTRODUCTION AND LITERATURE REVIEW}

"I am not crazy, I just do not know what to do!", my friend exclaimed in response to my suggestion that she seek career counseling in helping her prepare for an upcoming job search. As her brown eyes began to flood with tears, she looked away and added; "I just feel so overwhelmed... I came here for a job, a better chance, but this is harder than I expected, and I only have a few short months to make it happen... it has to happen.” (E. Mills, personal communication, March, 2015). "I understand", I replied, while searching for the right words to say. I quickly realized the misconception between needing career assistance and a cultural stereotype associated with the English word "counseling" could be creating an unnecessary barrier. Her visa was time sensitive, and her stress level was high. Coupled with the uncertainty of having to navigate the job search process in a foreign language and culture, her career decision-making attempts thus far had failed to provide her accurate, timely or reliable resources. She was not the first international student to express to me the difficulties in making complex career decisions upon graduating from college. I began to wonder just how different domestic and international student's career needs were and where, or with whom, international students sought assistance. I needed to dig a little deeper to find out more.

\section{A Definition of Career Decision-Making Difficulty}

The Institute for International Education (2016) suggests that the number of international students studying at universities in the United States continues to increase, thus compounding the need for timely and culturally competent resources. Within the 2015/2016 academic year, the number of international students increased by $7 \%$ to a record high of 1,043,839 students, with 
69,000 more students compared to the previous year. The majority of these international students originate from: China (32\%), India (16\%), and Saudi Arabia (6\%), representing a combined total of $54 \%$ of the total enrollment of international students in the United States. Their top fields of study include engineering, business management and math, and computer science (IIE, 20116). While most of the international students are seeking a bachelor's degree (over 400,000 students), these enrollments are close in comparison to those seeking graduate degrees (over 350,000 students). Contributing overall \$35 billion dollars to the United States economy, international students are making significant contributions in higher education throughout the United States.

The National Association for Colleges and Employers (NACE), connects college career service professionals in nearly 2,000 colleges and universities nationwide and is the leading source of information on the employment of college students. NACE forecasts trends in the job market, tracks salaries, informs recruiting and hiring practices and identifies best practices in career services. They have defined career readiness as "the attainment and demonstration of requisite competencies that broadly prepare college graduates for a successful transition into the workplace (naceweb.org)". Gati and Asher (2001) define career decision-making as the process people go through when they search for career alternatives, compare them, and make a choice. Often first steps in the career-decision making process begin in college, and just as important as understanding ideal career decision-making behaviors and attitudes, it is also important to understand the challenges associated with career decision-making (Mau, 2004).

\section{Three Types of Career Decision-Making Difficulty}

Several factors can contribute to decision-making difficulties among job seekers. Often indecision occurs during the early stages of the career decision-making process, particularly for 
college students who may have difficulty making a decision due to a) lack of readiness, b) lack of information or c) inconsistent information (Gati, Krausz, \& Osipow, 1996).

Lack of Readiness. Lack of readiness is the only career decision-making category to take place prior to beginning the decision making process (Gati, Krausz \& Osipow, 1996). This category includes three subcategories that may prove as obstacles to a student's willingness or readiness to begin the career decision-making process: a) lack of motivation to begin the process, b) general indecisiveness regarding all decisions, and c) dysfunctional beliefs or irrational expectations (Nevo, 1987) regarding the process (Gati, Saka \& Krausz, 2001).

Lack of Information. Lack of information is an area of difficulty occurring during the career decision-making process (Gati, Krausz \& Osipow, 1996). This category includes four subcategories pertaining to lack of information about: a) self, b) occupations, c) career alternatives, and d) ways to obtain additional information about self or occupations (Gati, Saka \& Krausz, 2001).

Inconsistent Information. Like the above-mentioned categories, inconsistent information is also an area of difficulty occurring during the career decision-making process (Gati, Krausz \& Osipow, 1996). A student may experience difficulty relating to inconsistent information from one of three subcategories: a) unreliable information, b) internal conflicts, and c) external conflicts (Gati, Saka \& Krausz, 2001) all of which vary based on individualized experiences and background.

In combination, career readiness, and the use of consistent and reliable information leads to job search clarity. Within a social cognitive theory framework, job search clarity helps students overcome career decision-making difficulty. In particular, Wanberg, Hough, and Song 
(2002), defined job search clarity as the extent to which job seekers have a clear understanding of career information including types of occupations, alternatives or desired employment. Job seekers who lack job search clarity may not have the resources or be aware alternate options needed in order to make an informed decision (Gati, Krausz \& Osipow, 1996; Wanberg et al., 2002). On the other hand, job search clarity can direct activities pertaining to career decisionmaking through a process of self-regulated learning and help-seeking (Lent, Brown, \& Hackett, 1994).

International Student Indecision. Despite their desire to study and work in the United States, career decision-making can present many challenges for international students as language barriers, academic differences and vocational concerns attribute to factors leading to stress and indecision (Leong \& Sedlacek, 1986; Mori, 2000; Pederson, 1991; Sandhu \& Asrabadi, 1994). These factors combined define acculturative stress. At many institutions, international students have reported experiencing more need for counseling services compared to their American counterparts, however they are often hesitant to seek assistance (Byon, Chan \& Thomas, 1999; Kilinc \& Granello, 2003; Mori, 2000; Nilsson, Berkel, Flores \& Luca, 2004, Singaravelu, White \& Bringaze, 2005; Zhang \& Dixon, 2003). Depending on factors such as age, length of stay in the United States or familiarity with a college environment, the resulting culture shock and acculturative stress can take on many forms including negative symptoms associated with lower career aspirations and outcome expectations (Reynolds \& Constantine, 2007), lower social self-efficacy and higher levels of anxiety (Constantine, Okazaki, \& Utsey, 2004).

While studies have outlined the need for improved career guidance and career counseling, most recent studies have narrowed student populations by life span, counselor training, and culture-specific career resources (Dagley \& Salter, 2004; Goodman \& Hansen, 
2005; Guindon \& Richmond, 2005; Harris-Bowlsbey, 1996; Hartung, 2005; Herr, 1996; Plant, 2004; Savickas, 1997; Tractenberg, Streumer, \& Van Zolingen, 2002). Research on the needs of international students studying in the United States have typically emphasized 5 main areas of concern: 1) academics; citing academic challenges associated with language and course structure as a main concern (Deressa \& Beavers; 1988; Mau \& Jespen, 1990; Parr, Bradley \& Bingi, 1992) , 2) physical health, when international students have difficulties interacting with United States health care providers and understanding the health care system (Prieto, 1995)

3) financial concerns, if and when students face financial hardships due to their limited visa status and immigration regulations prohibit them from working off campus (Mori, 2000) 4) vocational concerns, in relation to deciding between a home and host country careers (Cadieux \& Wehrly, 1986) and most commonly reported 5) social challenges, which involve isolation, homesickness, and symptoms associated with depression (Das, Chow \& Rutherford, 1986; Cadieux \& Wehrly, 1986).

\section{Instructional Designers}

Richey, Klein and Tracey (2011, p. 8), define instructional design as "the science and art of creating detailed specifications for the development, evaluation and maintenance of situations which facilitate learning and performance" and instructional designers have been charged with "translating principles of learning and instruction into specifications for instructional materials and activities" (Smith \& Ragan, 1993, p. 12). In order to achieve this the instructional designer must be able to demonstrate their understanding of the problem through careful analysis of the context and learners to bridge the "gap" with a solution that facilitates human learning (Ertmer, \& Newby, 1993). 
Stolovitch \& Keeps (2006) describe how the field has evolved over time from a number of disciplines such as psychology, communications, neuro-science, management science, information science, economics, ergonomics and measurement and evaluation. Also included in the definition are applied fields such as instructional technology, human resource development, organizational development, and industrial engineering (Stolovitch \& Keeps, 2006, p.xiii). Instructional design, and more specifically efforts aimed at impacting human performance, have grown to become a "distinct specialty with its own international, national and local professional societies as well as numerous publications, university programs and certification structures relevant and essential for today's organizational success" (Stolovitch \& Keeps, 2006, p.xiii).

Careers in Instructional Design and Technology. The $21^{\text {st }}$ century poses challenges to educators - including instructional designers - as learner's attitudes toward learning and technology evolve at a very fast pace. There are many examples in literature that discuss who instructional designers are, what they do as professionals, the instructional design models they use, and the challenges they face (Cox \& Osguthorpe, 2003; Gibbons, 2003; Gibby, Quiros, Demps, \& Liu, 2002; Rowland, 1992; Schweir, Hill, Wager, \& Spector, 2006). Richey, Fields \& Foxon (2001), specify four specific challenging roles for the instructional designer: analyst, evaluator, e-learning specialist, and project manager, and most recently instructional designers have been referred to as "agents of change" (Schwier et al., 2006; Yusop \& Correia, 2012). The challenge in describing the profession is that it takes on different tiles, roles, and responsibilities both around the world and even within the same institution or organization (Sharif \& Cho, 2015). According to Reiser, (2001), instructional design was not recognized as its own field until the 1960 's, and because of the vague descriptions of the profession, the poorly informed perceptions 
of instructional designers could pose challenges to professional identities, and may negatively impact the status of instructional designers in the workplace.

Schwier et al., (2006), described how the instructional designer's primary concern should be their identity, emphasizing the need for multiple identities, roles and activities that define why instructional designers practice, rather than how they practice; insinuating that instructional designers may be acting as agents of social change more than they realize. The study further explains the confusion surrounding why people come to instructional designers only as an afterthought as the "grand purpose" and understanding of instructional design is not shared among instructional designers themselves.

This lack of consistency in the expectations and identity of instructional design adds a complex layer to the career decision-making process. Due to the evolving nature of this field, professional development for individuals in this field is no simple task, and must foster continuous collaboration to be as dynamic as the domain itself with emphasis on continuous collaboration and refinement for a magnitude of roles. Furthermore, aiding instructional designers in career decision-making should take into consideration the alignment with the nature of the work, and cultural context of its workers. Not all people experience success in finding college majors and jobs that match their attributes, rather understanding oneself is the first step in finding a career that is a good fit. However, this goal is often inhibited by the fact that many students lack an understanding about themselves or the job market (Gati, Krausz \& Osipow, 1996).

As education and the economy continue to change, new graduates cannot stay static. To be prepared to respond to change, instructional designers not only need to strive for life-long learning, but for the cooperative exchange of challenges, ideas and best practices (Sharif \& Cho, 
2015). Therefore, it is increasingly important for current and prospective students to understand career options, and the ways in which their education prepares them for the world of work. This is even harder for international students who must in addition to navigating a traditional job search, must adjust to a new culture, set of values and expectations of a particular discipline, department or profession in a host country (Arthur, 2007; Savickas, 1997).

In order to make wise career decisions, students must identify their personal characteristics and take into consideration how those align with information about their chosen vocation (Jespen, 1984; Mau, 2001). Individuals must account for ways internal and external factors may interfere with the decision-making process, such as procrastination, or pressure from society or family and prepare to become lifelong learners. Continuous professional development may create the need to focus career efforts toward specific academic populations, or identify critical needs for professionals who can effectively guide and counsel students of culturally diverse backgrounds. Exploring the career readiness and career decision-making of international instructional designers will extend career resources beyond the educational organization and create a foundation for understanding the pressures and needs of this population.

The challenges in responding to the career needs of international students (Shen \& Herr, 2004) and the assumption that domestic and international students need the same career resources warrant further investigation. International instructional design students are a minority population that may not have the voice to successfully advocate for their career needs. This may be because they are unaware of the need for career readiness skills, may not readily acknowledge the depth of the career decision-making process, and/or may not interpret their situations as ones in need of assistance. They therefore may be less likely to seek career assistance or resources available on campuses or within professional development organizations. In turn, practitioners 
and university personnel working with international instructional design students would be unaware of their needs and would subsequently be less likely to intervene or offer assistance when necessary (Mau, 2001). Findings from this study will help fill the gap that exists in current research and therefore benefit students, faculty and professional organizations who work with international students in instructional design. The following outlines important factors in a student's career decision-making process beginning with an explanation of Social Cognitive Career Theory, self-efficacy and perceived barriers to success. This chapter concludes by explaining how self-regulated learning and help-seeking behaviors intersect with external, experiential and internal influences.

\section{Theoretical Framework}

\section{Social Cognitive Career Theory}

Few theories are as comprehensive in describing social learning for job seekers as the Social Cognitive Career Theory (SCCT). This theory is used to explain the relationships between career-relevant activities, (environmental and self-career exploration, career resources and training), and self-regulatory variables (job search self-efficacy and job search clarity). Social cognitive career theory explains interaction between behavior, cognitive and other personal factors and environmental events. These factors interact as determinants in a process known as triadic reciprocal causation (Bandura 1986). In recent years, SCCT has been used to better understand the career development processes (Lent, Brown, \& Hackett, 1994) and according to Lent et al. (1994), SCCT describes how people's environments expose them to career relevant activities that influence the development of self-efficacy, outcome expectancy and goals/interests that influence career decision-making. 
Self-Efficacy. Self-efficacy has been defined as the belief in one's ability to successfully perform a specific task and has been linked to a series of behaviors including persistence in the midst of obstacles and successful performance (Bandura, 1977, 1986). Bandura's (1977) theory of self-efficacy is widely used as a foundation for behavioral studies, including career decisionmaking (Betz \& Hackett 1981; Foltz \& Luzzo, 1998; Peterson \& delMas, 1996; Quimby \& O’Brien, 2004; Ryan, Solberg, \& Brown, 1996; Taylor \& Betz, 1983; Tien, Lin \& Chen, 2005; Zeldin \& Pajares, 2000) and focuses on personal belief or level of self-confidence that a course of action will lead to the mastery of a task or behavior. He asserted that self-efficacy is dynamic and can be developed through a process by which an individual acquires and retains new behavioral patterns. Bandura's theory states that individuals with high self-efficacy will persist in an activity or move toward a goal, such as career decision-making, even when the outcome is uncertain requiring an individual to overcome perceived or actual barriers. Bandura (1997) described four resources for creating and strengthening self-efficacy: a) enactive mastery experiences, b) vicarious (e.g. modeled) experiences, c) verbal persuasion and d) physiological and affective states. Bandura proposed that successful accomplishments in these four areas results in positive self-efficacy expectation.

Enactive Mastery Experiences. Enactive mastery experiences refer to one's past experiences from which an individual refers to the skills or abilities that were vital to the success of a task in the past, and applies them to the likelihood for success of a similar task in the present. By drawing on past experiences, individuals can decide if they possess the appropriate abilities to succeed with the new task (Bandura, 1997). The degree to which an individual recognizes mastery experiences and is able to discern effort and difficulty in the present task will form personal self-efficacy. An individual with a high sense of self-efficacy is inclined to 
attribute deficient performances to unfavorable situational factors, lack of effort, or poor strategies; comparatively those with low self-efficacy tend to ascribe their deficient performances to low ability (Bandura, 1997). As people develop and accumulate new experiences, they continue to reconstruct a pattern of past successes and failures and determine conditions under which these successes and failures have occurred. This process of selfreflection allows individuals to strengthen self-efficacy and determine what it takes to succeed (Bandura, 1997; Brown \& Lent, 2006).

Vicarious Experiences. Vicarious experience is obtained by observing a peer's achievements and comparing one's ability to those of someone else. When people witness others like themselves achieve success, they may be able to persuade themselves that they possess the same ability to achieve success; consequently improving their self-efficacy (Schunk et al., 2009). In most cases the greater the assumed similarity between the individuals, the more persuasive the models for success and failure. These thoughts and comparisons can be effective when enhancing self-efficacy.

Verbal Persuasion. When a person reflects on their own experiences, self-appraisals stem partly from the opinions of significant others. Verbal persuasion can be considered a means for strengthening self-esteem and fostering an individual's belief in their ability to succeed. The degree to which the verbal persuasion has influence on an individual depends on who the persuaders are, their knowledge and their credibility (Bandura, 1997). People tend to believe most evaluation that comes from others who are competent, skillful and knowledgeable in their related fields. Conversely, derogatory verbal persuasion can reduce self-efficacy and diminish aspirations. The power of verbal persuasion should not be underestimated as it influences one's 
belief in their potential and can shape the course or outcome of an individual's decision-making (Bandura, 1997).

Physiological and Affective States. Physiological factors such as a nervous heartpounding or stomachaches can partly influence the capability of an individual to develop selfefficacy for a particular behavior or task. The extent to which somatic experiences trigger or influence individual's physiological state differ based on an individual's focus and interpretation or perception. The extent to which an individual can reduce stress levels, and correct negative emotions will impact their ability to enhance their self-efficacy (Bandura, 1997).

Self-efficacy develops through one or more of the four factors mentioned above. Individuals with low self-efficacy might try and avoid certain tasks, seeking only those activities and environments which they believe themselves to be capable of handling. Comparatively, those with high self-efficacy might attempt to attain and maintain mastery of most types of tasks. Bandura (1997) stated "individuals who approached the employment problem with confidence in their capability to find a job were able to ferret out job opportunities and present themselves sufficiently well to gain job offers" (p. 429). Within modern career decision-making, the degree to which an individual can relate to personal life, ability and achievement as well as their own expectation for stress management impacts their decision-making and how much effort they are willing to put into their career path. Self-efficacy plays a crucial role in helping individuals cope with the realities of the changing demands for career readiness (Bandura, 1997) and can influence a student's willingness to seek assistance.

\section{Self-Regulation as Help-Seeking within Career Decision-Making}


In today's knowledge-driven economy goal setting and goal attainment is essential to future academic pursuits, employment opportunities and career decision making (Kenny, Bluestein, Haase, Jackson \& Perry, 2006). Because of the desire to achieve and succeed has been highlighted in individual career development, how well students seek out and acquire career related knowledge, skills and abilities will impact their career decision-making in the future. According to Lapan (2004), academic achievement and goal setting play a pivotal role in the selection of career paths and may increase or diminish employment opportunities. Emphasizing the enhancement of academic achievement as it pertains to decision-making, Zimmerman and Schunk (2004) described self-regulated learning as foundational for improving student success. Lapan (2004) integrated achievement of self-regulated learners into a context model of career development by describing how an individual's style of engagement toward a possible career develops within an interwoven structure of demographic, social-cultural, economic and political contexts. This model includes six primary constructs, a) the preservation of positive expectations, b) the development of career exploration and goal formation, c) the generation of enhanced self-understanding of occupational possibilities, d) the pursuit of one's intrinsic interests and preferences, e)the self-regulated ability to achieve academically, and f) the possession of social skills and work-readiness behaviors (Lapan, 2004). Each of the six constructs can promote change or rigidity within the process and can provide an individual a basis for approaching career readiness (Lapan, 2004; Turner \& Conkel, 2010).

Help-seeking. To demonstrate career readiness, individuals will need information and insight that may come by way of seeking assistance from other people or seeking nonhuman sources of information such as written resources and online material (Zimmerman \& Pons, 1986). Help-seeking is an important component of self-regulated learning and is central to the 
career decision-making process (Lapan, 2004). Lapan (2004) presented a three-step sequence to describe the characteristics of self-regulated learning theory. The first step stresses the strategies adopted by self-regulated learners during the planning performance and outcome phase (Lapan, 2004). The second highlights how self-regulated learners use help-seeking strategies and the third step summarizes valued outcomes from engaging self-regulated learners during the learning process (Lapan, 2004; Lapan, Kardash \& Turner, 2002).

In the first step, utilizing a self-regulatory cycle proposed by Zimmerman (2000), Lapan (2004) highlights a three-phase self-regulatory cycle involving forethought, performance control and self-reflection. The forethought phase suggests individuals would purposefully engage in learning, and employ task analysis and self-efficacy. By setting meaningful goals, and developing procedural and conditional knowledge corresponding to their career planning, individuals could devote themselves to enhancing their decision-making (Lapan, 2004; Lapan et al., 2002; Zimmerman, 2000). The performance control phase of the learning process involves self-control and self-observation. By refining learning using a variety of strategies, such as task simplification and help-seeking, individuals could prioritize next steps and make more effective decisions by gaining feedback on changes needed in order to reach a performance goal (Lapan, 2004; Zimmerman, 2000, 2008). The third and final self-reflection phase allows learners to evaluate their performance and promote self-improvement, collaboration and goal attainment (Lapan, 2004). Self-regulated learners are likely to blame their poor performance on insufficient efforts or ineffective strategies and upon self-reflection, may make appropriate changes or changes in strategies to improve performance in the future.

When students engage in this three-step phase self-regulatory cycle, they are likely to make adjustments to their help-seeking and learning activities. Step two in Lapan's three-step 
sequence describes how self-regulated learners are willing to internalize the need to learn about uninteresting tasks. This may lead students to seek assistance, more information, or ask for help. As students do more of these externally motivating behaviors, they are likely to experience more self-determination in their career decision-making (Lapan et al., 2002).

In step three, students who practice the three-phase self-regulatory cycle are more engaged in learning activities. Levels of engagement have been found to be associated with social and cognitive development (Lapan, 2004). The more self-regulated learning strategies the engaged students use, the more enhanced their sense of satisfaction levels was (Lapan, Kardash, \& Turner, 2002). According to Lapan (2004), by completing these three steps, learners can internalize and integrate proactive and self-directed strategies into their learning process and adapt appropriate performance enhancing means to pursue their future career path.

\section{Summary}

The goals of this study are shaped by social cognitive career theory and its impact on the career decision-making process. SCCT acknowledges factors such as race/ethnicity, culture, gender, overall ability and help-seeking tendencies in career transition and supports an understanding of formative career interests in a variety of contexts (Russell \& Petrie, 1992; Peterson \& Delmas, 1996; Astin, 1999, Tinto, 1993). Shaping career awareness and resources help to strike a balance between challenge and support. By comparing the perspectives among international and domestic students, this type of inquiry can help insure that culturally inclusive and contextually comprehensive career support services are in place that can contribute toward a student's ability to make well-informed career decisions. 


\section{LITERATURE REVIEW}

\section{Career Decision-Making Difficulty}

The majority of students will have to make career decisions including identifying career problems to solve (Holland, 1973). Career decision-making difficulty is becoming an important construct in understanding the career development of college students and has been linked to career indecision (Mau, 2001; Osipow \& Gati, 1998). Career indecision has been referred to as a problem that occurs during the career decision-making process and Gati and Asher, (2001), define career decision-making as the process people go through when they search for viable career alternatives, compare them and then choose one. Often, the first step to choosing a career begins in college. Students choose to attend a college for a variety of reasons, but many attend primarily to prepare for a successful career. Students typically choose a college major that relates to a chosen career field. However, these decisions are often difficult to make, especially for international students as career decision-making is often made prior to matriculation. All students may experience some level of anxiety and conflict at some point during the process that will require them to set goals and make independent decisions regarding their employment (Chickering \& Reisser, 1993).

Employment is an important step in achieving a successful college to career transition, and it is vital that students take proactive steps to be resourceful by becoming more aware of their strengths and weaknesses and specific career development needs (Rothman, Maldonado \& Rothman, 2008). However, career decision making difficulty, as it relates to international students, has been a continual concern among faculty, staff and international students (Mau, 2000). Blustein \& Ellis (2000) argued that one of the greatest challenges for career assessment in the $21^{\text {st }}$ century is the need to affirm cultural diversity in order for resources to be relevant for all 
cultural groups (Fouad \& Zao, 2000), however these cultural implications have remained relatively unexamined.

It is well documented that students who struggle with uncertainty for long periods of time are more likely to leave college without completing a degree program (Blustien \& Ellis, 2000; Gati, 1996; Gordon, 1995; 1998; Jurgens, 2000; Tinto, 1993). A large number of international students are uncertain about long-term career goals for a variety of reasons (Bluestien \& Ellis, 2000) and current research conducted into career transition needs of international students indicate various levels of career readiness as some students lack information about personal values, interests, skills, career options or decision making resources (Gati, 1996; Gordon, 1995; 1998; Jurgens, 2000). In addition, student may be unprepared to make a college to career transition because they lack readiness to begin the decision making process or because they have received unreliable or inconsistent information (Gati, Krausz \& Osipow, 1996). Often through a college experience, students may change their minds about their career path (Gordon, 1995).

Regardless of the reason, the magnitude of international student career needs and their preference for seeking career guidance is typically divergent from domestic students (Cheng, Leong, \& Geist, 1993; Crockett \& Hayes, 2001; Leong \& Sedlacek, 1986; 1989; Manese, Leong \& Sedlacek, 1995; Yang, Wong, Hwang \& Heppner, 2002). Contributing variables including competing cultural values, language barriers, differences in home and host educational systems, and diverse levels of student expectation for, and definitions of, success set them apart from domestic students (Cheng, et.al, 1993; Hayes \& Lin, 1994; Leong \& Sedlacek, 1986;1989; Misra, Crist \& Burant, 2003; Sandhu \& Asrabadi, 1994).

If international students are to perceive their educational experiences as being supportive and relevant, resources must be provided as a means for accurate information and guidance in a 
contextually appropriate environment to facilitate adjustment and promote conditions for successful goal attainment through a college to career transition (Arthur, 2007; Yoon \& Portman, 2004). Recognizing the numerous career transition barriers including the student's administrative processes, and cultural awareness could impede support efforts, this study serves as a collection of perspectives aimed at comparing how international and domestic students and faculty approach career decision-making and career development.

\section{Self-Efficacy and Help Seeking in Career Development}

Self-efficacy can be defined as an individual's judgement of their capabilities to organize and execute a course of action required to attain designated types of performance (Bandura, 1986). In general, self-efficacy represents an individual's perception of their capabilities to successfully perform across a variety of situations including life's challenges (Judge, Erez \& Bono, 1998). Students form their self-efficacy perceptions by interpreting information from four sources: mastery experiences, vicarious experiences, verbal messages from others and their own physiological states (Bandura, 1997). Bandura (1995) further emphasized that the actions, feelings, thoughts and motivation of people are highly influenced by their efficacy beliefs. Highly generalized self-efficacy means that individuals have strong belief in their own capacities (Judge et al., 1998). Individuals with high self-efficacy tend to persist longer in the face of challenges, reinforcing their belief that they will successfully perform well in a given situation (Regenold, Sherman, \& Fenzel, 1999; Strauser, 1995).

In addition, prior studies have shown that self-efficacy is a pivotal factor in career decision-making intention, behavior and career development (Bandura, Barbaranelli, Caprara, \& Pastorelli, 2001; Eden \& Aviarm, 1993). The perception of employability refers to an individual's self-efficacy through a personal belief about the possibility of obtaining new, equal 
or better employment (Berntson, 2008). Self-regulated learners with high levels of self-efficacy are not passive but rather seek out information and assistance when needed (Zimmerman, 1986; Zimmerman \& Martinez-Pons, 1990). Research suggests that students who seek help when necessary are more likely to use other strategies as well (Karabenick \& Knapp, 1991).

Help Seeking. Help-seeking can be defined as the process of seeking assistance from other individuals or sources that facilitate accomplishing desired goals (Karabenick \& Berger, 2013). In the context of career development this may include activities such as searching on employment websites, or utilizing in person assistance for resume critiques and mock interviews. Help-seeking in higher education is recognized as consisting of both adaptive and nonadaptive behaviors (Alexitch, 1997, 2002, 2006; Karabenick \& Knapp 1991; Newman, 1990, 1994). Adaptive help-seeking occurs when students experience a difficulty and actively seek assistance. Newman (2006) states that adaptive help-seeking is contingent upon the student's recognition of needing assistance, knowing what type of help to seek and where, or with whom, to go to for assistance. In comparison, nonadaptive help seeking typically involves two types of behavior: 1) seeking assistance when it is not needed, and 2) avoidance (Newman, 2008; Ryan Pintrich, \& Midgley, 2001).

Human and Nonhuman Resources. Help-seeking also consists of human and nonhuman sources (Zimmerman \& Pons, 1986). Research suggests that seeking a human resource can be considered a form of behavioral self-regulated learning that requires students to adopt an active role in finding a solution (Karabenick \& Sharma, 1994; Newman, 1994; Pintrich \& Zusho, 2007; Schunk \& Zimmerman, 1997; Zimmerman, 2008). Seeking help that involves others either directly or indirectly results in a unique set of self-regulated strategies. The student to advisor interaction is a prime example of an extended relationship with multiple instances where 
expressed help-seeking questions and answers can be provided in person (Karabenick \& Berger, 2013). However help-seeking may prove challenging under certain academic circumstances or cultural contexts.

Too often students do not consider human sources for help-seeking as an option even when faced with significant decisional difficulties (Nota, Soresi, Solberg \& Ferrari, 2004), despite access to an advisor or other resources for assistance. This could possibly be because they are embarrassed to publically disclose the need for help, students may see the need as a threat to their self-esteem, or help-seeking may not be perceived as culturally appropriate (Karabenick, 1998, 2003; Mori, 2000; Ryan \& Pintrich, 1997).

As a result, an increasingly high number of students tend to seek help from unofficial sources or sources that do not involve direct contact with people (Rickwood, Deane, Wilson \& Ciarrochi, 2005). Researchers have investigated the support that online resources and information searching provides. (Makitalo-Siegl, Kohnle \& Fischer, 2011; Puustien, Bernicot \& Bert-Erboul, 2001). These nonhuman resources may take on various forms depending on the type of task at hand (e.g., locating a single piece of information or answering a complex question) and the resource utilized (e.g., handout, book, library database or website) Previous studies on information searching have reported that searching usually involves a cyclical process in which the searcher: 1) builds a representation of their goal, 2) selects an item among the sources of available for information 3) extracts content information likely to match the search objective, 4) integrates new information with current information and 5) repeats the cycle as many times as needed to meet search goals (Guthrie, 1988; Rouet, 2006; Rouet \& Tricoat, 1996). Information searching is a self-regulated activity that requires self-awareness to identify one's information needs and assess when enough information has been acquired. Even so, when the 
boundary between help-seeking and information searching becomes blurred it raises the question of whether or not students possess the prerequisite skills needed to perform these activities successfully within the appropriate contexts (Walraven, Brand-Gruwel, \& Boshuizen; 2008).

According to Popadiuk and Arthur (2013), international students' decision-making and help-seeking process tends to be a collective endeavor including influences from sources and people whom they have relationships with in both home and host countries. Although helpseeking is recognized as a component of self-efficacy, which consists not only of self-regulatory learning but one's belief that they can perform well (Bandura, 1986; Pintrich, 2000; Schunk \& Ertmer, 2000; Winnie, 1995) the social interactivity of help-seeking renders itself to a process susceptible to a host of influences to which other forms of self-regulated learning are immune including cultural competence.

\section{Specific Career Needs of International Students}

Often the very reasons international students choose to study in the United States stem from motivation linked to academic and employment goals (Arthur, 2007; Crockett \& Hayes, 2011; Leong \& Chou, 1996); Luzzo, Henao \& Wilson, 1996; Kaczmarek, Matlock, Merta, Ames \& Ross, 1994; Mori, 2000; Tidwell, \& Hanassab, 2007; Zhang \& Dixon, 2003). Although international students represent a large pool of highly educated talent, due to visa restrictions, they are often forced to make complex career decisions surrounding the feasibility and value associated with pursuing a career inside or outside of the United States soon after matriculation (Bartram, 2007; Baruch, Budhwar \& Khatri, 2007; Geddie, 2013). This necessitates timelier career resources in earlier stages of academic programs, and has created a need to shape cultural awareness (Geddie, 2013) for international student support (Arthur \& Flynn, 2007, Mosneaga \& Winther, 2013). These cultural factors further complicate the career decision-making process, as 
students may be unfamiliar with navigating the United States residency requirements and might reluctantly choose to return home upon graduation (Arthur \& Flynn, 2012).

By taking into consideration the appropriate context for which students are making decisions, resources can accommodate various stages of career development at both the undergraduate and graduate level (Bridgestock, 2009). At most institutions, enrollment trends indicate an increase in graduate international student enrollment, which are juxtaposed to the traditional types of career service provided during major identification and exploration stages for undergraduate students. As a result, graduate international students may neglect traditional career counseling appointments and rely more readily on influential relationships with their peers for career guidance (Rice, et al., 2009; Knox, Schlosser, Pruitt \& Hill; 2006; Tenenbaum, Crosby, \& Gliner, 2001; Shen \& Herr, 2004).

\section{Help-Seeking Behavior Among International Students}

Although the American College Health Association's (2014) report estimates that 37.4\% of college students in the United States had a concern that could be addressed in counseling, college and university counseling centers and services are commonly underutilized by international students (Hyun, Quinn, Madon \& Lustig, 2007). According to a study conducted by the University of California, Berkley, $44 \%$ of their international graduate students reported emotional or stress related concerns that were interfering with their academic success or wellbeing (Hyun, Quinn, Madon \& Lustig, 2007). International students tend to be more hesitant than their United States peers in seeking counseling, (Byon, Chan \& Thomas, 1999; Carr, Koyama, \& Thiagarajan, 2003; 2005 Constantine et al., 2005; Mori 2000; Singaravelu et al., 2005; Zhang \& Dixon, 2003) and individual characteristics such as gender, or social support impact a student's help-seeking behaviors. In a study by Kahn \& Williams (2003), students who concealed 
distressing information had weaker social supports and were more likely to utilize counseling services compared to those with strong social supports who relied on friends or family for guidance. Several studies also suggest that international students with strong social support tended to seek alternative sources of help such as friends, advisors and professional organizations (Shen \& Herr, 2004; Singaravelu et al., 2005) compared to traditional forms of counseling.

International students may experience additional challenges related to help-seeking behaviors compared to domestic students, as language barriers, cultural values, and limited (if any) prior experience with counseling may inhibit their willingness to seek assistance (Mori, 2000). Cultural values tend to impact international student's behavior as they often maintain negative perceptions toward seeking help from counseling services and may favor friends and family, or a collectivist approach to help, compared to seeking assistance from outside sources which may or may not result in immediate outcomes (Byon et al., 1999; Yi et al., 2003). Shen \& Herr (2004) found that international students did not perceive that they were being helped by career services and did not believe that the services were worthwhile; suggesting that even if students were to seek out career services, differences in values and expectations may result in dissatisfaction. The student's level of unfamiliarity with counseling and help-seeking overall can lead to significant cultural barriers when seeking career guidance. Students who come from countries where career assistance is absent or limited, may lack the motivation to seek career assistance in the United States (Shen \& Herr, 2004). Their limited knowledge regarding services available to them can also contribute to the student's misconception toward, or avoidance of, resources during the career decision-making process.

The basis for the level of appropriate use of career counseling is understated. In a study by Bradley, (2000), the domestic and international students were compared and the results 
indicated that domestic student use of services was higher with no reason to assume that the domestic student usage was more appropriate. In comparison, Kearney et al., (2005) compared Asian American and Caucasian American students that resulted in indirectly related patterns of international student help-seeking. In a third study, Fallon \& Barbara (2005), revealed a gap in the help-seeking perceptions of Asian student's need for medical help and seeking treatment. Explanations on low usage of university assistive services by international students are usually given in cultural terms, and the non-western beliefs cited as a negative stigma toward helpseeking is often perceived (Car et al., 2003; Constantine et al., 2005; Kilinc and Granello, 2003; Mori, 2000; Zhang \& Dixon, 2003). Other cultural factors include norms for privacy, lack of familiarity with counseling, and language differences. Consistent with this, students with higher levels of acculturation to the host country have been shown to have significantly more positive attitudes to help-seeking (Bradley, 2000; Car et al., 2003; Constantine et al., 2005; Kilinc and Granello, 2003; Mori, 2000; Vogel, Wade \& Haake, 2006; 2007; Zhang \& Dixon, 2003). These over simplistic interpretations have gone unchallenged.

Multiculturalism and globalization have become two dominant themes within career counselor education over the past years. Within career counseling in general, a wealth of cultural and student identity development models, conceptual and practical frameworks, and instruments have been created to assess multicultural career readiness (Creed, Muller \& Patton, 2003; Jepsen \& Dickson 2003; Koivisto, Vinokur, \& Vuori, 2011; Merriam, Courtenay \& Cervero, 2006; Saks \& Ashforth, 2002). Among the most widely used are a common value that together career counselors, resources and professional development organizations involved with international students can identify, develop and implement new career competencies or approaches that would 
enable these services to work more effectively and ethically with culturally diverse groups of people (Smith \& Khawaja, 2011).

Globalization's impact on international graduate student's career readiness represents a somewhat broader phenomenon than multiculturalism, although the two are interrelated. Whereas multiculturalism in career counseling first emerged in the context of increasing the effectiveness of counselors working with ethnically diverse client populations in the United States (Byars-Winston, \& Fouad, 2006), globalization relates more to the ways in which internationalization of the world's economies and corresponding social structures are impacting personal, social and career decision making (Leong \& Brown, 1995). People from around the world are experiencing transformations in forms of work, exchanges of knowledge and ideas regarding what constitutes a career (Canen \& Canen, 2001). In essence, the outcome of global changes taking place through academia, trade and exchange of information in diverse cultures are identifying similar or common needs (Cook, Heppner \& O’Brien, 2005). Career counseling practices are changing in response to these needs and training programs and resources are having to adjust so that graduates are aware of, and prepared to make, culturally competent career decisions and overcome barriers within the career decision-making process (Arthur \& McMahon, 2005).

\section{Barriers to Help-Seeking within Social Cognitive Career Theory}

Based on Bandura's general Social Cognitive Career Theory, the student's environmental and behavioral influences shape career development (Lent, Brown \& Hacket, 1994). SCCT suggests an array of factors that interact when job seekers take steps toward a career goal and help construct and outline the various motivators and enablers (student, faculty and peers) that impact career decision-making. Zimmerman (2008) has long recognized that self-regulated 
learning (SRL) involves others who help learners by providing the resources, in the form of information or skills, they need to be successful, and can be tied to social forms of learning such as seeking help from peers, parents or teachers (Zimmerman, 2008). A self-regulated learner is one who displays personal initiative, perseverance, and adaptive skills in pursuing his or her selfset goals. As it pertains to career decision making this may include how to seek and obtain employment, seeking career guidance, or independently applying strategies learned to changing situations (Schunk \& Zimmerman, 1997).

Research has shown that cultural or social contexts (cultural values, personal identity) play critical roles in determining how candidates approach each aspect of the job search process to reach a career decision (Adams, Cahill, \& Ackerlind, 2005; Byars \& Hackett, 1998; Gushue, 2006; Lent, Brown \& Hacket, 1994; Schaub \& Tokar, 2005). Individuals in today's society must adapt themselves to the social and cultural environment through self-regulation and play an active role in making meaning out of their experience, and building their careers (Savickas \& Baker, 2005) which may include seeking assistance from others. Help-seeking can be defined as the process of seeking assistance from other individuals or other sources that facilitate accomplishing desired goals (Zimmerman, 2008), which in the context of career planning may include external, experiential and individual influences.

External Influences. International students who encounter vocational hardships and obstacles while navigating American work culture, are at risk for needing more assistance than their US counterparts (Takeuchi, Alegria, Jackson \& Williams, 2007). As international students interact further with their environment, and become more comfortable with it, this risk is expected to decrease over time. International students arriving in the United States, may therefore, report experiencing more stress and mental health problems when compared with their 
American classmates and other international students who have lived in the United States for longer periods of time. Some international job seekers arrive from countries where formal career guidance is not provided and career exploration options are limited as individuals are encouraged to pursue a profession that benefits the national economy, or are encouraged to make a career decision with strong influence from family, caste, or class (Singaravelu, White \& Bringaze, 2005). Limited resources that assume the student's desire is to pursue employment in the United States instead of guiding the student in exploring all options and contributing influences, further necessitate the present study.

Experiential Influences. International job seekers also face educational pressure to learn, conform to and succeed in a new educational environment (Church, 1982) by making personal, social, and financial adjustments to cope with familial pressures to succeed in their chosen field of study (Cheng, et al., 1993; Kaczmarek, et la., 1994; Pedersen, 1991; Sandhu \& Asrabadi, 1994, Singaravelu, White, \& Bringaze, 2005). The overall adjustment to studying in a foreign country may affect international graduate student's considerations of whether to stay or work abroad. International job seekers must adapt to a new culture and education system and those who make a positive adjustment to life in the United States may find the decision to pursue employment back home more difficult, as they have become comfortable where they are studying and satisfied with the experience (Baruch et al., 2007). In the absence of career services, international job seekers may rely on peers and colleagues for guidance. Studies on the support from professors (Trice, 2003) and fellow students have shown positive correlations between socialization, academic adjustment and persistence (Geelhoed, Abe \& Talbot, 2003).

Internal Influences. SCCT proposes that people develop an interest in a career path when they expect an overall positive outcome to following that path (Lent et al., 1994). When 
working with international job seekers one could assume a positive overall outcome would increase the interest in staying or working abroad and vice versa. However, personal cultural adjustments can further complicate perceptions of nontrustworthy career guidance, and their overall unawareness of career information or unrealistic expectations of how university faculty will support their overall career development (Leong, \& Sedlacek, 1986; Yuen, \& Tinsley, 1981; Pedersen, 1991).

There may be instances when an individual's self-efficacy is high, as they believe they can achieve their career goals, but their family pressure, or neglect in using support services (Flores \& Heppner, 2002), may lead them to report negative outcome expectancy (Lent et al., 2002). The highest level of positive career interest in decision-making was expressed by those who simultaneously possess strong self-efficacy, utilize career resources, have strong ties to supportive family, and faculty and perceive the labor market as approachable.

\section{Resources through Professional Organizations}

Traditionally college and university career resources for international students attend to the ethical responsibly and cultural competence required by most institutions of higher education, but professional development resources add another key element to the scope of their member benefits. Internationalization of professional development societies in its more modern forms, has also been driven by the related phenomenon of globalization. While a diverse student membership offers an opportunity to fulfill their mission as a distinctive voice in higher education, the career and developmental needs of its international student body pose serious challenges to the future of the organization if the students are to continue to perceive their resources as timely, informative and helpful (Geddie, 2013). Our concept of professional development must be broadened to include career readiness skills to help serve as a resource for 
students long after they have completed their degree. Professional organizations career readiness resources can be developed to support international graduate students in this process. In order to achieve these efforts current graduate students must adapt life-long learning attitudes. Only with an attitude of continuous improvement will students achieve the increased efficiency and effectiveness organizations and employers are seeking (Rothwell \& Kazanas, 2008) and succeed in finding and sustaining their employability. Students must be prepared to make informed career decisions and proactively plan their job search strategies, including participation in professional organizations, well in advance of gradation in order to meet the demands of our workforce today (Tull, Nino \& Holmes, 2014).

Professional Development. Rothwell and Kazanas, (2008) define professional development as “an individual's gradual and continuing mastery of a field's body of knowledge, methods and procedures" and help further explain that instructional designers should continuously strive to build professional knowledge, and maintaining awareness of new developments and approaches. The International Board of Standards for Training and Performance Instructions (IBSTPI, 2000), list one of the 23 instructional design competencies as (Instructional Design Competencies: The Standards, 2000): [ability to], ..."update and improve one's attitudes, skills and knowledge, pertaining to instructional design and related fields." While there have been many discussions on how instructional designers need to be trained within their chosen field, there is limited literature on what they need to continue their professional development (Sharif \& Cho, 2015). Instructional design professional development programs need to provide comprehensive career preparation, exposure to a wide range of career options and foster networking opportunities. Through these communities, graduate students are not only exposed to larger bodies of knowledge and skills, but they have opportunity to expand 
professional networks and refine their career readiness skills with the help of their family, peers and faculty advisors.

\section{Purpose of Study}

Although career readiness has been studied extensively and evidence suggests that resources and resourcefulness enhance career decision-making, there is a gap in the research focusing on the career decision-making of graduate international instructional design students. In addition, although academic and social interactions are key factors associated with undergraduate retention, there is limited research that targets graduate students and the resources that serve as a career guidance for this population. The purpose of this mixed methods study was to examine and compare differences between career decision-making difficulties and career needs of graduate domestic and international instructional design students.

This study aimed to facilitate understanding of how career decision-making can be enhanced in higher education through a professional organization and was conducted because of the following conditions: a) international and domestic instructional design graduate students need to cope with many challenges, including career decision-making in a rapidly changing world, b) individual differences in self-regulated learning and help-seeking may affect how students perceive their employability, which may in turn affect their career readiness and c) international students face increasing difficult college-to-career transitions in finding employment after graduation.

This study may provide important insights regarding international student's context of career decision-making, individual help-seeking behaviors and career readiness. It also posits self-regulated learning, and help-seeking within the career decision-making process as possible 
beneficial correlates. By better understanding the help-seeking tendencies and career needs of domestic and international students, resources can be developed to support these students groups and lead to a better facilitation of support in responding to their needs. Additionally, by acknowledging the strengths and challenges associated with a student's self-regulated learning, advisors and professional organizations can help mediate a balance between the utilization of human and nonhuman help-seeking resources in obtaining timely, accurate and consistent career information. Further guiding students through the career decision-making process may increase the student's tendency to employ comprehensive strategies in searching and obtaining relevant resources in a timelier manner, leading to positive outcomes.

\section{Research Questions}

The following research questions guide the study:

$\mathrm{RQ}_{1}$ : What are the career needs of international and domestic instructional design students?

$\mathrm{RQ}_{2}$ : What career decision-making difficulties do international and domestic instructional design students encounter?

$\mathrm{RQ}_{3}$ : What help-seeking resources are domestic and international students utilizing when making career decisions? 


\section{CHAPTER II}

\section{METHOD}

\section{Research Design}

This mixed methods study included the collection of qualitative and quantitative data to address the career decision-making difficulties and career needs of graduate domestic and international instructional design students. Mixed methods research has been defined as a philosophically-underpinned model of inquiry combining qualitative and quantitative models of research so that evidence may be mixed and knowledge is increased in a more meaningful manner than either model could achieve alone (Creswell \& Plano; Creswell \& Clark, 2007).

There is limited evidence informing the comparison of career needs between international and domestic graduate instructional design students. This supports the need for explorative qualitative work aimed at describing unknown phenomena, especially in unique contextual settings, such as a professional field (Morse, 1994, 2008; Sofaer, 1999). Additionally, through the utilization of qualitative methods, data was collected and compared on influences within career decision-making that helped identify significant challenges students face in effectively using career resources.

\section{Setting}

Data was collected through a premier instructional design professional organization, the Association for Educational Communication and Technology (AECT). AECT is a professional association of educators and practitioners whose activities are directed toward improving instruction through technology. AECT members are employed at vast locations including but not limited to: colleges and universities, Armed Forces, hospitals, museums and libraries. Their 
members have a wide variety of roles and responsibilities including the study, planning, application and production of communication media for instruction (www.aect.org).

According to the AECT membership homepage, the association has become a major organization for those actively involved in the designing of instruction and a systematic approach to learning. It provides an international forum for the exchange and dissemination of ideas for its members and for target audiences and is the national and international spokesperson for the improvement of instruction. AECT is the most recognized association of information concerning a wide range of instructional and educational technology and along with its members, 24 state and six international chapter affiliates, all members are passionate about finding better ways to help people learn. AECT is the oldest professional home for this field of interest and has continuously promoted high standards, both in scholarship and in practice. AECT has a Graduate Student Assembly (www.aect.site-ym.com/).

\section{Participants}

Participants were limited to AECT graduate student members. AECT consists of 2,300 members, including 760 graduate students of which approximately 150 are international graduate student members. A maximum variation purposeful sampling method was used to generate a group of domestic and international instructional design students who were willing to discuss their career development needs, and resources utilized. Specifically the domestic and international students were asked about challenges when making career decisions, and resources utilized during the decision-making process. Current graduate students as well as recent graduates (class of 2016/2017) were eligible to participate. This sampling technique captured a wide range of perspectives relating to the research questions and assumed that the investigator wanted to discover, understand and gain greater insight into a phenomenon and therefore must 
select a sample from which the most can be learned while considering multiple perspectives and making comparisons (Merriam, 1998).

\section{Procedures}

Data collection took place in two phases during the Summer 2017 semester. The data collection procedures were intended to be completed within six weeks, but were expanded in order to reach more participants. The first recruitment phase of the study was designed to invite international and domestic instructional design graduate student members of AECT to participate in an online survey. The researcher sent emails to the membership through the AECT list serve to generate interest in this study, including the international division within the organization as well as advising contacts within instructional design. A copy of the International Review Board approval and the approved participant consent form was sent with the survey materials to the participants electronically. The second phase consisted of semi-structured phone interviews. Following the completion of the survey participants were given an opportunity to indicate if they would be willing to participate in a follow up phone interview. The quantitative phase was conducted first, followed by the qualitative phase in adherence to an explanatory sequential mixed methods design (Creswell, 2003) as the researcher used data from the first phase to guide the conversation in the second phase.

Initially two weeks were set aside for recruitment, one week was set aside to promote and administer the survey instrument electronically, and a total of three weeks were allotted to arrange and complete the individual interviews with participants. Efforts were made to have a diverse pool of participants and resulted in repeating the 6 week procedure in its entirety for a combined total of 12 weeks for data collection. 


\section{Instruments}

Demographic Survey. All participants completed an electronic demographic survey that was attached to the Career Decision-Making Questionnaire. This survey was created through Qualtrics and was sent to members via an email link (Appendix A). The demographic information collected on the survey included: age, sex, race/ethnicity, program of study, degrees earned, and career resources utilized by international and domestic instructional design students. The survey led right into the 35 item Career Decision-Making Difficulties Questionnaire. Those who were willing to participate in a phone interview indicated their willingness at the end of the survey by including their name, email and phone number. Interview questions (Appendix B) were sent to all participants in advance along with the email confirmation of the date and time for the phone interview. Post interview member-checking included review of the interview notes via email.

Career Decision-Making Difficulties Questionnaire. The Career Decision-Making Difficulties Questionnaire (CDDQ) (Gati, Krausz, \& Osipow, 1996) was originally created as a 44-item Likert-type questionnaire based on three categories of difficulties: 1) lack of readiness, 2) lack of information, and 3) inconsistent information. This study used the abridged version of the CDDQ (Appendix A) which contained 35 Likert-type questions to identify sources of difficulty within 10 subscales: Lack of Readiness due to a) lack of motivation, b) indecisiveness, c) dysfunctional myths, or d) lack of knowledge about the decision making process; Lack of Information about a) self, b) occupations, or c) ways of organizing information and Inconsistent Information about a) unreliable information, b) internal conflicts, or c) external conflicts (Gati, Saka \& Krausz, 2001). The questionnaire asked participants to rate their level of difficulty in each area on a 9-point scale $(1=$ does not describe me to $9=$ describes me well) (Gati, Krausz, \& 
Osipow, 1996). The questionnaire also asked participants to rate their overall severity of career decision making difficulties on a 9 -point scale ( $1=$ not severe at all to $9=$ very severe). The questionnaire was scored by calculating mean responses for questions within each main category and within each subscale.

Gati, Krausz, and Osipow (1996) measured parametric properties of the CDDQ with both Israeli and American samples for people in transition. American students $(n=304)$ between the ages of 17-23, and Israeli students $(n=259)$ between the ages of 19-23 years old participated in two separate studies. Both populations showed acceptable variability and correlations among the scales. Reliability of the categories Lack of Readiness, Lack of Information, and Inconsistent Information were $.70, .93$, and .91 respectively for the Israeli sample, and $.63, .95$, and .89 respectively for the American sample. The reliability for both the Israeli and American sample for the entire CDDQ instrument was reported as .95.

Osipow \& Gati (1998) found similar results with an American sample ( $\mathrm{n}=403)$ of college students with reliability of the categories Lack of Readiness, Lack of Information, and Inconsistent Information reported as $.62, .94$, and .86 respectively. Reliability for the entire instrument was reported as .94 (Osipow \& Gati, 1998). More scoring and interpretation information on the psychometric properties of the CDDQ can be found in Appendix D.

Semi-structured Interviews. Qualitative researchers are intrigued with the complexity of social interactions as expressed by the participants through the meaning they themselves attribute to their interactions (Marshall \& Rossman, 2014). Therefore, the best way to obtain information about the career decision-making experiences of international and domestic instructional design students was within a conversational format (Merriam, 1998) and for the purpose of this research consisted of a phone interview. The interview process began with 
reviewing the participant's demographic information as indicated on the survey. This information was used to start a conversation and served as valuable background material as interview data was collected.

As Smith and Osborn (2003) advised, the interview started with the most general question possible (Appendix B). As general questions can sometimes produce insufficient responses, the researcher was prepared to offer a collection of probing questions intended to elicit more specific information (Smith \& Osborn, 2003). Most importantly for this phenomenological approach, the researcher invited concrete accounts of actual experiences that had occurred. Furthermore, these guiding questions provided a basis for the participants to discuss both pleasant and challenging aspects of career decision-making. Every attempt was made to follow the participants and understand their story rather than merely follow a standardized list of questions. This approach is consistent with the phenomenological methodology chosen as the participants are consider to be the experts and it is the meanings associated with their experiences that are of interest to the researchers (Hays \& Singh, 2011; Smith \& Osborn, 2003). Additionally the researcher was interested in further clarifying how subjective and objective feedback affected the interview experience or expanded the discussion. Descriptive and reflective notes captured the responses of the participants. Further, a descriptive and reflective field note journal maintained self-reflective thoughts and feelings of the researcher (Hays \& Singh, 2011). These were used during data analysis in effort to increase the trustworthiness of the narrative data. Along with a thank you note (Appendix C) participants received a copy of the interview notes for member checking with a request that any changes or clarifications be returned to the researcher within 5 days of receipt (Merriam, 2002). 
Data Confidentiality. Efforts were implemented to insure the privacy of study participations and their responses to all instruments. Upon participating in the phone interview, participants identified their name, email and interview time. This information was provided to the researcher via email. At the start of each interview, the researcher reminded the participants of the confidentiality measures in place as well as the informed consent document which they had signed on the survey. Interview notes were kept in a secure location throughout the duration of the study and were destroyed at the conclusion of the study according to the IRB guidelines at the researcher's institution. Before the interview data analysis began, the students were assigned a participant number (ranging from 2-21) as well as a letter indicating their domestic (D) or international (I) status in order to insure their names were kept confidential during reporting. Personal communication citations throughout contain the (D) and (I) indicators for context.

\section{Data Analysis}

The purpose of this study was to compare and contrast the differences between the career decision-making of international and domestic instructional design graduate students. The constant comparative method was used for data analysis (Table 1). This method involves an iterative process of constantly collecting data and comparing each piece of data with others (Glaser \& Strauss, 1967). The responses to survey questions and interviews served as the major source of data. 


\section{Table 1.}

\section{Data Analysis Plan}

\begin{tabular}{|c|c|c|c|c|c|c|c|}
\hline Research Question & $\begin{array}{l}\text { Quant. } \\
\text { Variables }\end{array}$ & $\begin{array}{l}\text { Source } \\
\text { Close-Ended } \\
\text { Data }\end{array}$ & $\begin{array}{l}\text { Analysis } \\
\text { Across All } \\
\text { Quant Data }\end{array}$ & $\begin{array}{l}\text { Qualt. } \\
\text { Variables }\end{array}$ & $\begin{array}{l}\text { Source } \\
\text { Open- } \\
\text { Ended } \\
\text { Data With } \\
\text { Protocol } \\
\end{array}$ & $\begin{array}{l}\text { Analysis } \\
\text { Across All } \\
\text { Qual Data }\end{array}$ & $\begin{array}{l}\text { Merging the } \\
\text { Two Sets of } \\
\text { Results }\end{array}$ \\
\hline $\begin{array}{l}\text { What are the career } \\
\text { needs of international } \\
\text { and domestic } \\
\text { instructional design } \\
\text { students? }\end{array}$ & $\begin{array}{l}\text { Questions } \\
\text { pertaining to } \\
\text { Readiness }\end{array}$ & $\begin{array}{l}\text { CDDQ } \\
\text { Questions } \\
\# 1-11 \\
{ }^{*} \mathrm{Q} \# 7 \text { is a } \\
\text { validity item } \\
\text { and is } \\
\text { expected to be } \\
\text { high }>4\end{array}$ & $\begin{array}{l}\text { Mean scores } \\
\text { calculated for } \\
\text { each question, } \\
\text { and for each } \\
\text { category and } \\
\text { compared } \\
\text { between } \\
\text { groups - } \\
\text { domestic and } \\
\text { international. } \\
\text { Independent t- } \\
\text { scores between } \\
\text { categorical } \\
\text { means used for } \\
\text { comparison } \\
\text { between } \\
\text { groups }\end{array}$ & $\begin{array}{l}\text { Interview } \\
\text { Questions \# } \\
1,2,3,9\end{array}$ & $\begin{array}{l}\text { Phone } \\
\text { Interview }\end{array}$ & $\begin{array}{l}\text { Member } \\
\text { Checking } \\
\text { Interview } \\
\text { Notes - } \\
\text { Coded } \\
\text { Using } \\
\text { triangulation } \\
\text { procedures } \\
\text { for codes, } \\
\text { theme } \\
\text { development } \\
\text { and } \\
\text { subthemes }\end{array}$ & $\begin{array}{l}\text { Summarize and } \\
\text { interpret } \\
\text { separate results } \\
\text { Identify } \\
\text { content areas } \\
\text { represented in } \\
\text { both data sets } \\
\text { to compare, } \\
\text { contrast and } \\
\text { synthesize } \\
\text { results in a } \\
\text { discussion and } \\
\text { table }\end{array}$ \\
\hline $\begin{array}{l}\text { What career decision- } \\
\text { making difficulties } \\
\text { do international and } \\
\text { domestic } \\
\text { instructional design } \\
\text { students encounter? }\end{array}$ & $\begin{array}{l}\text { Questions } \\
\text { pertaining to } \\
\text { Inconsistent } \\
\text { Information }\end{array}$ & $\begin{array}{l}\text { CDDQ } \\
\text { Questions } \\
\# 25-34\end{array}$ & & $\begin{array}{l}\text { Interview } \\
\text { Questions } \\
\# 4 \mathrm{a}, 5,10\end{array}$ & $\begin{array}{l}\text { Phone } \\
\text { Interview }\end{array}$ & $\begin{array}{l}\text { Axial coding } \\
\text { for final set of } \\
\text { themes and } \\
\text { subthemes }\end{array}$ & $\begin{array}{l}\text { Turn qual } \\
\text { themes into } \\
\text { counts -stat } \\
\text { analysis } \\
\text { including } \\
\text { thematic } \\
\text { counts with } \\
\text { aim to relate } \\
\text { data in both } \\
\text { sets }\end{array}$ \\
\hline
\end{tabular}




\section{Quantitative Data Analysis}

The Career Decision-Making Difficulties' Questionnaire (CDDQ) developed by Gati, Kraus and Osipow (1996) explores the difficulty in career decision making. Items are reported on a 9 point Likert scale ranging from 1 (does not describe me well) to 9 (describes me well). The CDDQ consists of 10 scales that are divided into three groups. The first group, lack of readiness contains 12 items and measures for lack of motivation, indecisiveness and dysfunctional beliefs. The second group, lack of information, contains a total of 12 items and measures for lack of knowledge about the process, lack of information about self, lack of information about occupations and lack of information about ways of obtaining information. The last group, inconsistent information, contains 11 items and measures for unreliable information, external conflicts and international conflicts. To score the CDDQ, points are added for each of the subscales for each scales and converted to means. Higher scores correspond to more difficulty with career decision making. An independent samples t-test was conducted to evaluate differences between student groups (domestic and international students) for each category.

\section{Qualitative Data Analysis}

Qualitative data analysis was an ongoing process involving continual reflection on the data, asking analytical questions, and making an interpretation of the larger meaning of the data (Creswell, 2003). As the aim of this analytical approach was to explore the participant's view and to understand and integrate an insider's perspective of the phenomena under study as far as possible. Initial coding included the researchers first attempt to understand the qualitative data by comparing it to the survey results. 
Coding. Key phenomenological elements were maintained throughout data analysis including: suspending assumptions regarding the phenomenon, gaining access to the lived experiences through interviews, analyzing the meaning given to the phenomenon by each participant, and identifying basic components that are general across the phenomenon (Hays \& Singh, 2012; Wertz, 2005). The researcher bracketed personal assumptions and biases that might be relevant to the research project noting biases and influence on the coding process.

The analysis of data was guided by Strauss \& Corbin's (1998) qualitative method for open, axial and selective coding with the goal of discovering the relevant categories and relationships among them. Category construction began immediately after the first interview and evolved as data was collected from all participants. Interviews lasted no longer than 60 minutes. Interview notes were read carefully to obtain a sense of the whole conversation and notate any initial first impressions. The analysis of the notes was coded and the coded data was compared within and across interviews to identify themes that captured reoccurring patterns in the data (Merriam, 1998). The purpose of open coding was to uncover, name and develop concepts of information and is the first creative step in this method of data analysis. Axial coding involved making connections between sets of properties within and among categories to form subcategories (Strauss \& Corbin, 1998). During axial coding the researcher went through each interview question line by line, in attempt to understand the stated actions and reasons, assumptions and thoughts described by the participants (Hays \& Singh, 2011). It was during this second and more focused step in the question and discovery process followed by selective coding whereby core categories were identified. Through focused coding the emerged themes and survey results were linked to student needs, overall difficulty and help-seeking resources utilized and included a constant comparative process (Hays \& Singh, 2011). All data results were 
provided to a research expert for triangulation and then reanalyzed after coding and category construction to refine, reconfigure and substantiate themes that were relevant and meaningful to the study's purpose (Merriam, 1998).

Reflective Journal. During the interview process the researcher kept a reflective journal on the thoughts, impressions and experience of the researcher with each participant. This was used during the process of triangulation as a way to help identify any bias and to help bracket assumptions. Through the process of triangulation, the researcher reviewed the topics, categories and subcategories to finalize a list of codes, topics, categories and subcategories. As a way to consolidate the findings, similar units were clustered to describe textures of the experience and the researcher created structural descriptions (Hays \& Singh, 2012; Hays \& Wood, 2011) by seeking variations in experience. This procedure was revised and reviewed until a final set of related descriptions, themes and subthemes were created.

Validity. The researcher adhered to a non-foundational approach to validity, where uncertainty is the inevitable consequence of individual's finite knowledge of ourselves and the world we live in (Hays \& Singh, 2012; Denzin \& Lincoln 2011). The non-foundational approach involved developing specific techniques to be used for this particular study in order to enhance its trustworthiness including efforts to enhance credibility, transferability, dependability and conformability. Specifically, credibility was demonstrated through the use of memos, and an audit trail. Transferability was demonstrated through the solicitation of a sample that met the predetermined criteria and dependability was demonstrated by the use of triangulation of data sources and member checking. Finally, confirmability was demonstrated by bracketing the researcher's assumptions to consider the influences of their experience on the research project (Hays \& Singh, 2012; Smith \& Osborn, 2003). 
Validation of findings occurred throughout the research process as it related directly to the quality of the design, procedures, and the researcher's data collection and interpretation skills (Creswell, 2003). The researcher has over 10 years of experience in intercultural communication through career counseling and was able to engender trust with the domestic and international student participants. This is particularly important because English might not necessarily be the first language of several of the student participants and confidence in communication skills vary. Other measures built into this investigation to enhance validity included member checking, and the inclusion of a research expert conducting a critical review of data analysis procedures and findings as they emerged. 


\section{CHAPTER III}

\section{RESULTS}

This mixed methods study compared the career needs of domestic and international instructional design graduate students. The results demonstrate that both domestic and international students have specific needs and face career decision-making difficulties, however within several categories, international students indicated more salient difficulties compared to their domestic student counterparts. This study also demonstrates that graduate students in instructional design experience career decision-making difficulty at various ages, in various stages of career development and throughout various levels of education and employment.

\section{Participants}

A total of 84 graduate instructional design students consisting of 32 international students and 52 domestic students took the online demographic survey and questionnaire, of those, 20 participated in a follow up interview. Student's countries of origin are listed in Table 2.

Table 2

Country Groups

\begin{tabular}{|c|c|c|c|c|c|c|c|c|c|}
\hline African & $\mathrm{n}$ & Asia-Pacific & $\mathrm{n}$ & $\begin{array}{l}\text { Eastern- } \\
\text { European }\end{array}$ & $\mathrm{n}$ & $\begin{array}{l}\text { Latin } \\
\text { American/ } \\
\text { Caribbean }\end{array}$ & $\mathrm{n}$ & $\begin{array}{l}\text { Western } \\
\text { European/ } \\
\text { Other }\end{array}$ & $\mathrm{n}$ \\
\hline India & 2 & Bangladesh & 2 & Serbia & 1 & $\begin{array}{l}\text { Antigua and } \\
\text { Barbuda }\end{array}$ & 2 & Canada & 1 \\
\hline \multirow[t]{4}{*}{ Tunisia } & 1 & $\begin{array}{l}\text { Brunei } \\
\text { Darussalam }\end{array}$ & 1 & & & Montserrat & 1 & Turkey & 3 \\
\hline & & China & 9 & & & Peru & 1 & $\begin{array}{l}\text { United } \\
\text { States }\end{array}$ & 52 \\
\hline & & Indonesia & 1 & & & Puerto Rico & 2 & & \\
\hline & & Japan & 1 & & & Saint Lucia & 1 & & \\
\hline
\end{tabular}




$\begin{array}{llll}\text { Saudi Arabia } & 1 & \begin{array}{l}\text { Trinidad } \\ \text { and Tobago }\end{array} & 1 \\ & & \text { Venezuela } & 1\end{array}$

Note: Country groups based on UN categories for Regional Groups www.un.org/depts/DGACM/RegionalGroups.shtml

This study was limited to graduate student members of the professional organization AECT. The participants reported 15 males and 69 females, ranging in age from 18-46+ in various stages of their graduate programs. Groups are compared in Table 3.

Table 3

Student Demographics

\begin{tabular}{lcc}
\hline & $\begin{array}{c}\text { Domestic } \\
\mathrm{N}=52\end{array}$ & $\begin{array}{c}\text { International } \\
\mathrm{N}=32\end{array}$ \\
\hline Gender & 8 & 7 \\
Male & 43 & 25 \\
Female & 1 & \\
Non-Responses & & \\
Age & & 1 \\
18-25 & 7 & 12 \\
$26-30$ & 6 & 4 \\
$31-35$ & 9 & 5 \\
$36-40$ & 12 & 1 \\
$41-45$ & 18 & 9 \\
$46+$ & & \\
Non-Responses & 6 & 5 \\
Race & 62 & 6 \\
Black & 2 & 4 \\
White & 2 & 16 \\
Hispanic & & 1 \\
Other & & \\
Non-Responses & 52 & 4 \\
Status & & 6 \\
US Citizen & & \\
Permanent Resident & & \\
International Student Visa & & \\
Non-Responses & &
\end{tabular}




\begin{tabular}{lcc} 
Degree & & \\
Graduate Certificate & 2 & 1 \\
Master's Degree & 12 & 4 \\
PhD & 24 & 23 \\
Recent Master's Graduate & 6 & 1 \\
Recent PhD Graduate & 6 & 3 \\
Non-Responses & 2 & \\
Number of Years in Graduate Program & 12 & 4 \\
$1^{\text {st }}$ Year Student & 10 & 9 \\
$2^{\text {nd }}$ Year Student & 6 & 5 \\
$3^{\text {rd }}$ Year Student & 7 & 6 \\
$4^{\text {th } \text { Year Student }}$ & 1 & 3 \\
$5^{\text {th } \text { Year Student }}$ & 1 & 2 \\
$6^{\text {th } \text { Year Student }}$ & 4 & 3 \\
More Than 6 Years & 11 & \\
Non-Responses & & \\
\hline
\end{tabular}

\section{Career Needs of International and Domestic Instructional Design Students}

The first area for investigation focused on student needs. To be successful in a radically changing world of work, students must be willing to overcome career related difficulties and make numerous important decisions that affect major areas of his or her life. For some college students, this decision requires little effort or thought, but for many students in this study they lacked the essential elements necessary to make career related decisions, especially in the predecision making phase (readiness). Within the Career Decision-Making Difficulty Questionnaire (CDDQ) the first category pertained to career readiness as indicated in questions 1-12 (Figure 1).

\begin{tabular}{l}
$\begin{array}{l}\text { Q1. I know that I have to choose a career, but I don't have the motivation to make the } \\
\text { decision now ("I don't feel like it"). }\end{array}$ \\
$\begin{array}{l}\text { Q2. Work is not the most important thing in one's life and therefore the issue of choosing } \\
\text { a career does not worry me much. }\end{array}$ \\
\hline $\begin{array}{l}\text { Q3. I believe that I do not have to choose a career now because time will lead me to the } \\
\text { "right" career choice. }\end{array}$ \\
Q4. It is usually difficult for me to make decisions.
\end{tabular}


Q5. I usually feel that I need confirmation and support for my decisions from a professional person or somebody else I trust.

Q6. I am usually afraid of failure.

Q7. I like to do things my own way.

Q8. I expect that entering the career I choose will also solve my personal problems.

Q9. I believe there is only one career that suits me.

Q10. I expect that through the career I choose I will fulfill all my aspirations.

Q11. I believe that a career choice is a one-time choice and a life-long commitment.

Q12. I always do what I am told to do, even if it goes against my own will.

Figure 1. Readiness

Domestic and international student group readiness scores varied (Table 3). When comparing the student groups, mean scores lower than 3.33 are considered negligible, mean scores between 3.33 and 6.34 are considered moderate and mean scores higher than 6.34 are considered salient (Gati, Krausz, and Osipow, 1996). Complete scoring instructions and psychometric properties are outlined in Appendix D. Within this category, domestic students yielded levels of moderate and salient difficulty in questions 3, 4, 5 and 8 compared to the international students who indicated levels of moderate and salient difficulty in questions 5, 6, 7, 8, and 10. Neither categories indicated difficulty in the category of motivation, however both domestic and international students scored in the salient difficulty range within the indecisive category. Although both domestic and international students indicated moderate to salient career difficulty within the category of dysfunctional beliefs, international students scored higher in every question except one (Q\#12). The follow up interviews with students gave specific examples within this category and their testimonies help provide context within the category of readiness. 
Table 4.

Readiness Results Q1-Q12

\begin{tabular}{|c|c|c|c|c|c|c|c|c|c|c|c|c|c|}
\hline Category & Q\# & $\begin{array}{c}\text { Dom } \\
\mathrm{N}\end{array}$ & $\begin{array}{l}\text { Dom } \\
\text { Mean }\end{array}$ & $\mathrm{SD}$ & $\begin{array}{c}\text { Sample } \\
\text { var }\end{array}$ & Kurtosis & Skew & $\begin{array}{c}\text { Intl } \\
\mathrm{N}\end{array}$ & $\begin{array}{c}\text { Intl } \\
\text { Mean }\end{array}$ & $\mathrm{SD}$ & $\begin{array}{l}\text { Sample } \\
\text { var }\end{array}$ & Kurtosis & Skew \\
\hline \multicolumn{14}{|l|}{ Motivation } \\
\hline & Q1 & 52 & 1.61 & 1.44 & 2.08 & 8.67 & 2.91 & 32 & 1.81 & 2.79 & 7.83 & 2.12 & 1.68 \\
\hline & Q2 & 52 & 2.67 & 2.10 & 4.42 & .970 & 1.32 & 32 & 2.28 & 2.59 & 6.72 & .290 & 1.01 \\
\hline & Q3 & 52 & 3.15 & 2.71 & 7.38 & -.047 & .995 & 32 & 2.46 & 3.02 & 9.16 & -.212 & .993 \\
\hline \multicolumn{14}{|c|}{ Indecisiveness } \\
\hline & Q4 & 52 & 2.98 & 2.29 & 5.27 & -.047 & .903 & 32 & 2.71 & 2.51 & 6.33 & -.327 & .585 \\
\hline & Q5 & 52 & 4.34 & 2.94 & 8.70 & -1.45 & .251 & 32 & 5.75 & 3.09 & 9.54 & -.933 & -.512 \\
\hline & Q6 & 52 & 4.44 & 2.88 & 8.32 & -1.39 & .204 & 32 & 4.06 & 3.27 & 10.7 & -1.09 & .329 \\
\hline \multicolumn{14}{|c|}{$\begin{array}{l}\text { Dysfunctional } \\
\text { Beliefs }\end{array}$} \\
\hline & Q7 & 52 & 7.21 & 1.71 & 2.95 & 2.33 & -1.40 & 32 & 6.59 & 2.51 & 6.31 & -.845 & -.339 \\
\hline & Q8 & 50 & 2.44 & 2.04 & 4.16 & .762 & 1.31 & 32 & 4.90 & 3.51 & 12.3 & -1.34 & -.050 \\
\hline & Q9 & 52 & 2.01 & 1.68 & 2.84 & 3.43 & 1.93 & 32 & 2.37 & 2.09 & 4.37 & 1.62 & 1.00 \\
\hline & Q10 & 51 & 4.31 & 2.86 & 8.17 & -1.27 & .257 & 32 & 6.40 & 3.08 & 9.53 & -.541 & -.821 \\
\hline & Q11 & 52 & 2.03 & 1.83 & 3.37 & 3.94 & 2.03 & 32 & 3.28 & 3.07 & 9.43 & -.381 & .792 \\
\hline & Q12 & 52 & 2.65 & 1.92 & 3.72 & .873 & 1.26 & 32 & 2.12 & 2.13 & 4.56 & -.956 & .609 \\
\hline
\end{tabular}

Note: Bold font indicates moderate $(\mathrm{n}>3.33)$ or salient $(\mathrm{n}>6.34)$ levels of difficulty,

(Gati, Krausz, and Osipow, 1996).

Readiness. Career readiness accounts for the career decision-making that precedes

engagement in the career decision-making process and helps to indicate if personal services to students would be beneficial. Students in both the domestic and international student groups indicated a lack of readiness. During the follow up interviews, one domestic female student summed up their concern by sating "[My concerns are] probably the same as others: finding a job related to your career field and figuring out how to pay your bills - and your tuition loans." (E. Mills, personal interview, participant D13, 2017).

Scores within this category for both student groups reported dysfunctional beliefs as the area of greatest decision-making difficulty; this was evidenced by their expressed needs for confirmation from a confidant or someone they trusted when making decisions as well as their overall fear of failure. These difficulty scores were supported in the interviews. A female 
domestic student commented "[originally] I believed all I could do was be a teacher and I did not think I could earn a masters or PhD, I thought my role was to be a teacher and so I did not get much support from my family economically - when there is a lot of people telling you you cannot do something and you begin to believe it until you have your own education and prove it to yourself" (E. Mills, personal interview, participant D8, 2017). Similarly, a female international student stated, "I consulted my family on decisions about my new position - so yes, they do [have an impact]. I don't change jobs without consulting them” (E. Mills, personal interview, participant I3, 2017).

Both domestic and international students expressed concerns with indecisiveness toward their chosen field. In particular, the fear of failure scored higher for domestic students compared to international students. This concept came up in several interviews. A male domestic student mentioned, "...[I have a] fear of failure- that I will not find the job I want and have my peers judge me and I will have all this education and cannot do anything with it... you have no way of knowing what is coming next because you haven't been taught or trained or learned how to survive after college" " (E. Mills, personal interview, participant D21, 2017). Another domestic male student explained "It is a new field that I am not particular comfortable with, not yet" (E. Mills, personal interview, participant D2, 2017). Likewise, a female domestic student mentioned, "I am not sure how to make that transition from taking classes [to working]. Who is going to hire me for IDT?" (E. Mills, personal interview, participant D9, 2017). And yet another male domestic student further elaborated by stating "I am still making [career] decisions ... so I am still in that process, when I look at job applications they are looking for a lot of skills and I have yet to develop the skills they are looking for..." (E. Mills, personal interview, participant D19, 2017). Similarly, a female domestic student gave a detailed example of the concept of passing 
time leading to a correct choice by stating "This may sound a little bit new age but Theory of Happenstance - an actual theory of intentional serendipity - I want to put myself in a position to talk to or interact with people who could possibly hire me... I managed to get a position teaching high school Biology because I was in the right place and the right time." (E. Mills, personal interview, participant D4, 2017).

In comparison, international students scored higher in levels of difficulty when asked whether the career they chose would solve personal problems. One female international student commented, "it is really challenging - you can finish your courses and graduate, that is challenging, but for me I think it is more about how my PhD study can lead me to continue to seek my goal" (E. Mills, personal interview, participant I11, 2017). However, students could not always rely on circumstances or acquaintances to be in support of their career decisions; and in many cases students gave accounts where people were a source of pressure for career decisions. One female international student stated "They even ask me: instructional technology what is that? Creating a you tube video? ... yeah, there is so much more to it than that-or people [at work] say you are "technology" can you fix my computer? No...No, people don't understand" (E. Mills, personal interview, participant I17, 2017). Additionally a female domestic student further elaborated “...sometimes I doubt myself and what I am qualified for so I take it upon myself to ask fellow friends and professionals for their opinion” (E. Mills, personal interview, participant D13, 2017). However, self-doubt and the need for reassurance were not the only challenges mentioned. Several career difficulties stemmed from lack of information or inconsistent information. 


\section{Career Decision-Making Difficulties Students Encounter}

Within the Career Decision-Making Difficulty Questionnaire (CDDQ) the second category, questions 13-24, pertained to lack of information (Figure 2). In this category, students were given opportunity to indicate whether they had adequate information for decision-making. This category contained the lowest levels of difficulty for both the domestic and international student groups compared to the other constructs.

Q13 - I find it difficult to make a career decision because I do not know what steps I have to take.

Q14 - I find it difficult to make a career decision because I do not know what factors to take into consideration.

Q15 - I find it difficult to make a career decision because I don't know how to combine the information I have about myself with the information I have about the different careers.

Q16 - I find it difficult to make a career decision because I still do not know which occupations interest me.

Q17 - I find it difficult to make a career decision because I am not sure about my career preferences yet (for example, what kind of a relationship I want with people, which working environment I prefer).

Q18 - I find it difficult to make a career decision because I do not have enough information about my competencies (for example, numerical ability, verbal skills) and/or about my personality traits (for example, persistence, initiative, patience).

Q19 - I find it difficult to make a career decision because I do not know what my abilities and/or personality traits will be like in the future.

Q20 - I find it difficult to make a career decision because I do not have enough information about the variety of occupations or training programs that exist.

Q21 - I find it difficult to make a career decision because I do not have enough information about the characteristics of the occupations and/or training programs that interest me (for example, the market demand, typical income, possibilities of advancement, or a training program's perquisites). 
Q22 - I find it difficult to make a career decision because I don't know what careers will look like in the future.

Q23 - I find it difficult to make a career decision because I do not know how to obtain additional information about myself (for example, about my abilities or my personality traits).

Q24 - I find it difficult to make a career decision because I do not know how to obtain accurate and updated information about the existing occupations and training programs, or about their characteristics.

Figure 2. Lack of Information

Domestic and international student scores for lack of information were low, but varied

(Table 4). When comparing the student groups, mean scores lower than 3.33 are considered negligible, mean scores between 3.33 and 6.34 are considered moderate and mean scores higher than 6.34 are considered salient (Gati, Krausz, and Osipow, 1996). Complete scoring instructions and psychometric properties are outlined in Appendix D. The international students scored moderate difficulty in only one question, compared to the domestic students who did not have any statistically significant difficulty scores in this category. The lack of moderate to high scores in this category suggest that students may have information available to them, however several scores were close to the moderate range, indicating that although not salient, the stages in the process and information about occupations could potentially cause difficulty. In support of this, the interview responses indicate students lacked confidence in next steps or lacked sufficient experience to discern between information about self or occupations needed to make informed decisions.

Table 5

Lack of Information Questions Q13-Q24 


\begin{tabular}{|c|c|c|c|c|c|c|c|c|c|c|c|c|c|}
\hline Category: & Q\# & $\begin{array}{c}\text { Dom } \\
\mathrm{N}\end{array}$ & $\begin{array}{l}\text { Dom } \\
\text { Mean }\end{array}$ & $\mathrm{SD}$ & $\begin{array}{c}\text { Sample } \\
\text { var }\end{array}$ & Kurtosis & Skew & $\begin{array}{c}\text { Intl } \\
\mathrm{N}\end{array}$ & $\begin{array}{c}\text { Intl } \\
\text { Mean }\end{array}$ & $\mathrm{SD}$ & $\begin{array}{c}\text { Sample } \\
\text { var }\end{array}$ & Kurtosis & Skew \\
\hline \multicolumn{14}{|l|}{$\begin{array}{l}\text { Stages of } \\
\text { Process }\end{array}$} \\
\hline & Q13 & 52 & 2.67 & 1.97 & 3.91 & .273 & 1.12 & 32 & 2.68 & 2.92 & 8.54 & -.385 & .800 \\
\hline & Q14 & 51 & 2.96 & 2.38 & 5.67 & .366 & 1.19 & 32 & 3.06 & 3.08 & 9.54 & -.754 & .665 \\
\hline & Q15 & 52 & 3.09 & 2.49 & 6.24 & -.046 & .944 & 32 & 3.03 & 3.13 & 9.83 & -.382 & .798 \\
\hline \multicolumn{14}{|l|}{ Self } \\
\hline & Q16 & 52 & 2.50 & 2.30 & 5.31 & 1.23 & 1.50 & 32 & 2.09 & 2.00 & 4.02 & .661 & .809 \\
\hline & Q17 & 51 & 2.35 & 2.24 & 5.03 & 1.30 & 1.62 & 32 & 2.18 & 2.17 & 4.73 & .321 & .804 \\
\hline & Q18 & 52 & 2.19 & 2.01 & 4.04 & 2.47 & 1.80 & 32 & 2.59 & 2.91 & 8.50 & .622 & 1.15 \\
\hline & Q19 & 52 & 1.80 & 1.41 & 2.00 & 2.29 & 1.82 & 32 & 2.06 & 2.12 & 4.51 & .085 & .882 \\
\hline \multicolumn{14}{|l|}{ Occupations } \\
\hline & Q20 & 51 & 2.84 & 2.50 & 6.25 & .428 & 1.28 & 32 & 2.65 & 3.32 & 11.07 & .041 & 1.15 \\
\hline & Q21 & 52 & 3.09 & 2.62 & 6.91 & .001 & 1.14 & 31 & 2.29 & 2.93 & 8.61 & .626 & 1.30 \\
\hline & Q22 & 51 & 2.98 & 2.58 & 6.69 & -.120 & 1.11 & 31 & 2.16 & 2.77 & 7.67 & 1.40 & 1.40 \\
\hline \multicolumn{14}{|l|}{$\begin{array}{l}\text { Ways of } \\
\text { Obtaining } \\
\text { Info }\end{array}$} \\
\hline & Q23 & 52 & 2.00 & 2.01 & 4.07 & 4.74 & 2.30 & 32 & 1.93 & 2.09 & 4.38 & -.493 & .763 \\
\hline & Q24 & 52 & 2.63 & 2.28 & 5.21 & .519 & 1.29 & 32 & 2.25 & 2.40 & 5.80 & -.245 & .925 \\
\hline
\end{tabular}

Note: Bold font indicates moderate $(\mathrm{n}>3.33)$ or salient $(\mathrm{n}>6.34)$ levels of difficulty, (Gati, Krausz, and Osipow, 1996).

Lack of Information. As it pertained to lack of information about self of career options one female domestic student stated “...IDT jobs - I noticed somethings vary as to what that means and what you would be doing" (E. Mills, personal interview, participant D6, 2017). Comparatively, a female international student mentioned "my goal is to become a faculty member in a research university so there is no doubt the job has to match my research interestbut I am still framing my interests" (E. Mills, personal interview, participant I11, 2017). This sentiment was echoed by a female domestic student who stated "there are some [job descriptions] that are labeled ID in higher education and then when you are in the job it is more like tech support or educational technologist. For me actually being the instructional designer, not a lot of faculty understand that role." (E. Mills, personal interview, participant D14, 2017). The lack of discernment toward career information was also reinforced when another female 
domestic student stated "One thing is finding - among the hundreds of job postings - what you need ...it is hard to know what the job really is and what is included" (E. Mills, personal interview, participant D16, 2017). Several students indicated they would need more information on types of skills and experiences needed in the field. One male domestic student summarized this need by stating "I would say the first thing [I need is] knowledge about the field -what careers are a part of that career, characteristics about those careers and what is needed to fulfill them - knowledge is the biggest thing and what those options are and then to have real experience or opportunities to practice and get a taste for those experiences -if there were any way to offer me some degree of experience that would be helpful" (E. Mills, personal interview, participant D19, 2017).

\section{Help-Seeking Resources Students Utilize}

Within the Career Decision-Making Difficulty Questionnaire (CDDQ) the third category pertained to inconsistent information as indicated in questions 25-35 (Figure 3). This category asked students to specify whether the information they needed could be relied upon to be timely, accurate and helpful.

Q25 - I find it difficult to make a career decision because I constantly change my career preferences (for example, sometimes I want to be self-employed and sometimes I want to be an employee).

Q26 - I find it difficult to make a career decision because I have contradictory data about my abilities and/or personality traits (for example, I believe I am patient with other people but others say I am impatient).

Q27 - I find it difficult to make a career decision because I have contradictory data about the existence or the characteristics of a particular occupation or training program.

Q28 - I find it difficult to make a career decision because I am equally attracted by a number of careers and it is difficult for me to choose among them.

Q29 - I find it difficult to make a career decision because I do not like any of the occupation or training programs to which I can be admitted. 
Q30 - I find it difficult to make a career decision because the occupation I am interested in involves a certain characteristic that bothers me (for example, I am interested in medicine, but I do not want to study for so many years).

Q31 - I find it difficult to make a career decision because my preferences cannot be combined in one career, and I do not want to give any of them up (e.g., I wouldlike to work as a free-lancer, but I also wish to have a steady income).

Q32 - I find it difficult to make a career decision because my skills and abilities do not match those required by the occupation I am interested in.

Q33 - I find it difficult to make a career decision because people who are important to me (such as parents or friends) do not agree with the career options I am considering and/or the career characteristics I desire.

Q34 - I find it difficult to make a career decision because there are contradictions between the recommendations made by different people who are important to me about the career that suits me or about what career characteristics should guide my decisions.

Q35 - Finally, how would you rate the degree of your difficulty in making a career decision?

Figure 3. Inconsistent Information

The scores for both the domestic and international student groups varied (Table 5). When comparing the student groups, mean scores lower than 3.33 are considered negligible, mean scores between 3.33 and 6.34 are considered moderate and mean scores higher than 6.34 are considered salient (Gati, Krausz, and Osipow, 1996). Complete scoring instructions and psychometric properties are outlined in Appendix D. Within this category, domestic students mean scores were higher than international students. The highest scores for both domestic and international students pertained to the question about choosing among various career options. Compared to the other two constructs within career decision-making difficulty, the mean scores for inconsistent information support the notion that students who have help-seeking needs know who or what to resource for support. The interview responses indicated student's resourcefulness for finding information when their first attempt or immediate contacts were unsuccessful. Several students commented on the pressure to succeed and provide for themselves or families as it related to their career expectations. 
Table 6

Inconsistent Information Q25-Q35

\begin{tabular}{|c|c|c|c|c|c|c|c|c|c|c|c|c|c|}
\hline Category: & Q\# & $\begin{array}{c}\text { Dom } \\
\mathrm{N}\end{array}$ & $\begin{array}{l}\text { Dom } \\
\text { Mean }\end{array}$ & SD & $\begin{array}{c}\text { Sample } \\
\text { var }\end{array}$ & Kurtosis & Skew & $\begin{array}{c}\text { Intl } \\
\mathrm{N}\end{array}$ & $\begin{array}{c}\text { Intl } \\
\text { Mean }\end{array}$ & SD & $\begin{array}{c}\text { Sample } \\
\text { var }\end{array}$ & Kurtosis & Skew \\
\hline \multicolumn{14}{|l|}{$\begin{array}{l}\text { Unreliable } \\
\text { Info }\end{array}$} \\
\hline & $\begin{array}{l}\text { Q25 } \\
\text { Q26 } \\
\text { Q27 }\end{array}$ & $\begin{array}{l}51 \\
51 \\
51\end{array}$ & $\begin{array}{l}2.35 \\
2.05 \\
2.23\end{array}$ & $\begin{array}{l}2.13 \\
1.92 \\
2.08\end{array}$ & $\begin{array}{l}4.55 \\
3.69 \\
4.34\end{array}$ & $\begin{array}{l}1.72 \\
4.42 \\
3.32\end{array}$ & $\begin{array}{l}1.63 \\
2.19 \\
1.99\end{array}$ & $\begin{array}{l}32 \\
32 \\
31\end{array}$ & $\begin{array}{l}2.18 \\
1.81 \\
1.80\end{array}$ & $\begin{array}{l}2.75 \\
2.36 \\
2.45\end{array}$ & $\begin{array}{l}7.57 \\
5.57 \\
6.02\end{array}$ & $\begin{array}{l}.191 \\
1.50 \\
1.73\end{array}$ & $\begin{array}{l}1.16 \\
1.39 \\
1.55\end{array}$ \\
\hline \multicolumn{14}{|l|}{$\begin{array}{l}\text { Internal } \\
\text { Conflicts }\end{array}$} \\
\hline & $\begin{array}{l}\text { Q28 } \\
\text { Q29 } \\
\text { Q30 }\end{array}$ & $\begin{array}{l}51 \\
51 \\
50\end{array}$ & $\begin{array}{l}\mathbf{3 . 4 7} \\
1.54 \\
2.14\end{array}$ & $\begin{array}{l}2.87 \\
1.50 \\
2.11\end{array}$ & $\begin{array}{l}8.25 \\
2.25 \\
4.49\end{array}$ & $\begin{array}{c}-.876 \\
13.5 \\
2.99\end{array}$ & $\begin{array}{l}.790 \\
3.55 \\
2.02\end{array}$ & $\begin{array}{l}32 \\
31 \\
32\end{array}$ & $\begin{array}{l}2.65 \\
1.45 \\
1.84\end{array}$ & $\begin{array}{l}2.69 \\
2.26 \\
2.21\end{array}$ & $\begin{array}{l}7.26 \\
5.12 \\
4.91\end{array}$ & $\begin{array}{c}-.049 \\
3.73 \\
-.374\end{array}$ & $\begin{array}{r}.949 \\
1.99 \\
.969\end{array}$ \\
\hline & Q31 & 51 & 3.19 & 2.71 & 7.36 & -.277 & 1.03 & 32 & 2.65 & 3.03 & 9.20 & .059 & 1.06 \\
\hline & Q32 & 51 & 2.01 & 1.70 & 2.89 & 5.64 & 2.24 & 32 & 2.09 & 2.40 & 5.76 & .064 & 1.04 \\
\hline & $\begin{array}{l}\text { Q33 } \\
\text { Q34 } \\
\text { Q35 }\end{array}$ & $\begin{array}{l}50 \\
51 \\
51\end{array}$ & $\begin{array}{l}1.46 \\
1.86 \\
\mathbf{3 . 4 9}\end{array}$ & $\begin{array}{l}.908 \\
1.54 \\
2.43\end{array}$ & $\begin{array}{l}.824 \\
2.40 \\
5.93\end{array}$ & $\begin{array}{c}5.41 \\
1.64 \\
-.798\end{array}$ & $\begin{array}{l}2.33 \\
1.75 \\
.729\end{array}$ & $\begin{array}{l}32 \\
32 \\
32\end{array}$ & $\begin{array}{l}1.34 \\
1.56 \\
3.28\end{array}$ & $\begin{array}{l}2.28 \\
2.52 \\
2.56\end{array}$ & $\begin{array}{l}5.20 \\
6.38 \\
6.59\end{array}$ & $\begin{array}{l}2.29 \\
3.74 \\
.038\end{array}$ & $\begin{array}{l}1.82 \\
2.00 \\
.665\end{array}$ \\
\hline
\end{tabular}

Note: Bold font indicates moderate $(\mathrm{n}>3.33)$ or salient $(\mathrm{n}>6.34)$ levels of difficulty,

(Gati, Krausz, and Osipow, 1996).

Inconsistent Information. For the subcategory of inconsistent information, students appeared to be most concerned with unreliable information and internal conflicts such as contradictory preferences. In comparison, the interview responses indicated more external conflicts pertaining to disagreements with significant people in their lives. Domestic students scored higher than international students when asked if they found it difficult to make a career decision due to contradictions between the recommendations made by people they trusted, the career that suited them, or the career characteristics that should guide their decisions. This was also underscored in the interviews when asked about the impact culture, advisors, and family had on their career decision-making. 
One female international student stated "My parents are back in China and are not highly educated, I am the first college student in my family and now PhD student in my family. They can give me spiritual support but mostly I am very independent" (E. Mills, personal interview, participant I11, 2017). When asked specifically about family pressure, a female international participant mentioned, "My family is not really interested in hearing about my decisions - because I am the first person to go to college in my family and first person to come to the US to graduate. They don't know this field or what this college life is like - I am the authority in my family to talk about my career-but with my friends I don't like them interfering in my career choices, only my advisor or role models - they can impact my career" (E. Mills, personal interview, participant I20, 2017). Another male domestic student living abroad further elaborated by stating "Many students in Korea are in the degree programs their parents wanted them in while they recognize full well that their passions lay elsewhere. I was able to follow my interests from the time I graduated high school. This may be my family rather than the larger culture, though" (E. Mills, personal interview, participant D15, 2017). In comparison, a male domestic student stated, "That is probably the biggest pressure, I have a family [to support] and it is the biggest factor in my career decisions, everything else is second to that" (E. Mills, personal interview, participant D19, 2017).

Several international students were aware of how their culture impacts their career decision- making. In fact, students commented on how being from a specific country was significant in their decision-making. One female international student mentioned "There are two things - when you say you are Hispanic you are automatically attached to the language - people assume you want to learn, or to be, or work in a Spanish speaking environment and that is not necessarily the way it is when searching for a job... When you say Spanish is your first language 
and English is your second language people believe your English is not that strong. For instance when I was applying for the doctorate at my school I was offered to do it in Spanish, being from a Spanish country and speaking Spanish leads to assumptions even if you don't want them to... People really think that if they understand a tiny bit [of culture] they understand it all, but they do not"”, (E. Mills, personal interview, participant I12, 2017). This acknowledgement for the differences between cultures was also expressed by a female international student who shared "In [my home country] we have a feeling for needing long term or secure jobs where you can work a long time instead of working at a job for a short time and moving around like here [in America]” (E. Mills, personal interview, participant I20, 2017).

Other international students alluded to "hidden rules" or cultural nuances they had to overcome. A female international student gave an account of her experience by stating: "I am learning to work here I am still trying to improve my speaking and writing as opposed to English native speakers who don't have that problem, even though we are learning English for a long time, speaking and writing are challenging-and the other problem is that there are rules that we need to follow here and obey but there are unwritten rules that you have to obey - if you contact your professor you need to talk about a particular things- how you contact people or how you need to talk to advisors are different from my home country-what professors consider is wrong is totally different here in the United States. I need to learn those hidden rules and that takes time” (E. Mills, personal interview, participant I20, 2017). Similarly a female international student mirrored that sentiment by stating "Because I am from China, even though I have been in the US for several years I believe I still need to improve my English and understanding about American culture” (E. Mills, personal interview, participant I11, 2017). 
In comparison, domestic students indicated little awareness of cultural impacts on their career and many were unable to describe it in detail. In most instances, domestic students instead provided examples pertaining to race and gender as opposed to country of origin. One female domestic student stated "I would like to say no [culture does not have an impact], but...I am white, - meaning I do have a benefit in America ... I like to talk about science and what is coming up and even my coworkers felt that was strange. I don't know if that is a cultural influence but it has influenced my decision to live and work in a city environment vs a rural environment” (E. Mills, personal interview, participant D4, 2017). Another female domestic student further elaborated by stating "[I am a] US Citizen, I really cannot think of a way that it does [impact] other than some of the jobs as faculty-the faculty culture - there is a sort of a prestige along with those positions, but strictly instructional design jobs I cannot think of anything cultural that would impact the process for me” (E. Mills, personal interview, participant D6, 2017). A female domestic student mentioned "I am an American where women are breaking through the glass ceiling. Ifeel empowered to make decisions for myself and my family” (E. Mills, personal interview, participant D7, 2017). This was mirrored by a similar statement by a female domestic student who said "Growing up in the US and being more current we don't really have issues. We have more opportunities, even being a female ... but I have experience issues in the workplace.... My culture has not influenced in my job search processmy past experiences maybe have influenced how I have approached things once I am in a job but not necessarily job search” (E. Mills, personal interview, participant D13, 2017). Additionally, a female domestic student described the cross section of culture and networking by stating "culture can be defined in different ways. In terms of ethnicity - I do certainly think about some connections with the same background as me are helpful - I am black - so people with the same 
background, or in my sorority, or church - networking - might mention "did you see that opening" - In fact one of my friends have helped me in looking at positions in a different school district - that might not be culture...rather networking" (E. Mills, personal interview, participant D9, 2017). Another male domestic student echoed that response by stating "Yes - I am African American - I hear a lot of talk about different issues in the business world - I haven't had issues with that. But I am sure my ethnicity influences [my decision-making]” (E. Mills, personal interview, participant D21, 2017).

American culture was also described in terms of social economic status. One female domestic participant stated "I am looking for white collar positions vs blue collar positions and plus I am in the northern area of the nation so that has an impact on culture and diversity - not just being a woman - being a woman is not often diverse enough compared to ethnic culture” (E. Mills, personal interview, participant D14, 2017). Comparatively other domestic participants were unable to describe cultural impact. A male domestic student stated "I don't interact with any international students but I would imagine there is a difference, the thing that comes to my mind is that where I am looking for careers is limited to the US where international students may consider two areas - so location is different and there are cultural differences, but because I am not an international student I don't know how my culture and citizenship makes a differencebut I know that it does” (E. Mills, personal interview, participant D19, 2017).

In contrast, an American expectation for success was underscored in the following statement from a male domestic participant "So in my family - my mother is a CEO my dad is a regional director for a Fortune 500, my mom has a masters and my dad went to college - there was an expectation that you will go to college, move up the chain and be in a senior leadership position - it was never a question of if I would go to college or get a graduate degree - 
expectations set by my family and the culture of the city I grew up - everyone was highly educated - it was an expectation” (E. Mills, personal interview, participant D16, 2017).

Internal Conflicts. When it came to describing what was most important in their career decisions pertaining to employment, several domestic students commented on their desire for high earning potential and flexibility in contrast the majority of international students who stressed the need for fit within an organization or company. A female domestic student stated "In order of importance to me: Job duties that sound interesting and challenging to me. Good pay. Good benefits" (E. Mills, personal interview, participant D7, 2017) and another female domestic student echoed "I consider location and schedule and hours and finally compensation including benefits [most important]" (E. Mills, personal interview, participant D9, 2017) followed by a third female domestic student who shared "If I were looking for a position after graduation I would look for something with creativity - not just copy and pasted templates for learning, but rather a position with freedom for professional growth" (E. Mills, personal interview, participant D2, 2017). A male domestic student summarized these statements by stating "I look at advancement - is there potential for me to advance in a certain number of years -I also look at the pay scale - and the possibility to move up quickly before 5 years." (E. Mills, personal interview, participant D21, 2017).

Comparatively international students were focused on job fit. One female student stated, "The most important thing is the job description - it is about my qualifications" (E. Mills, personal interview, participant I18, 2017) followed by another female international student who said "The most important thing is that I do what I love doing and that I am able to work where I love to work" (E. Mills, personal interview, participant I12, 2017), and echoed by another female international student who stated "it was important to me to plan - I considered the job and if it 
was a match my qualification and how it would help me gain experience in the field. The other considerations would be to gain a position where there is room for growth and [then consider] salary” (E. Mills, personal interview, participant I3, 2017). These statements combined led to further elaboration on the need for specific resources.

External Conflicts. Generally speaking, students were aware of resources they could turn to for assistance including human and non-human sources of information. However, both groups acknowledged the need for human support and assistance with careers. Within the follow up interviews, students vocalized a preference for human interaction over non-human help seeking sources but only under certain context.

Human Sources of Information. The most frequently mentioned human source for helpseeking was an academic advisor or mentor. One female international student shared "Honestly for the people I know there is only one person who tends to understand me [outside of academia]-but other than that I search [for answers] online because people don't know about instructional technology" (E. Mills, personal interview, participant I17, 2017). Another female domestic student stated "I have a trusted confidant I talk to about all potential jobs I would apply for. She knows me and my personality and can see when a job would be a good fit or not and provides me good advice about whether I should apply for the job and reads over my resume/vita for me before I submit it. The only time I would use a website is to check out more information about the company posting the job" (E. Mills, personal interview, participant D7, 2017). Followed by another female domestic student who commented "I am more likely to go to a person more than website - so my advisor and others in my cohort and conferences and classmates I have shared projects with would be the ones I would want to listen to. Networksthey grow like a spider web or river - for example a cohort partner of mine she and I worked on 
a project together and then I found 7 others who have similar ideas and I followed them on Twitter and then even saw a job opportunity posted. Like a ripple effect-it starts with a human element then I end up on technology along the way" (E. Mills, personal interview, participant D2, 2017).

Positive interactions with advisors were frequently mentioned. One male domestic student stated “...their advice was invaluable to me in deciding to apply to a reputable program and when I have had questions about [my] career path I would contact them to shoot me straight and provide insight drawn from their own experience" (E. Mills, personal interview, participant D19, 2017). Another female domestic student commented "they are always helpful and always there - I have a pretty good relationship with my advisor... they helped me in getting into the program as I have a different background... my advisor encourages me ... I see they are doing great [with] their publications and their knowledge - I hope one day I am like them" (E. Mills, personal interview, participant D4, 2017).

However, in terms of timeliness, some students turned to a mentor or colleague other than their advisor if they felt their advisor was not forthright in their communication or had research interests outside of their own. One female international student curtly stated "[my advisor is] so inadequate and delinquent about returning my questions it has been useless for me" (E. Mills, personal interview, participant I18, 2017). Another female international student mentioned "I do not actually I feel I get enough support from her - she is working on her doctorate and in and out of the office and out of the country and is unavailable- it would take a few days to reply. I was never really clear [on my plan] ... I would send my plan of work and it would take 2 weeks to get a response, other people had to help me - I did not want to take classes unnecessarily but I ended up taking one class that was not on my plan. I don't have the money or the time for 
that” (E. Mills, personal interview, participant I17, 2017).

Frequency of contact came up several times. One male domestic student indicated " $M y$ current advisor [and I] had some conversations about [my career], she [said] I think you could do things like "this" do you want to be a professor (?) - I was like errr maybe - Compared to my undergrad advisor we met all the time and she was constantly saying you should think about this, there is this job fair, or take a look at this job... her office was outside the classrooms and she was always available - but my current advisor is a professor with a different role and they advise in addition to being a professor as opposed to just advising” (E. Mills, personal interview, participant D16, 2017). Similarly, international students also felt pressured for time and information. One female international student stated "It is not really easy to find jobs, its challenging, we have limited amount of timing and people have to pay for our visa-and this year H1 Visas are more limited. I am a little worried about this. That is one of the biggest issuesthe second issue is that it is hard to save money here because internationals do not get paid [through financial aid]. I need to save some money before I graduate so I can move to another state - to work - but it is not very possible. [It] is kind of scary to think about the future when I graduate” (E. Mills, personal interview, participant I20, 2017).

Some of the students mentioned a struggle with their advisor or a frequent change in who they were to report to that caused a gap in services provided. It is in these instances that students had to demonstrate resourcefulness. One female international student explained "My direct current advisor and I are oil and water and it is not working for me so I have been connecting with another professor in the program and working directly under her where I think have flourished - she has taken the time to figure out who I am and what I am interested in what my passion is and she shares those with me. My current advisor is more for formal with class 
selection - he follows more of a template, where my faculty contact follows more a personal flow. I do have [career] resources but with my direct advisor no, but another faculty member in my cohort yes" (E. Mills, personal interview, participant D2, 2017). Frequent school changes and faculty turn over seem to have an impact on student's access to advisors as a career resource as well. A female international student stated "I don't even know who my advisor is at this moment - there have been a lot of changes at my school. At first I had an advisor that retired my first year there, then my second advisor did not advise me on anything and now I have 3rd advisor who I just met. Its not good.” (E. Mills, personal interview, participant I12, 2017).

Another female international student brought up challenging cultural aspects of working with their advisor by stating "I had some problem with my advisor... she and I did not have common project interest and it was not practical so I talked to another prof in my department who was studying something I was interested in - but my advisor was angry about suggesting to change-another hidden rule. The advisor I wanted decided not to be my advisor because my first advisor said something to her because she did not want to step on the foot on the professor who was in tenure.-another secret hidden rule - that no one [wants to] teach the international students. But I found someone who was really friendly and open to all students especially the internationals who knew the international students have problems and he agreed to help me no matter what other people say - his interests are still different from mine - he is not an advisor only [supportive] emotionally as a career mentor" (E. Mills, personal interview, participant I20, 2017).

Non-Human Sources of Information. Students from both groups indicated they would be comfortable seeking non-human sources of career information, and some stated this was their preference under certain circumstances. One female domestic student shared "I would probably 
would go to a non-human source first that is how I am wired. If I wanted to talk about a specific exponential thing I might look for a person, but I tend to go to the internet and industry based websites/blog” (E. Mills, personal interview, participant D7, 2017). Another female domestic student had a similar approach and mentioned, "I would first seek out a non-human source. Because what I would want to do is to narrow down who do I want to talk to. I would look up information like I said I do a lot of reading, if that is not satisfied or if I cannot figure out what job title I should be looking for I realize I need to talk to all the people-humans. Reading may not clarify it enough" (E. Mills, personal interview, participant D6, 2017). However, not all students knew where to look for career information. One female domestic student explained this in more detail by stating, "With technology - if you have a question in the middle of the nightfortunately I can go to the occupational outlook handbook and search engines for jobs and job boards that I can go to, but I still at the same time think it is important to talk to someone. For example there is a career development network in my area where I can easily access one of my peers - I think I am in a much better place to find help - but the average person may not know where to begin. Yesterday I spoke to someone in their late 30's struggling with career decisions and reached out to me for help. There is so much there - even if the information is helpful -but if you don't know where to begin a personal contact would be more important than an electronic resource - but you have to go and find them" (E. Mills, personal interview, participant D9, 2017).

Another female international student mentioned their hesitation with inaccurate sources of information from people by stating "Non-human sources are more updated [compared to a] person who "they may have heard something" or they tell you you need something on a website -the human part is not always more accurate than the website. However, after you have made 
this first search, and submitted everything then I would search for the human part but not before [a career decision], I have to have the information, the knowledge and the opportunity and requirements and then go to submit the papers [for a job. If there is a person who can help perfect, if not - it is just me against other people looking for the same employment" (E. Mills, personal interview, participant I12, 2017).

Students also described a need for more tailored career resources. One female domestic student commented "It is weird because my program is all online and we have doctoral enrollment counselors, but I have had 6 different ones, so I don't really establish relationship with them, they have advised on courses. The university now has a career services office, which I haven't started to look into yet. But it is probably in place due to changes to financial aid and being able to prove your graduate students are employable - that is my guess" (E. Mills, personal interview, participant D13, 2017). Another male domestic student described their recent finds "I found the articles on CV writing very valuable" (E. Mills, personal interview, participant D15, 2017). This comment was reinforced by another male domestic student who stated 'Since I am not looking for jobs yet I haven't vetted many online resources as much as others may have, but I will say that the human interaction between me and my advisor and faculty at other instructions has been what I needed most - everything else has been marginally beneficial. I do not see that changing a lot-even on AECT's website I would better benefit from a session on careers for graduate students than a pamphlet or website link" (E. Mills, personal interview, participant D19, 2017).

While the domestic and international student groups shared overlapping themes within their interview responses and personal experiences, their CDDQ average scores per category varied. Overall international students scored higher than the domestic students in the readiness 
category, whereas the domestic students scored higher in the inconsistent information categories. Scores for both groups were closest and lowest in the second category pertaining to lack of information about the career process indicating that they were aware of information about careers as well as themselves, however lacked application of the information they had received when presented with too many career options, or inconsistent information. A summary of the findings as they relate to the research questions as well as the independent t-test scores for each category can be found in Table 7. Additionally, a summary table of the qualitative findings are compared and contrasted between the domestic and international student groups below (Table 8).

Table 7

Overall Quantitative Findings Between Groups

\begin{tabular}{|c|c|c|c|c|c|}
\hline Construct & $\begin{array}{c}\text { Dom } \\
\text { Category } \\
\text { Mean } \\
\mu \\
\end{array}$ & $\begin{array}{c}\text { Intl } \\
\text { Category } \\
\text { Mean } \\
\mu \\
\end{array}$ & T-test & Var & df \\
\hline Lack of Readiness & & & -.602 & 2.74 & 22 \\
\hline Motivation & 2.47 & 1.81 & & & \\
\hline Indecisiveness & 3.92 & 4.17 & & & \\
\hline $\begin{array}{l}\text { Dysfunctional } \\
\text { Beliefs }\end{array}$ & 3.44 & 4.27 & & & \\
\hline Lack of Information & & & 1.06 & .165 & 22 \\
\hline $\begin{array}{l}\text { Stages of } \\
\text { Process }\end{array}$ & 2.90 & 2.92 & & & \\
\hline Self & 2.21 & 2.23 & & & \\
\hline Occupations & 2.97 & 2.36 & & & \\
\hline $\begin{array}{l}\text { Ways of } \\
\text { Obtaining Info }\end{array}$ & 2.31 & 2.09 & & & \\
\hline Inconsistent Informatior & & & & & \\
\hline Unreliable Info & 2.21 & 1.93 & 1.01 & .521 & 20 \\
\hline Internal Conflicts & 2.47 & 2.13 & & & \\
\hline External Conflicts & 2.27 & 2.06 & & & \\
\hline
\end{tabular}

Note: Bold font indicates moderate $(\mathrm{n}>3.33)$ or salient $(\mathrm{n}>6.34)$ levels of difficulty, (Gati, Krausz, and Osipow, 1996). 
Table 8

Overall Qualitative Findings Between Groups

\begin{tabular}{|c|c|}
\hline Research Question & Domestic Students \\
\hline $\begin{array}{l}\mathrm{RQ}_{1} \text { : What are the } \\
\text { career needs of } \\
\text { international and } \\
\text { domestic } \\
\text { instructional } \\
\text { design students? }\end{array}$ & $\begin{array}{l}\text { Domestic students were more aware of } \\
\text { the impact of social economic status, } \\
\text { gender and race. Students expressed a } \\
\text { desire to have employment benefits } \\
\text { when looking for positions. They also } \\
\text { articulated their needs for flexibility or } \\
\text { advancement more readily compared to } \\
\text { their international student counterparts. } \\
\text { This underscores the domestic student's } \\
\text { awareness to the variety of employment } \\
\text { options and may be a contributing factor } \\
\text { in their higher scores within the } \\
\text { inconsistent information category }\end{array}$ \\
\hline
\end{tabular}

$\mathrm{RQ}_{2}$ : What career

decision-making

difficulties do

international and

domestic

instructional

design

students

encounter?

Domestic students expressed they had information available to them but lacked the ability to decide or discern options that were best for them among the various choices. Students expressed high expectations for their success and often expressed a fear of failure. Domestic students questioned their academic return on investment, and expressed their awareness of the financial impact on their decisionmaking as it pertained to providing for themselves of their families now and in the future.

$\mathrm{RQ}_{3}$ : What helpseeking resources are domestic and international students utilizing when

\section{International Students}

Although similar to domestic student career needs, the international students greatest carer decision-making difficulty stem from lack of readiness. This may be attributed to the fact that the international students may be unaware or unfamiliar with career decision-making resources available to them, however in contrast to their domestic student colleagues the international students are more selfaware and able to articulate the impacts their home and host cultures have on their decision-making.

International students were working within two cultural contexts and experienced both internal and external career decision-making pressures. International students could express their decision-making difficulties as they pertained to their home and host culture. Students were seeking timely information that could help them achieve their goals, and often included the approval or input from family and friends within the decision-making process. Students expressed a need to work with advisors or mentors who were accepting of international student challenges.

International students sought mentors, advocates who could understand the time sensitive nature of their employment decisions, would take time to answer their questions and help them navigate a home or host country job search. They expressed an 
making career decisions? forced to choose between contradictory options. Overall the domestic students indicated they were able to find and compare non-human sources of information more readily and would chose non-human sources over humansources of information. However, the domestic students expressed the importance of networking from a student and professional employment perspective. overall lack of confidence in interacting with academic human help-seeking resources, however expressed a strong tie to family and friends who served as networks for assisting with their decision-making process. 


\section{CHAPTER IV}

\section{DISCUSSION}

Social Cognitive Career Theory, (SCCT) is a relatively new theory aimed at explaining the interrelated aspects of career development. SCCT includes how basic career interests develop, how choices are made and how career success can be obtained (Bandura, 1986; Lent et al., 1994). Self-efficacy refers to an individual's personal beliefs about their capabilities to achieve a desired course of action. However, unlike self-esteem, self-efficacy is dynamic and can change based on specific activities or environments. As a result people can vary in their selfefficacy as it relates to career decision-making. For example, in this research there were areas in which students indicated confidence or low difficulty scores within the Career Decision-Making Difficulty Questionnaire (CDDQ). This could stem from an individual's belief that their performance or tasks are easy to achieve. However, SCCT assumes that people are likely to become more interested in and pursue and/or effectively perform in areas in which they have strong self-efficacy beliefs. This is contingent upon having the necessary skills and support to be successful. It is within these support systems that this research derives its strongest implications.

Career decisions are among the most important decisions students can make at different stages within their lives and difficulties in career decision-making are among the most prevalent vocational problems (Amir \& Gati, 2006; Osipow, 1999). If not addressed, students run the risk of avoiding the decision-making process all together, halting their attempts, or making decisions that are less than optimal (Gati, et al., 1996). To be successful in a radically changing world of work, students must be eager to express and overcome career related difficulties. This study tried to take into account the difficulty factors that impact student success as it relates to career readiness, lack of information and inconsistent information. This study may benefit graduate 
students, their university advisors, and professional organizations by helping students and practitioners gain a better understanding of career decision-making difficulty, as well as helpseeking utility among graduate students. The results of this study advocate for stronger student support and attention toward a practice of more meaningful strategies for engaging students in the career development process, thereby creating more educational and vocational success. Additionally, suggestions and recommendations for career development for graduate students and ideas for possible future research are provided in the latter section of this chapter.

According to Osipow (1999), career indecision is a state that comes and goes over time, and is considered a critical part of student development. Many individuals face career decisions that stem from a variety of sources including difficulties with personal identity, and vocational understanding (Gati et al., 1996). When students in this study were asked what their specific career needs were, they were more likely to comment on uncertainty about the process and on their own resourcefulness in finding individuals whom they could turn to for advice rather than identifying a particular problem itself. The implication being that there is a greater need for more information about the stages of career decision-making, (including self-identity), and occupational information (including reliable and trustworthy information), rather than identifying any particular stigma attached to seeking assistance from human or non-human sources or an overall lack of information.

The higher levels of difficulty experienced by international students in the readiness category suggest that there is a greater need for information about services targeted at different student developmental levels taking into account years within their graduate program, duration of stay within the United States, and levels of work experience. Comparatively, domestic students expressed higher levels of career decision-making difficulty in the inconsistent 
information category; indicating that they sought and valued various career options, but had difficulty deciding and discerning best options for moving forward with their careers. This underscores a need for academic advisors to be aware of not only the clarity of information provided but also the quantity of options that students must choose from. In this study, domestic students expressed a delay in their decision-making when they felt there are too many choices. Emphasis should focus on providing career resources to address specific time sensitive needs for information and advisors should be mindful of how the impact on too much information or choices impact their student's career decision-making. This research also suggests that difficulties related to external and internal sources of conflict rely heavily on access to timely and accurate sources of information as well as an individual motivation and discernment for understanding and sorting through the various types of information available for consumption. Without such skills, student's career difficulties may prevent them from reaching a decision or may lead them to seek assistance in making a career related decision that have direct implications for advising and interventions.

\section{Implications for Academic Advisors}

This study revealed that students although often motivated to achieve career goals, may struggle with various aspects of the career decision-making process including various student needs, levels of difficulties and desired resources for assistance.

Career Needs of International and Domestic Instructional Design Students. A clear understanding of the influence of domestic and international student needs are critical to providing appropriate career guidance and effective career development interventions. Because decision-making must take into account not only what takes place in the student's present situation, but also on how they feel about their past experiences, and one's hopes or future 
aspirations, student career needs are complex. Individuals struggling with career decisions often seek assistance from an advisor, trusted friend, or family member. The interviews within this study suggested that most advisors and mentors were already serving students by answering basic questions concerning the job search process. Findings from this research suggest that career guidance and academic advisors should assist students in understanding the personal facets that influence their decision-making, and seek to affirm their career decisions. This thus alters an advisor's role from helping students in making matches within their career interests to helping nurture students throughout the entire career decision-making process. This shift requires advisors to take into consideration a more broad approach to addressing career needs that includes factors such as facilitating a student's sense of confidence and self-efficacy to achieve their goals, along with financial, personal or cultural circumstances within career decisionmaking (Dagley \& Salter, 2004; Parker, 2002).

Current research suggests that cultural differences between the student and advisor concerning help-seeking tendencies may lead to premature avoidance or termination of counseling among international students (Atkinson, 1983; Mori, 200; Pederson, 1991; Zhang \& Dixson, 2003). In response, advisor education programs could be developed to aid in preparing advisors for this type of caseload. Advisor education programs could increase the campus' focus on diversity and on career decision-making issues as greater multicultural competency may be the central factor in enhancing the help-seeking resources provided to students in the future. Advisor education programs could include reference materials such as handouts, or cultural guides to help advisors meet various levels of student needs and expectations for cultural understanding. Additionally, these resources may help advisors guide students to sources of credible and reliable career information that are culturally appropriate. By becoming more 
culturally aware and culturally sensitive to the various needs of the international student body advisors may find that the student's awareness of, frequency for, and outcomes associated with making informed career decisions are impacted. Practitioners should evaluate the effectiveness of their interactions with both domestic and international student groups. Through a constant improvement approach to student support, intervention efforts can be strengthened from data collected and experiences captured.

While students within this research were often critical of their needs and available resources for help, they were not indiscriminate in their criticisms. During the interviews students were able to account for times in which they had sought the guidance of peers and advisors, or in retrospect would recommend that students find ways to seek specific career guidance instead of relying solely on their own abilities.

\section{Career Decision-Making Difficulties of International and Domestic Students. In}

addition to career readiness difficulties, many students expressed internal and external sources of conflict within their decision-making process. Advisors can encourage students to consider the importance of significant others (family, mentors, or peers) and their impact on their perspective of career alternatives or decision-making. However, in order to be effective, advisors must first be able to recognize and anticipate cultural differences within career decision-making tasks. A vast array of difficulties among cultural groups may require differentiated approaches to student success that may ultimately prove to be overwhelming for academic advisors depending on the diversity among their students. As such, advisors could incorporate student leaders into the design, delivery and evaluation of help-seeking resources. These student leaders might benefit from working together with existing academic advisors to provide information as well as support for students in need of career assistance; therefore, creating a greater resource network. Special 
attention could be given to groups of international students, who in this sample, had higher levels of career decision-making difficulty and may be more likely to seek help from a friend or trusted mentor first before seeking a professional. However, as students, and advisors continue to approach career decision-making difficulties from a variety of interventions, several practical implications can also be applied to professional organizations who aim to assist students with help-seeking resources.

Help-Seeking Resources Utilized by Domestic and International Students. Gati, et al., (2001), have suggested the effectiveness of non-human sources of information as they relate to reducing career decision difficulties, and many organizations are taking advantage of webbased technologies to provide career service information, advising and student resources (Moneta, 2005). Professional organizations may consider offering career mentors who could research career difficulties, cultural differences, and employment best practices in attempt to provide less formal career guidance through a non-human resource such as a website or career resource database. Serving as outreach partners in developing this career resource these mentors could compile career information relevant to graduate instructional design student needs, aid in providing timely and accurate information, or more specifically research an international student's country of origin to help educate international students of the differences between home and host country job searches.

Students within this study rated greater difficulty before the decision-making process (readiness) than during the process (lack of information and inconsistent information). This may be because graduate students are more likely to be actively seeking career information. The study's findings suggest that more resources may be needed to prepare students within the areas of indecisiveness and dysfunctional beliefs. More specifically, the students who scored low in 
their readiness may benefit from face to face services with a long-term intervention whereas students with high readiness could use self-help services with little or no assistance from advisors (Mau, 2004).

By creating informational literature that specifically targets the needs of instructional design students information can be more easily administered to those who may be unfamiliar with the types of support and resources that are available to them. Additionally, this research suggests that expanding an organization's web-based resources to contain information about the various tenants of the career development and offering online resources within each stage of the career decision-making process could prove beneficial. Performance improvement practitioners could benefit from additional research by identifying and sharing challenges associated with working with diverse student populations.

\section{Limitations}

Although this study seeks to provide the linkage between SCCT and career decisionmaking difficulties, it has limitations. First career decision-making is limited to the perspectives and experiences of the participants. Although they may share many similarities and differences within their processes, their experiences were individual and case specific. Any discussion of student needs must take into account the heterogeneity of the domestic and international student population as well as the individuals who serve them. Since students come from diverse cultural, economic, social and linguistic backgrounds, they cannot unproblematically be characterized as having certain "qualities" or "experiences". Each person's experience is different and part of the value of the graduate student experience in the United States relies on each person's discovery and application of American culture. 
Despite the fact that each student gave an account of their career decision-making difficulty, analysis is limited to the career decision-making steps the students were able to take, and may not represent every required step or difficulty in the career decision-making process. This research intentionally studied a group of narrowly defined students and the results likely do not transfer to other disciplines nor are they likely transfer to other professional association's student members. It is also important to understand the context in which the questionnaire and interviews were administered. For the international students in particular, a student who is assessed as being indecisive could in fact be "normal" within his or her own cultural environment (Mau, 2004). In fact, family ties and pressure from family in their home country could lead students to rely more heavily on a support person's approval in career decision making. Specifically students from collective cultural backgrounds may involve parents, family members or close family friends in the decision-making process to a greater extent compared to their domestic student colleagues (Akutsu, Snowden, \& Organista, 1996; Mau, 2004; Pederson, 1991; Yi, Lin, \& Kishimoto., 2003). As indicated in the present study, international students were much more likely to experience internal and external conflicts compared to domestic students. Counselors working with international students need to pay more attention to the kind of conflicts students are struggling with and use culturally appropriate techniques and interventions to help them resolve any presenting problems (Mau, 2004).

This niche group of students required focused and targeted marketing that influenced the recruitment phase of the study. Recruitment time was doubled in order to expand the time for responses given the lack of response rate in the beginning of the study. Part of the recruitment difficulty was due to the fact that many international were not willing to come forward and address the challenges associated with career decision-making. They were hesitant to speak to 
their visa status or employment goals. As a result, this study contained a larger number of domestic student participants, and the time to collect data was extended from 6 to 12 weeks. Additionally, there were more female participants compared to male participants. A more diverse group of participants may have led to deeper understanding of the presenting problem and student's resourcefulness or need for assistance.

It is important to recognize that English may not be the first language of the international participants. Furthermore, career decision-making is very personal and often an emotionally sensitive topic (Krumboltz, 1993). Students, by virtue of cultural and language differences, may have experienced difficulty expressing their feelings about difficult career decisions (Reynolds \& Constantine; 2007). The limitations of this study provide avenues for future research.

\section{Future Research}

Feedback from this study helps to focus attention on areas of difficulty in career decisionmaking, differentiated needs between domestic and international student groups and the resources students utilize. Future research focusing on male and female differences in helpseeking behavior may uncover specific career needs for each group. As this study took place within one professional organization, it is unclear if the distinction in the career decision-making difficulties found between domestic and international students result from the nature of the context of this organization or the individual student's approach to career decision-making. This study should be replicated across multiple organizations, including comparisons between large and small organizations, to determine if domestic and international students' influence on career decision-making are yield similar results in other contexts. 
Future research could also focus on exploring factors that may encourage or discourage students from seeking assistance. Specific student characteristics should be investigated. For example, future research may focus on the interaction of a specific country of origin, which could include the cultural interactions between the advisor and the student. Additional student characteristics, specifically as they relate to the utilization of human and non-human resources may be especially productive and warrant further investigation into the influence of length of stay in the United States, education levels of significant others, and whether or not the student is the first persons in their family to attend a college or university. The results of this study confirm previous findings regarding the importance of relationships and resourcefulness in career decision-making (Brown \& McPartland, 2005; Phillips \& Jome, 2005).

This study also raises questions around the level of experience of the participants. Students in this study described their career decision-making difficulties as they related to being in a graduate degree program, which included various levels of experience and employment. Student participants could be examined more closely for nuanced differences between novice and experienced levels of employment as novice learners may struggle with different needs, access to information, or help seeking resources compared to those who have currently worked or were working full time in instructional design during the time of their studies. Results may influence specific factors such as cultural identity, values, or decision-making styles within career development.

Investigation into the development of integrative career resources including both human and non-human sources remains necessary (Goodman \& Hansen, 2005; Harris-Bowlsbey \& Sampson, 2011). A variety of research methodologies should be employed to investigate how and why learners make career decisions in the context of graduate studies. These new studies 
could help determine the applicability of career assessments and further expand the body of knowledge on multicultural counseling.

\section{Conclusion}

This study originated from discussions between a student service practitioner and a career center and grew out a concern for increased resources, specifically for international students. Current instructional designers came together to identify a problem and the researcher set about providing empirical support for the problem. Students did not distinguish between their needs and difficulties in the career decision-making process, but rather spoke of the two in context with one another. The implications of this study appear to be clear: Students need career services, more efforts need to focus on making students aware of the career resources they have at their disposal, and then perhaps more critically, more resources need to be allocated to provide those services to diverse groups of students.

This study also suggests that international students and domestic students have specific needs and helps bridge the gap between students and practitioners in the field. The results of this study further underscore the need for more student awareness. The mixed methods approach uncovered the influence of external and internal sources of conflict and behavior that had an impact on the career decision-making difficulties of each student. Phenomenology revealed previously unknown dimensions of relationships, information seeking, and specific career needs among the graduate instructional designers. Qualitative approaches such as interviewing, allowed the participants to describe their actual career decision-making difficulties in a real-world context. This approach led to new understanding of the career decision-making process, the multifaceted difficulties students encountered, and previously unexplored influences of the lack of consistent or reliable career information. 
The results of this study broaden the current literature on career decision-making difficulties. Specifically, the results of this study reinforce the need for career readiness skills training as well as accurate and consistent access to reliable career information. This study demonstrates that graduate instructional design students clearly need and utilize human and nonhuman sources of information when making career decisions. Every student deserves to derive a sense of satisfaction from his or her career decisions in order to be prepared to enter their chosen field of work; this research helps take one step toward advocating for that outcome. 


\section{References}

Adams, E., Cahill, B., \& Ackerlind, S. (2005). A qualitative study of Latino, lesbian and gay youths' experiences with discrimination and the career development process. Journal of Vocational Behavior, 66(2), 199-218.

Alexitch, L. (1997). Students' educational orientation and preferences for advising from university professors. Journal of College Student Development, 38(4), 333.

Alexitch, L. (2002). The role of help-seeking attitudes and tendencies in students' preferences for academic advising. Journal of College Student Development, 43(1), 5.

Alexitch, L. (2006) Help seeking and the role of academic advising in higher education. In

S. Karabenick \& R. Newman (Eds.), Help seeking in academic settings: Goals, groups, and contexts. (pp. 175-202). New York, NY: Routledge

Amir, T., \& Gati, I. (2006). Facets of career decision-making difficulties. British Journal of Guidance and Counseling, 34(4), 853-503.

Arthur, N. (2007). Career planning and decision-making needs of international students. In H. Singaravelu \& M. Pope (Eds.), A handbook for counseling international students in the United States (pp. 37-56). Alexandria VA: American Counseling Association.

Arthur, N., \& Flynn, S. (2013). International students' views of transition to employment and immigration. The Canadian Journal of Career Development, 12(1), 28-37.

Arthur, N., \& McMahon, M. (2005). Multicultural career counseling: Theoretical applications of the systems theory framework. The Career Development Quarterly, 53(3), 208-222. 
Association for Educational Communications and Technology, (2017). What is AECT. Retrieved from: http://aect.site-ym.com/

Astin, A. (1984). Student involvement: A developmental theory for higher education. Journal of college student personnel, 25(4), 297-308.

Atkinson, D., (1983), Ethnic similarity in counseling psychology: A review of research. The Counseling Psychologist, 11(3), 79-92.

Akutsu, P., Snowden, L. \& Organista, K. (1996). Referral patterns in ethnic-specific and mainstream programs for ethnic minorities and Whites. Journal of Counseling Psychology, 43(1), 56-64.

Bandura, A. (1977). Self-efficacy: Toward a unifying theory of behavioral change. Psychological Review, 84(2), 191-215.

Bandura A. (1986). Social foundations of thought and action: A social cognitive theory. Englewood Cliffs, NJ: Prentice Hall

Bandura, A. (1997). Self-efficacy and health behavior. In A. Baum, S. Newman, J. Wienman, R. West, \& C. McManus (Eds.), Cambridge handbook of psychology, health and medicine (pp. 160-162). Cambridge: Cambridge University Press.

Bandura, A. (1997). Self-efficacy: The exercise of control. Macmillan.

Bandura, A, Barbaranelli, C., Caprara, G., \& Pastorelli, C. (2001). Self-efficacy beliefs as shapers of children's aspirations and career trajectories. Child Development, 72(1), $187-$ 206.

Bandura, A., \& Cervone, D. (1986). Differential engagement of self-reactive influences in 
cognitive motivation. Organization Behavior and Human Decision Processes,

$38(1), 92-113$.

Bartram, B. (2007). The sociocultural needs of international students in higher education: A comparison of staff and student views. Journal of Studies in International Education, 11(2), 205-214.

Baruch, Y., Budhwar, P., \& Khatri, N. (2007). Brain drain: Inclination to stay abroad after studies. Science Direct, 42(1), 99-112.

Berntson, E. (2008). Investigating the relationship between employability and self-efficacy: A cross lagged analysis. European Journal of Work and Organizational Psychology, 17(4), 413-425.

Betz, N., \& Hackett, G. (1981). The relationship of career-related self-efficacy expectations to perceived career options in college women and men. Journal of Counseling Psychology, 28(5), 399.

Betz, N., \& Hackett, G. (2006). Career self-efficacy theory: Back to the future. Journal of Career Assessment, 14(1), 3-11.

Blustein, D. \& Ellis, M. (2000). The cultural context of career assessment. Journal of Career Assessment, 8(4), 379-390.

Bridgstock, R. (2009).The graduate attributes we've overlooked: Enhancing graduate employability through career management skills. Higher Education Research and Development, 28(1), 31-44.

Bradley, G. (2000). Responding effectively to the mental health needs of international students. Higher Education, 39(4), 417-433. 
Brown, S. \& McPartland, E. (2005). Career interventions: Current status and future directions. In W. Walsh, \& M Savickas (Eds.), Handbook of vocational psychology (pp. 195407). Mahwah, NJ: Lawrence Erlbaum Associates.

Byars, A., \& Hackett, G. (1998). Applications of social cognitive theory to the career development of women of color. Applied and Preventive Psychology, 7(4), 255-267.

Byars-Winston, A., \& Foaud, N. (2006). Metacognition and multicultural competence: Expanding the culturally appropriate career counseling model. The Career Development Quarterly, 54(3), 187-201.

Byon, K., Chan, F., \& Thomas, K. (1999). Korean international student's expectations about counseling. Journal of College Counseling, 2(2), 99-109.

Cadieux, R. and Wehrly, B. (1986), Advising and counseling the international student. New Directions for Student Services 1986(36), 51-63.

Canen, A., \& Canen, A. (2001). Looking at multiculturalism in international logistics: an experiment in a higher education institution. International Journal of Educational Management, 15(3), 145-152.

Carr, J., Koyama, M., \& Thiagarajan, M. (2003). A woman's support group for Asian international students. Journal of American College Health, 52(3), 131-134.

Cheng, D., Leong, F. L., \& Geist, R. (1993). Cultural differences in psychological distress between Asian and Caucasian American college students. Journal of Multicultural Counseling and Development, 21(3), 182-190.

Chickering, A., Reisser, L. (1993). Education and identity (2 ed.). San Francisco, CA: JosseyBass. 
Church, A., (1982). Sojourner adjustment. Psychological Bulletin, 91(3), 540-572.

Constantine, M., Okazaki, S., \& Utsey, S., (2004). Self-concealment, social self-efficacy, acculturative stress, and depression in African, Asian, and Latin American international college students. American Journal of Orthopsychiatry, 74(3), 230-241.

Constantine, M., Kindaichi, M., Okazaki, S., Gainor, K.., \& Baden, A.(2005). A qualitative investigation of the cultural adjustment experiences of Asian international college women. Cultural Diversity and Ethnic Minority Psychology, 11(2), 162-175.

Cook, E., Heppner, M., \& O’Brien, K. (2005). Multicultural influences in women's career development: An ecological perspective. Journal of Multicultural Counseling and Development, 33(3), 165.

Cox, S., \& Osguthorpe, R. (2003) How do instructional design professionals spend their time? TechTrends, 47(3), 45-47.

Creed, P., Muller, J., \& Patton, W. (2003). Leaving high school: The influence and consequences for psychological well-being and career-related confidence. Journal of Adolescence, 26(3), 295-311.

Creswell, J. (2003). Research design: Qualitative, quantitative, and mixed methods approaches. Thousand Oaks: Sage Publications.

Creswell, J., \& Plano Clark, V. (2011). Designing and conducting mixed methods research. Los Angeles: Sage. 
Crockett, S. \& Hayes, D. (2011). Understanding and responding to the career counseling needs of international college students on U.S. Campuses. Journal of College Counseling, 14(1), 65-79.

Dagley, J., \& Salter, S. (2004). Practice and research in career counselling and development2003. The Career Development Quarterly, 53(2), 99-157.

Das, A., Chow, S., \& Rutherford, B. (1986). The counseling needs of international students. International Journal for the Advancement of Counseling, 9(2), 167-174.

Denzin, N., \& Lincoln, Y. (Eds.). (2011). The Sage handbook of qualitative research. Thousand Oaks, CA: Sage.

Deressa, B., \& Beavers, I. (1988). Needs assessment of international students in College of Home Economics. Educational Research Quarterly, 12(2), 51-56.

Eden, D., \& Aviram, A. (1993). Self-efficacy training to speed reemployment: Helping people to help themselves. Journal of Applied Psychology, 78(3), 352.

Ertmer, P. \& Newby, T., (1993). Behaviorism, cognitivism, constructivism: Comparing critical features from an instructional design perspective. Performance Improvement Quarterly, $6(3), 50-72$.

Fallon, F., \& Barbara, D. (2005). Are our international students using the health system effectively? In ISANA Conference, Christchurch, New Zealand.

Flores, L., Heppner, M. (2002) Multicultural career counseling: Ten essentials for training. Journal of Career Development, 28(3), 181-202. 
Foltz, B., \& Luzzo, D. (1998). Increasing the career decision-making self-efficacy of nontraditional college students. Journal of College Counseling, 1(1), 35-44.

Fouad, N. \& Zao, K. (2000). Meeting and revolution: Future trends in vocational assessment. Journal of Career Assessment, 8(4), 403-409.

Gati, I. (1996). Computer-assisted career counseling: Challenges and prospects. In M. L. Savickas \& W. B. Walsh (Eds), Handbook of career counseling theory and practice (pp. 169-190). Palo Alto: CA: Davies-Black.

Gati, I, \& Asher, I. (2001). Prescreening, in-depth exploration, and choice: From decision theory to career counseling practice. The Career Development Quarterly, 50(2), 140-157.

Gati, I., Krausz, M., \& Osipow, S. (1996). A taxonomy of difficulties in career decisionmaking. Journal of Counseling Psychology, 43(4), 510-526.

Gati, I., Osipow, S., Krausz, M., \& Saka, N. (2000). Validity of the career decisionmaking difficulties questionnaire: Counselee versus career counselor perceptions. Journal of Vocational Behavior, 56(1), 99-113.

Gati, I., \& Saka, N. (2001). Internet-based versus paper-and-pencil assessment: Measuring career decision making difficulties. Journal of Career Assessment, 9(4), 397-416

Gati, I., Saka, N., \& Krausz, M. (2001). 'Should I use a computer-assisted career guidance system?' It depends on where your career decision making difficulties lie. British Journal of Guidance \& Counseling, 29(3), 301-321 
Geddie K. 2013. The transnational ties that bind: relationship considerations for graduating international science and engineering research students. Population, Space and Place, 19(2), 196-208.

Geelhoed, R., Abe, J., \& Talbot, D. (2003). A qualitative investigation of U.S. students' experiences in an international peer program. Journal of College Student Development, 44(1), 5-17.

Gibbons, A. (2003). What and how do designers design? A theory of design structure. TechTrends. 47(5), 22-25

Gibby, S., Quiros, O., Demps, E., \& Liu, M. (2002). Challenges of being an instructional designer for new media development: A view from the practitioners. Journal of Educational Multimedia and Hypermedia, 11(3), 195-219.

Glaser, B., \& Strauss, A. (1967). The discovery of ground theory. Alpine, New York.

Goodman, J., \& Hansen, S. (2005). Career development and guidance programs across cultures: The gap between policies and practices. The Career Development Quarterly, $54(1), 57-65$.

Gordon, V. (1995). The undecided student: An academic and career advising challenge. Springfield, IL: Thomas.

Gordon, V. (1998). Career decidedness types: A literature review. The Career Development Quarterly, 46(4), 386-403.

Guindon, M., \& Richmond, L. (2005). Practice and research in career counseling and development-2004. The Career Development Quarterly, 54(2), 90-137. 
Gushue, G. (2006). The relationship of ethnic identity, career decision-making self-efficacy and outcome expectations among Latino high school students. Journal of Vocational Behavior, 68(1), 85-95.

Guthrie, J. (1988). Locating information in documents: examination of a cognitive model. Reading Research Quarterly, 23(2), 178-199.

Harris-Bowlsbey, J. (1996). Synthesis and antithesis: Perspectives from Herr, Bloch, and Watts. The Career Development Quarterly, 45(1), 54-57.

Harris-Bowlsbey, J. and Sampson, J. (2005), Use of technology in delivering career services worldwide. The Career Development Quarterly, 54(1): 48-56.

Hartung, P. (2005). Internationalizing career counseling: Emptying our cups and learning from each other. The Career Development Quarterly, 54(1), 12-16.

Hayes, R. and Lin, H. (1994). Coming to America: Developing social support systems for international students. Journal of Multicultural Counseling \& Development, 22(1): 7-16.

Hays, D., \& Singh, A. (2011). Qualitative inquiry in clinical and educational settings. Guilford Press.

Hays, D., \& Wood, C. (2011). Infusing qualitative traditions in counseling research designs. Journal of Counseling \& Development, 89(3), 288-295.

Herr, E. (1996). Toward the convergence of career theory and practice: Mythologies, issues, and possibilities. In M. L. Savickas \& W. B. Walsh (Eds.), Handbook of career counseling theory and practice (pp. 13-35). Palo Alto, CA: Davies-Black Publishing.

Holland, J. (1973). Making Vocational Choices. Englewood Cliffs, NJ: Prentice Hall. 
Hyun, J., Quinn, B., Madon, T., \& Lustig, S. (2007). Mental health need, awareness, and use of counseling services among international graduate students. Journal of American College Health, 56(2), 109-118.

International Board of Standards for Training, Performance and Instruction (2012). Instructional designer competencies. Retrieved from: http://www.ibstpi.org/wpcontent/uploads/2012_ ibstpi_Instructional_Design_Competencies.pdf

International Board of Standards for Training, Performance and Instruction (2000), Instructional Designer Competencies, Retrieved September 2016, from: http://www.ibstpi.org

Institute of International Education. (2016). "International Students by Field of Study, 2014/2015 - 2015/16." Open Doors Report on International Educational Exchange. Retrieved from: http://www.iie.org/opendoors

Jespen, A., (1984). The developmental perspectives on vocational behavior: A review of theory and research. In S. Brown \& R. Lent (Eds.), Handbook of counseling psychology (pp. 178-215). New York: Wiley,

Judge, T., Erez, A., \& Bono, J. A. (1998). The power of being positive: The relation between positive self-concept and job performance. Human Performance, 11(2), 167-187.

Jurgens, J. (2000). The undecided student: Effects of combining levels of treatment parameters on career certainty, career indecision, and client satisfaction. The Career Development Quarterly, 48(3), 237-250. 
Kaczmarek, P., Matlock, G., Merta, R., Ames, M. H., \& Ross, M. (1994). An assessment of international college student adjustment. International Journal of the Advancement of Counseling, 17(4), 241-247.

Kahn, J., \& Williams, M. (2003). The impact of prior counseling on predictors of college counseling use. Journal of College Counseling, 6(2), 144-154.

Karabenick, S. (2003). Help seeking in large college classes: A person-centered approach. Contemporary Educational Psychology, 28(1), 37-58.

Karabenick S., Berger J. (2013). Help seeking as a self-regulated learning strategy. In Bembenutty H., Cleary T. J., Kitsantas A. (Eds.), Applications of self-regulated learning across diverse disciplines: A tribute to Barry J. Zimmerman (pp. 237-261). Charlotte, NC: Information Age Publishing.

Karabenick, S., \& Knapp, J. (1991). Relationship of academic help seeking to the use of learning strategies and other instrumental achievement behavior in college students. Journal of Educational Psychology, 83(2), 221-230

Karabenick, S., \& Sharma, R. (1994). Seeking academic assistance as a strategic learning resource. In P. Pintrich, D. Brown, D. \& C. E. Weinstein (Eds.), Student motivation, cognition, and learning: Essays in honor of Wilbert J. McKeachie (pp.189-211). Hillsdale, NJ: Erlbaum

Kearney, L. Draper, M., \& Baron, A. (2005). Counseling utilization by ethnic minority college students. Cultural Diversity and Ethnic Minority Psychology, 11(3), 272-285. 
Kenny, M., Blustein, D., Haase, R., Jackson, J., \& Perry, J. (2006). Setting the stage:

Career development and the student engagement process. Journal of Counseling

Psychology, 53(2), 272.

Kilinc, A., \& Granello, P. (2003). Overall like satisfaction and help-seeking attitudes of Turkish college students in the United States: Implications for college counselors. Journal of College Counseling, 6(1), 56-68.

Knox, S., Schlosser, L., Pruitt, N., \& Hill, C. (2006). A qualitative examination of graduate advising relationships: The advisor perspective. The Counseling Psychologist, 34(4), 489518.

Koivisto, P., Vinokur, A., Vuori, J. (2011). Effects of career choice intervention on components of career preparation. Career Development Quarterly, 59(4), 345-366.

Krumboltz, J. D. (1993). Integrating career and personal counseling. Career Development Quarterly, 42(2), 143-146.

Lapan, R. (2004). Career development across the K-16 years: Bridging the present to satisfying and successful futures. Alexandria, VA: American Counseling Association

Lapan, R., Kardash, C., \& Turner, S. (2002). Empowering students to become selfregulated learners. Professional School Counseling, 5(4), 257-265.

Lent, R., Brown, S., \& Hacket, G. (1994). Toward a unifying social cognitive theory of career and academic interest, choice and performance. Journal of Vocational Behavior, 45(1), 79-122. 
Leong, F., \& Chou, E. (1996). Counselling international students and sojourners. In P. Pedersen, J. Draguns, W. Lonner, \& J. Trimble (Eds.). Counselling across cultures (pp. 210-242). Thousand Oaks, CA: Sage.

Leong, F., \& Brown, M. (1995). Theoretical issues in cross-cultural career development: Cultural validity and cultural specificity. In W. Walsh \& S. Osipow (Eds.), Contemporary topics in vocational psychology. Handbook of vocational psychology: Theory, research, and practice (pp. 143-180). Hillsdale, NJ: Lawrence Erlbaum Associates.

Leong, F., \& Sedlacek, W., (1986). A comparison of international and U.S. students' preferences for help sources. Journal of College Student Personnel, 27(5), 426-430.

Leong, F., \& Sedlacek, W., (1989). Academic and career needs of international and United States college students. Journal of College Student Development, 30(2), 106-111.

Luzzo, D., Henao, C., \& Wilson, M. (1996). An innovative approach to assessing the academic and social needs of international students. Journal of College Student Development, $37(3), 351-352$

Makitalo-Siegl, K., Kohnle, C., \& Fischer, F. (2011). Computer-supported collaborative inquiry learning and classroom scripts: Effects on help-seeking processes and learning outcomes. Learning and Instruction, 21(2), 257-266.

Manese, J., Leong, F., \& Sedlacek, W. (1995). Background attitudes and needs of undergraduate international students. College of Student Affairs Journal, 6(1), 19-28.

Marshall, C., \& Rossman, G. (2014). Designing qualitative research. Sage Publications. 
Mau, W. (2000). Cultural differences in career decision-making styles and self-efficacy. Journal of Vocational Behavior, 57(3), 365-378.

Mau, W. (2001). Assessing career decision-making difficulties: A cross-cultural study. Journal of Career Assessment, 9(4), 353-364.

Mau, W. (2004). Cultural dimensions of career decision-making difficulties. The Career Development Quarterly, 53(1), 67-77.

Mau, W., \& Jespen, D. (1990). Help-seeking perceptions and behaviors: a comparison of Chinese and U.S. graduate students. Journal of Multicultural Counseling \& Development, 18(2), 94-104.

Merriam, S. (1998). Qualitative Research and Case Study Applications in Education. Revised and Expanded from "Case Study Research in Education.". San Francisco, CA: JosseyBass.

Merriam, S., \& Associates (2002). Qualitative research in practice: Examples for discussion and analysis. San Francisco, CA: Jossey-Bass.

Merriam, S., Courtenay, B., \& Cervero, R. (2006). Global issues and adult education: perspectives from Latin America, Southern Africa, and the United States. Jossey-Bass.

Misra, R., Crist, M., \& Burant, C. (2003). Relationships among life stress, social support, academic stressors, and reactions to stressors of international students in the United States. International Journal of Stress Management, 10(2), 137-157.

Moneta, L. (2005). Technology and student affairs: Redux. New Directions for Student Services, 2005(112), 3-14. 
Mori, S. (2000). Addressing the metal health concerns of international students. Journal of Counseling \& Development, 78(2), 137-144.

Morse, J. (1994). Designing funded qualitative research. In N. Denzin \& Y. Lincoln (Eds.), Handbook of qualitative research (pp. 220-235). Thousand Oaks, CA: Sage Publications.

Morse, J. (2008). Styles of collaboration in qualitative inquiry. Qualitative Health Research, 18(1), 3-4.

Mosneaga, A. and Winther, L. (2013) Emerging talents? International students before and after their career start in Denmark. Population, Space and Place, 19(2), 181-195.

National Association of Colleges and Employers, (2016). Retrieved from: http://www.naceweb.org/knowledge/career-readiness-competencies.aspx

Nevo, O. (1987). Irrational expectations in career counseling and their confronting arguments. Career Development Quarterly, 35(3), 239-250.

Newman, R. (1990). Children's help-seeking in the classroom: the role of motivational factors and attitudes. Journal of Educational Psychology, 82(1), 71-80.

Newman, R. S. (1994). Adaptive help seeking: A strategy of self-regulated learning. In D. H. Schunk \& B. J. Zimmerman (Eds.), Self-regulation of learning and performance: Issues and educational applications (pp. 283-301). Hillsdale, NJ: Lawrence Erlbaum Associates. 
Newman, R. (2006). Students' adaptive and nonadaptive help seeking in the classroom: Implications for the context of peer harassment. In S. Karabenick \& R. Newman (Eds.),

Help seeking in academic setting: Goals, groups, and contexts, (pp. 225-258) New York, NY: Routledge.

Newman, R. (2008). Adaptive and nonadaptive help seeking with peer harassment: An integrative perspective of coping and self-regulation. Educational Psychologist, 43(1),115.

Nilsson, J., Berkel, L., Flores, L., \& Lucas, M. (2004). Utilization rate and presenting concerns of international students at university counseling center; Implications for outreach programming. Journal of Career Development, 19(2), 49-59.

Nota, L., Ferrari, L., Solberg, S., \& Soresi, S. (2007). Career search self-efficacy, family support, and career indecision with Italian youth. Journal of Career Assessment, 15(2), 181-193.

Osipow, S. (1999). Assessing career indecision. Journal of Vocational Behavior, 55(1), 147-154.

Osipow, S. \& Gati, I. (1998). Construct and concurrent validity of the career decisionmaking difficulties questionnaire. Journal of Career Assessment, 6(3), 347-364.

Parker, P. (2002). Working with the intelligent career model. Journal of Employment Counseling, 39(2), 83-96.

Parr, G., Bradley, L., \& Bingi, R. (1992). Concerns and feelings of international students. Journal of College Student Development, 33(1), 20-25.

Pederson, P., (1991). Multiculturalism as a generic approach to counseling. Journal of 
Counseling and Development, 70(1), 6-12.

Peterson, S., \& delMas, R. (1996). Effects of career-decision-making self efficacy on the retention of underprepared adults: A path analytic study of student persistence. Paper presented at Annual Meeting of the American Educational Research Association, New York, NY.

Phillips, S., \& Jome, L. (2005). Vocational choices: What do we know? What do we need to know. In W. Walsh, M. Savickas, \& P Hartung (Eds.), Handbook of vocational psychology: Theory, research, and practice, (pp. 127-153), Mahwah, NJ: Routledge.

Pintrich, P. (2000). The role of goal orientation in self-regulated learning. In M. Boekaerts, P. R. Pintrich, \& M. Zeidner (Eds.), Handbook of self-regulation (pp. 451-502). San Diego, CA: Academic.

Pintrich, P., \& Zusho, A. (2007). Student motivation and self-regulated learning in the college classroom. In R. Perry, \& J. Smart (Eds.), The scholarship of teaching and learning in higher education: An evidence-based perspective (pp. 731-813). New York: Springer.

Plant, P. (2004). Quality in career guidance: Issues and methods. International Journal for Educational and Vocational Guidance, 4(2), 141-157.

Popadiuk, N., \& Arthur, N. (2014). Key relationships for international student university to work transitions. Journal of Career Development, 41(2), 122-140.

Prieto, S., (1995). International student populations and needs assessment, In S. Stabb, S. Harris, \& J Talley (Eds.), Multicultural Needs Assessment for College and University Student Populations (pp.203-223). Springfield, IL: Charles Thomas Publisher. 
Puutstien, M., Bernicot, J., \& Bert-Erboul, A. (2011). Written computer-mediated requests for help by French-speaking students: An analysis of their forms and functions. Learning and Instruction, 21(2), 281-289.

Quimby, J., \& O’Brien, K. (2004). Predictors of student and career decision making self-efficacy among nontraditional college women. The Career Development Quarterly, 52(4), 323339.

Regenold, M., Sherman, M. F., \& Fenzel, M. (1999). Getting back to work: Self-efficacy as a predictor of employment outcome. Psychiatric Rehabilitation Journal, 22(4), 361.

Reiser, R. (2001). A history of instructional design and technology. In R. Reiser \& J. Dempsey (Eds.), Trends and Issues in Instructional Design and Technology, (pp. 5767). Englewood Cliffs, NJ: Prentice Hall College Division.

Reynolds, A., \& Constantine, M. (2007). Cultural adjustment difficulties and career development of international college students. Journal of Career Assessment, 15(3), 338-350.

Rice, K., Choi, C., Zhang, Y., Huan, J., Nesic, A., Bigler, M., Anderson, D., \& Villegas, J. (2009). International student perspectives on graduate advising relationships. Journal of Counseling Psychology, 56(3), 376-391.

Richey, R., Fields, D., \& Foxon, M. (2001). Instructional design competencies: The standards (3rd ed.). Syracuse, NY: ERIC Clearinghouse.

Richey, R., Klein, J., \& Tracey, M. (2011). The instructional design knowledge base: theory, research, and practice. New York: Routledge. 
Rickwood, D., Deane, F., Wilson, C., \& Ciarrochi, J. (2005). Young people's help-seeking for mental health problems. Australian E-Journal for Advancement of Mental Health, 4(3), 218-251.

Rothman, T., Maldonado, J., \& Rothman, H. (2008). Building self-confidence and future career success through a pre-college transition program for individuals with disabilities. Journal of Vocational Rehabilitation, 28(2), 73-83.

Rothwell, W., \& Kazanas, H. (2008). Mastering the instructional design process: A systematic approach. San Francisco, CA: Pfeiffer.

Rouet, J. (2006). The skills of document use: From text comprehension to Web-based learning. Mahwah, NJ: Erlbaum.

Rouet, J., \& Tricot, A. (1996). Task and activity models in hypertext usage. In H.Van Oostendorp, \& S. DeMul (Eds.), Cognitive aspects of electronic text processing (pp. 239264). Norwood, NJ: Ablex.

Rowland, G. (1992). What do instructional designers actually do? An initial investigation of expert practice. Performance Improvement Quarterly, 5(2), 65-86.

Russell, R., \& Petrie, T. (1992). Academic adjustment of college students: Assessment and counseling. In S. D. Brown \& R. W. Lent (Eds.), Handbook of counseling psychology (pp. 485-511). Oxford, England: John Wiley.

Ryan, A., \& Pintrich, P. (1997). "Should I ask for help?" The role of motivation and attitudes in adolescents' help-seeking in math class. Journal of Educational Psychology, 89(2), 329341. 
Ryan, A., Pintrich, P., \& Midgley, C. (2001). Avoiding seeking help in the classroom: Who and why? Educational Psychology Review, 13(2), 93-114.

Ryan, N., Solberg, V., \& Brown, S. (1996). Family dysfunction, parental attachment, and career search self-efficacy among community college students. Journal of Counseling Psychology, 43(1), 84-89.

Saks, A., \& Ashforth, B. (2002). Is job search related to employment quality? It all depends on fit. Journal of Applied Psychology, 87(4), 646-654.

Sandhu, D., \& Asrabadi, B. (1994). Development of an acculturative stress scale for international students: Preliminary findings. Psychological Reports, 75(1), 435-448.

Savickas, M. (1997). Career Adaptability: An integrative construct for life-span, lifespace theory. The Career Development Quarterly, 45(3), 247-259.

Savickas, M., \& Baker, D. (2005). The history of vocational psychology: Antecedents, origin, and early development. In W. B. Walsh \& M. L. Savickas (Eds.), Handbook of vocational psychology (pp. 15-50). Mahwah, NJ: Erlbaum.

Schaub, M., \& Tokar, D. M. (2005). The role of personality and learning experiences in social cognitive career theory. Journal of Vocational Behavior, 66(2), 304-325.

Schunk, D., \& Ertmer, P. (2000). Self-regulation and academic learning: Self-efficacy enhancing interventions. In M. Boekaerts, P. Pintrich, \& M. Zeidner (Eds.), Handbook of selfregulation (pp. 631-649). San Diego: Academic Press. 
Schunk, D., \& Zimmerman, B. (1997). Social origins of self-regulatory competence. Educational Psychologist, 32(4), 195-208.

Schwier, R., Hill, J., Wager, W., \& Spector, J. M. (2006). Where have we been and where are we going? Limiting and liberating forces in IDT. In M. Orey, J. McLendon, \& R. Branch (Eds.), Educational Media and Technology Yearbook (pp. 75-96). Westport, CT: Libraries Unlimited.

Sharif, A., \& Cho, S. (2015). 21st-century instructional designers: Bridging the perceptual gaps between identity, practice, impact and professional development. International Journal of Educational Technology in Higher Education, 12(3), 72-85.

Shen, Y., \& Herr, E. (2004). Career placement concerns of international graduate students: A qualitative study. Journal of Career Development, 31(1), 15-29.

Singaravelu, H., White, L., \& Bringaze, T. (2005). Factors influencing international students' career choice. Journal of Career Development, 32(1), 46-59.

Smith, R., \& Khawaja, N. (2011). A review of the acculturation experiences of international students. International Journal of Intercultural Relations, 35(6), 699-713.

Smith, J., \& Osborn, M. (2003). Interpretative phenomenological analysis. In J. A. Smith (Eds.), Qualitative research methods: A practical guide to research methods (pp. 51-80). London: Sage.

Smith, P., \& Ragan, T., (1993). Instructional design. New York: Macmillan.

Sofaer, S. (1999). Qualitative methods: what are they and why use them? Health Services Research, 34(5), 1101. 
Strauser, D. (1995). Applications of self-efficacy theory in rehabilitation counseling. Journal of Rehabilitation, 61(1), 7-11.

Strauss, A., \& Corbin, J. (1998). Basics of qualitative research: Grounded theory procedures and techniques (2nd ed.). Thousand Oaks, CA: Sage.

Stolovitch, H., \& Keeps, E. (2006). Handbook of human performance technology: Principles, practices, and potential. John Wiley \& Sons.

Takeuchi, D., Alegría, M., Jackson, J., \& Williams, D. (2007). Immigration and mental health: Diverse findings in Asian, Black, and Latino populations. American Journal of Public Health, 97(1), 11-12.

Tan, C., Ang, R., Klassen, R., Yeo, L., Wong, I., Heun, V., \& Chong, W. (2008). Correlates of academic procrastination and students' grade goals. Current Psychology, 27(2), 135-144.

Taylor, K., \& Betz, N. (1983). Applications of self-efficacy theory to the understanding and treatment of career indecision. Journal of Vocational Behavior, 22(1), 63-81.

Tenenbaum, H., Crosby, F., \& Gliner, M. (2001). Mentoring relationships in graduate school. Journal of Vocational Behavior, 59(3), 326-341.

Tien, H., Lin, C., \& Chen, S. (2005). A grounded analysis of career uncertainty perceived by college students in Taiwan. The Career Development Quarterly, 54(2), 162-174.

Tidwell, R. \& Hanassab, S. (2007). New challenges for professional counselors: The higher educational international student population. Counseling Psychology Quarterly, 20(4), 313-324. 
Tinto, V. (1993). Leaving college: Rethinking the causes and cures of student attrition (2nd Ed.). Chicago: University of Chicago Press.

Tractenberg, L., Streumer, J., \& Van Zolingen, S. (2002). Career counselling in the emerging postindustrial society. International Journal for Educational and Vocational Guidance, 2(2), 85-99.

Trice, A. (2003). Faculty perceptions of graduate international students: The benefits and challenges. Journal of Studies in International Education. 7(4), 379-403.

Tull, R., Nino, M., \& Homes, K. (2014). Building a community of practice among STEM graduates students to foster academic and professional success, presented at the $121^{\text {st }}$ ASEE Annual Conference \& Exposition, Indianapolis, IN, June 2014.

Turner, S., \& Conkel, J. (2010). Evaluation of a career development skills intervention with adolescents living in an inner city. Journal of Counseling \& Development, 55(4), 457465.

US Department of State (2017), Laws and Regulations. Retrieved from: https://travel.state.gov/content/visas/en/law-and-policy/laws-and-regulations.html

Vogel, D., Wade, N., \& Haake, S. (2006). Measuring the self-stigma associated with seeking psychological help. Journal of Counseling Psychology, 53(3), 325-337.

Vogel, D., Wade, N., \& Hackler, A. (2007). Perceived public stigma and the willingness to seek counseling: The mediating roles of self-stigma and attitudes towards counseling. Journal of Counseling Psychology, 54(1), 40-50. 
Walraven, A., Brand-Gruwel, S., \& Boshuizen, H. (2008). Information-problem solving: A review of problems students encounter and instructional solutions. Computers in Human Behavior, 24(3), 623-648.

Wanberg, R., Hough, L., \& Song, Z. (2002). Predictive validity of a multidisciplinary model of reemployment success. Journal of Applied Psychology, 87(6), 1100-1120.

Wertz, F. (2005). Phenomenological research methods for counseling psychology. Journal of Counseling Psychology, 52(2), 167-177.

Yang, E., Wong, S., Hwang, M., \& Heppner, M. (2002). Widening our global view: The development of career counseling services for international students. Journal of Career Development, 28(3), 203-213.

Yi, J., Jun-Chih G. \& Kishimoto, Y. (2003). Utilization of counseling services by international students. Journal of Instructional Psychology, 30(4), 333-342.

Yoon, E., \& Portman, T. (2004). Critical issues of literature on counseling international students. Journal of Multicultural Counseling and Development, 32(1), 33-44.

Yuen, R. \& Tinsley, H. (1981). International and American student expectancies about counseling. Journal of Counseling Psychology, 28(1), 66-69.

Yusop, D., \& Correia, A. (2012). The civic-minded instructional designers framework: An alternative approach to contemporary instructional designers' education in higher education. British Journal of Educational Technology, 43(2), 180-190.

Zeldin, A., \& Pajares, F. (2000). Against the odds: Self-efficacy beliefs of women in 
mathematical, scientific, and technological careers. American Educational Research Journal, 37(1), 215-246.

Zhang, N. \& Dixon, D. (2003). Acculturation and adaptation revisited. Journal of CrossCultural Psychology, 30(4), 422-442.

Zimmerman, B. (1986). Development of self-regulated learning: Which are the key sub processes? Contemporary Educational Psychology, 16(3), 301-313.

Zimmerman, B. (2000). Attaining self-regulation: A social cognitive perspective. In M. Boekaerts, P. Pintrich, \& M. Zeidner (Eds.), Handbook of self-regulation (pp. 13-39). San Diego, CA: Elsevier Academic Press.

Zimmerman, B. (2008). Investigating self-regulation and motivation: Historical background, methodological developments, and future prospects. American Educational Research Journal, 45(1), 166-183.

Zimmerman, B., \& Martinez-Pons, M. (1986). Development of a structured interview for assessing student use of self-regulated learning strategies. American Educational research Journal, 23(4), 614-628.

Zimmerman, B., \& Martinez-Pons, M. (1990). Student differences in self-regulated learning: Relating grade, sex, and giftedness to self-efficacy and strategy use. Journal of Educational Psychology, 82(1), 51-59.

Zimmerman, B., \& Schunk, D. (2004). Self-regulating intellectual processes and outcomes: A social cognitive perspective. In Dai, D. \& Sternberg, R. (Eds.), Motivation, emotion, 
and cognition: Integrative perspectives on intellectual functioning and development, (pp. 323-349). Mahwah, NJ: Erlbaum. 
APPENDIX A

CAREER DECISION-MAKING QUESTIONNAIRE

CDDQ34-ise-perdoc

Itamar Gati, Th. D.

School of Edueutium, Hebrew University, Jerwalem, ISRAEI.

e-mai: ilamac antichuilas it

Fex: $(-972)-2-5480034$

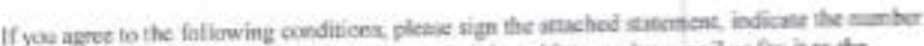

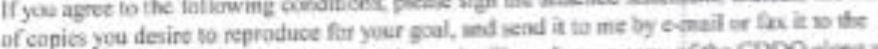

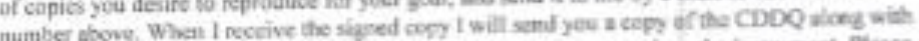
yur eany of the siuged permission slip that will allow you to reproduce the imurumert. Plesse

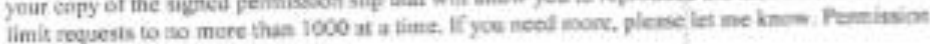
expirs ves year afler is is granted.

Notet The instrameat mest be reprodeced in its entirety. Perminies te repeadoes separate items is not graated.

1. I agree to reproduce the imstrunent in is earicty with ne changes in onntene of format

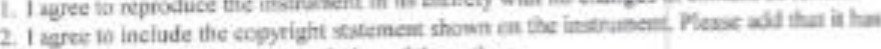

been reproduced with the pernission ef the asthon

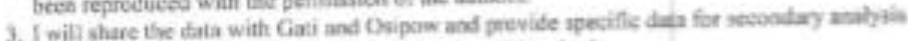

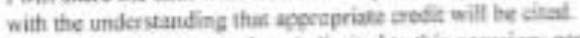

4. This permissien to reprediwe is limad to thís occanions permissian copirss in anc yea

fium the Cute af the permission letter; permissicn is linited to 1000 sopies, fitur

pepreduction recquests must be ipecificalby and scpuritich requestod.

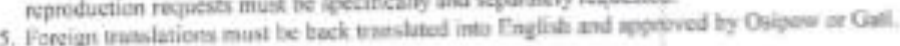

I agre so the above sonditices:

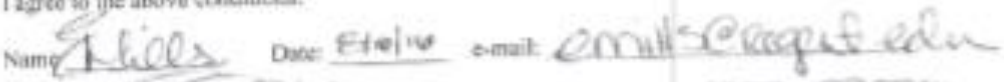

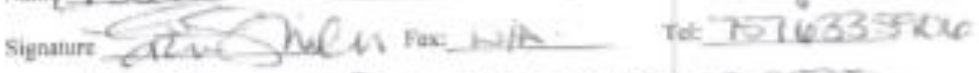

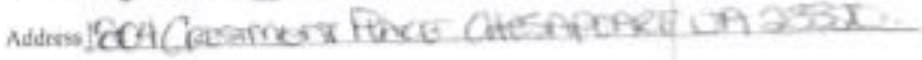

Singerely.

Traner Gati

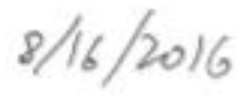

latame Canti. Ph. D.

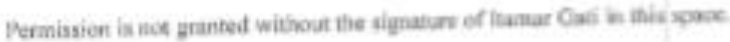

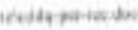




\section{Career Decision-Making Difficulties Questionnaire}

This questionnaire will determine influences and impacts of career decision-making.

Please begin by filling in the following demographic information:

a) What is your name?

b) What is your country of origin?

c) Please select the option that best describes your status: __ US Citizen, __ Permanent Resident, ___ International student on a visa, specify which type of visa:

d) What is your gender? Male __ Female __ Other__ I do not wish to respond

e) What is your age? $18-25 \_, 26-30 \_, 31-35 \_, 36-40 \_, 41-45 \ldots, 46+$

f) What is your race? White__, Black __, Hispanic__, Other__, Please specify:

g) What languages do you speak in addition to English? Arabic:_ Chinese:__ French_ German_Italian:_Japanese:_ Russian:_ Spanish:__ Turkish:__ Other_ Please specify:

h) What degree are you currently pursuing? _ Graduate Certificate _ Masters, __ PhD, _Recently graduated with Masters, __ Recently graduated with $\mathrm{PhD}$

i) How did you apply to the graduate program at your current university? _Applied through an Agency, _ Applied through a governmental program in your home country, _ Self-Application, _ Transferred from another graduate program in the US, _ Other: please specify

j) What is your current discipline?

k) What year are you in your graduate studies: $\ldots 1^{\text {st }}, 2^{\text {nd }},-3^{\text {rd }},-4^{\text {th }},-^{\text {th }},-^{6^{\text {th }}}-^{6 \text { th }}+$

1) Did you study in the US for any part of your undergraduate degree? $Y_{-} \mathrm{N}_{-}$

m) What university did you complete your under graduate degree from? 
n) What is the highest level of education of your father: NA

o) What is the highest level of education of your mother: NA

p) What is the highest level of education of your spouse: NA

q) Which career resource(s) have you found to be most helpful? Career Counselors Websites:__ University Resources:__ Family:_ Friends:__ Online Sources__ Other:_ Please specify:

r) Which career resource(s) have you found to be least helpful? Career Counselors Websites:__ University Resources:__ Family:_ Friends:_ Online Sources__ Other:_ Please specify:

s) Describe how often you meet with your academic advisor: Weekly Monthly Once a Semester___ Once Annually ___ I do not meet with my academic advisor

t) If you meet with your academic advisor, do you discuss your career? Yes__ No_

u) Has your advisor ever provided you with resources aid in your career decision-making process? Yes__ No__ Please specify:

The remaining questions will utilize a Likert scale. Below is a sample Likert scale question:

Have you considered what field you would like to major in or what occupation you would like to choose? Yes / No

If so, to what extent are you confident of your choice?

Not confident at all $\begin{array}{llllllllll}1 & 2 & 3 & 4 & 5 & 6 & 7 & 8 & 9 & \text { Very confident }\end{array}$

Next, you will be presented with a list of 35 statements concerning the career decision-making process. Please rate the degree to which each statement applies to you on the following scale:

Does not describe me $\begin{array}{llllllllll}1 & 2 & 3 & 4 & 5 & 6 & 7 & 8 & 9 & \text { Describes me well }\end{array}$

Circle 1 if the statement does not describe you and 9 if it describes you well. Of course, you may also circle any of the intermediate levels. 
Please do not skip any question.

Copyright (c) 2000, 2002, 2010 Itamar Gati and Samuel H. Osipow. All rights reserved.

\section{For each statement, please circle the number which best describes you.}

1. I know that I have to choose a career, but I don't have the motivation to make the decision now ("I don't feel like it").

Does not describe me $\begin{array}{llllllllll}1 & 2 & 3 & 4 & 5 & 6 & 7 & 8 & 9 & \text { Describes me well }\end{array}$

2. Work is not the most important thing in one's life and therefore the issue of choosing a career does not worry me much.

Does not describe me $\begin{array}{llllllllll}1 & 2 & 3 & 4 & 5 & 6 & 7 & 8 & 9 & \text { Describes me well }\end{array}$

3. I believe that I do not have to choose a career now because time will lead me to the "right" career choice.

Does not describe me $\begin{array}{llllllllll}1 & 2 & 3 & 4 & 5 & 6 & 7 & 8 & 9 & \text { Describes me well }\end{array}$

4. It is usually difficult for me to make decisions.

Does not describe me $\begin{array}{llllllllll}1 & 2 & 3 & 4 & 5 & 6 & 7 & 8 & 9 & \text { Describes me well }\end{array}$

5. I usually feel that I need confirmation and support for my decisions from a professional person or somebody else I trust.

Does not describe me $\begin{array}{llllllllll}1 & 2 & 3 & 4 & 5 & 6 & 7 & 8 & 9 & \text { Describes me well }\end{array}$

6. I am usually afraid of failure.

$\begin{array}{lllllllllll}\text { Does not describe me } & 1 & 2 & 3 & 4 & 5 & 6 & 7 & 8 & 9 & \text { Describes me well }\end{array}$

7. I like to do things my own way.

$\begin{array}{lllllllllll}\text { Does not describe me } & 1 & 2 & 3 & 4 & 5 & 6 & 7 & 8 & 9 & \text { Describes me well }\end{array}$

8. I expect that entering the career I choose will also solve my personal problems.

$\begin{array}{lllllllllll}\text { Does not describe me } & 1 & 2 & 3 & 4 & 5 & 6 & 7 & 8 & 9 & \text { Describes me well }\end{array}$

9. I believe there is only one career that suits me.

$\begin{array}{lllllllllll}\text { Does not describe me } & 1 & 2 & 3 & 4 & 5 & 6 & 7 & 8 & 9 & \text { Describes me well }\end{array}$

10. I expect that through the career I choose I will fulfill all my aspirations.

Does not describe me $\begin{array}{llllllllll}1 & 2 & 3 & 4 & 5 & 6 & 7 & 8 & 9 & \text { Describes me well }\end{array}$ 
11. I believe that a career choice is a one-time choice and a life-long commitment.

$$
\text { Does not describe me } \begin{array}{llllllllll}
1 & 2 & 3 & 4 & 5 & 6 & 7 & 8 & 9 & \text { Describes me well }
\end{array}
$$

12. I always do what I am told to do, even if it goes against my own will.

Does not describe me $\begin{array}{llllllllll}1 & 2 & 3 & 4 & 5 & 6 & 7 & 8 & 9 & \text { Describes me well }\end{array}$

13. I find it difficult to make a career decision because I do not know what steps I have to take.

Does not describe me $\begin{array}{llllllllll}1 & 2 & 3 & 4 & 5 & 6 & 7 & 8 & 9 & \text { Describes me well }\end{array}$

14. I find it difficult to make a career decision because I do not know what factors to take into consideration.

Does not describe me $\begin{array}{llllllllll}1 & 2 & 3 & 4 & 5 & 6 & 7 & 8 & 9 & \text { Describes me well }\end{array}$

15. I find it difficult to make a career decision because I don't know how to combine the information I have about myself with the information I have about the different careers.

Does not describe me $\begin{array}{lllllllllll}1 & 2 & 3 & 4 & 5 & 6 & 7 & 8 & 9 & \text { Describes me well }\end{array}$

16. I find it difficult to make a career decision because I still do not know which occupations interest me.

Does not describe me $\begin{array}{llllllllll}1 & 2 & 3 & 4 & 5 & 6 & 7 & 8 & 9 & \text { Describes me well }\end{array}$

17. I find it difficult to make a career decision because I am not sure about my career preferences yet (for example, what kind of a relationship I want with people, which working environment I prefer).

Does not describe me $\begin{array}{llllllllll}1 & 2 & 3 & 4 & 5 & 6 & 7 & 8 & 9 & \text { Describes me well }\end{array}$

18. I find it difficult to make a career decision because I do not have enough information about my competencies (for example, numerical ability, verbal skills) and/or about my personality traits (for example, persistence, initiative, patience).

Does not describe me $\begin{array}{llllllllll}1 & 2 & 3 & 4 & 5 & 6 & 7 & 8 & 9 & \text { Describes me well }\end{array}$

19. I find it difficult to make a career decision because I do not know what my abilities and/or personality traits will be like in the future.

Does not describe me $\begin{array}{llllllllll}1 & 2 & 3 & 4 & 5 & 6 & 7 & 8 & 9 & \text { Describes me well }\end{array}$

20. I find it difficult to make a career decision because I do not have enough information about the variety of occupations or training programs that exist.

Does not describe me $\begin{array}{llllllllll}1 & 2 & 3 & 4 & 5 & 6 & 7 & 8 & 9 & \text { Describes me well }\end{array}$ 
21. I find it difficult to make a career decision because I do not have enough information about the characteristics of the occupations and/or training programs that interest me (for example, the market demand, typical income, possibilities of advancement, or a training program's perquisites).

Does not describe me $\begin{array}{llllllllll}1 & 2 & 3 & 4 & 5 & 6 & 7 & 8 & 9 & \text { Describes me well }\end{array}$

22. I find it difficult to make a career decision because I don't know what careers will look like in the future.

Does not describe me $\begin{array}{llllllllll}1 & 2 & 3 & 4 & 5 & 6 & 7 & 8 & 9 & \text { Describes me well }\end{array}$

23. I find it difficult to make a career decision because I do not know how to obtain additional information about myself (for example, about my abilities or my personality traits).

Does not describe me $\begin{array}{llllllllll}1 & 2 & 3 & 4 & 5 & 6 & 7 & 8 & 9 & \text { Describes me well }\end{array}$

24. I find it difficult to make a career decision because I do not know how to obtain accurate and updated information about the existing occupations and training programs, or about their characteristics.

Does not describe me $\begin{array}{llllllllll}1 & 2 & 3 & 4 & 5 & 6 & 7 & 8 & 9 & \text { Describes me well }\end{array}$

25. I find it difficult to make a career decision because I constantly change my career preferences (for example, sometimes I want to be self-employed and sometimes I want to be an employee).

Does not describe me $\begin{array}{llllllllll}1 & 2 & 3 & 4 & 5 & 6 & 7 & 8 & 9 & \text { Describes me well }\end{array}$

26. I find it difficult to make a career decision because I have contradictory data about my abilities and/or personality traits (for example, I believe I am patient with other people but others say I am impatient).

Does not describe me $\begin{array}{llllllllll}1 & 2 & 3 & 4 & 5 & 6 & 7 & 8 & 9 & \text { Describes me well }\end{array}$

27. I find it difficult to make a career decision because I have contradictory data about the existence or the characteristics of a particular occupation or training program.

Does not describe me $\begin{array}{llllllllll}1 & 2 & 3 & 4 & 5 & 6 & 7 & 8 & 9 & \text { Describes me well }\end{array}$

28. I find it difficult to make a career decision because I am equally attracted by a number of careers and it is difficult for me to choose among them.

Does not describe me $\begin{array}{llllllllll}1 & 2 & 3 & 4 & 5 & 6 & 7 & 8 & 9 & \text { Describes me well }\end{array}$

29. I find it difficult to make a career decision because I do not like any of the occupation or training programs to which I can be admitted. 
Does not describe me $\begin{array}{llllllllll}1 & 2 & 3 & 4 & 5 & 6 & 7 & 8 & 9 & \text { Describes me well }\end{array}$

30. I find it difficult to make a career decision because the occupation I am interested in involves a certain characteristic that bothers me (for example, I am interested in medicine, but I do not want to study for so many years).

Does not describe me $\begin{array}{llllllllll}1 & 2 & 3 & 4 & 5 & 6 & 7 & 8 & 9 & \text { Describes me well }\end{array}$

31. I find it difficult to make a career decision because my preferences cannot be combined in one career, and I do not want to give any of them up (e.g., I wouldlike to work as a free-lancer, but I also wish to have a steady income).

Does not describe me $\begin{array}{llllllllll}1 & 2 & 3 & 4 & 5 & 6 & 7 & 8 & 9 & \text { Describes me well }\end{array}$

32. I find it difficult to make a career decision because my skills and abilities do not match those required by the occupation I am interested in.

Does not describe me $\begin{array}{llllllllll}1 & 2 & 3 & 4 & 5 & 6 & 7 & 8 & 9 & \text { Describes me well }\end{array}$

33. I find it difficult to make a career decision because people who are important to me (such as parents or friends) do not agree with the career options I am considering and/or the career characteristics I desire.

Does not describe me $\begin{array}{llllllllll}1 & 2 & 3 & 4 & 5 & 6 & 7 & 8 & 9 & \text { Describes me well }\end{array}$

34. I find it difficult to make a career decision because there are contradictions between the recommendations made by different people who are important to me about the career that suits me or about what career characteristics should guide my decisions.

$\begin{array}{lllllllllll}\text { Does not describe me } & 1 & 2 & 3 & 4 & 5 & 6 & 7 & 8 & 9 & \text { Describes me well }\end{array}$

35. Finally, how would you rate the degree of your difficulty in making a career decision?

Low $\begin{array}{llllllllll}1 & 2 & 3 & 4 & 5 & 6 & 7 & 8 & 9 & \text { High }\end{array}$

Optional: Would you be willing to participate in a phone interview to share more information on your career decision-making? If yes, please provide your email address and phone number where you can be reached for or further contact. Email: . Phone:

If you know of anyone who would also like to participate in the survey please feel free to forward them this link: . (Link to Qualtrics) 


\section{APPENDIX B}

\section{INTERVIEW PROTOCOL}

The interviewer will review and or clarify data from the survey before beginning to ask questions including confirmation of visa status and type of any international student participants.

1. What are the most important things you consider when looking for career opportunities?

2. How would you describe yourself in terms of your approach to career decision-making?

a. What are your strengths in career decision-making?

b. What are your weaknesses?

3. Does your culture influence your job search process? How?

a. Follow up for international students: When did you first enter the United States?

b. Follow up for domestic students: Have you ever traveled outside the United States? Where and how often?

4. What pressures do you face upon graduating college and looking for a job?

a. What impact do these pressures have on your career decision-making process?

b. Do family and friends impact your career decision making? If so in what ways?

c. Does your advisor have the same impact? Why or why not.

5. In what country are your seeking employment after graduation?

a. Follow up for international students: What factors influence your decision to pursue employment there?

b. Follow up for domestic students: What factors might influence your decision to consider a career abroad?

6. If you had a career question or concern how likely is it that you would consult another person before seeking assistance from a nonhuman source? (very likely or not likely, explain) 
7. If you had a career question or concern how likely is it that you would consult a nonhuman resource before seeking assistance from another person? (very likely or not likely, explain)

8. What resources have you found to be most helpful in the career decision-making process?

9. What resources have you found to be least helpful in the career decision-making process?

10. What are your plans after graduation?

11. Is there anything else you would like to add or advice you would give to fellow job seekers like yourself? 


\section{APPENDIX C \\ FOLLOW-UP EMAIL- THANK YOU AND MEMBER CHECKING}

Dear

Thank you for taking time to speak to me today. Your insight into the career decision-making of instructional design students has been insightful and informative. Attached please find the notes I took during our phone interview. Within 5 days of receipt of this email please read the notes, and confirm that the intent of your responses or accurate, notating any changes you deem appropriate.

Again thank you for your participation.

Sincerely,

Erin Mills

Old Dominion University 


\section{APPENDIX D \\ CAREER DECISION-MAKING DIFFICULTY SCORING INSTRUCTIONS AND PSYCHOMETRIC PROPERTIES}

The original CDDQ (Gati, Krausz, and Osipow, 1996) comprised of 44 items. In an effort to make the CDDQ more accessible we shortened it to a 34-item version by deleting those items that did not significantly contribute to the scales' internal-consistency-reliability. The Internet version has 34 items for this reason. We also recommend using the 34 item paper-and-pencil version for convenience. Each of the ten difficulty categories (described above) is represented by 2-5 items (for reliabilities see below). In addition, the $C D D Q$ includes two validity items.

\section{Scoring of the CDDQ (34 items)}

The Scale

$\underline{\text { Readiness }}$

Rm-Lack of motivation

Ri-General indecisiveness

4-6

Rd-Dysfunctional beliefs

8-11

Lack of Information about

Lp-The stages of the cdm process

Ls-Self

Lo-Occupations

La-Ways of obtaining additional inform.

Difficulties related to Inconsistent Information

Iu-Unreliable information

Ii-Internal conflicts

Ie-External conflicts

Category scores are computed as the mean of the items that are included in the scale.

Note: items 7 and 12 are validity items (item 7 is expected to be high > 4; item 12 is expected to be low <5)

\section{$\underline{\text { Major difficulty clusters }}$}

Readiness $\quad(\mathrm{Rm}+\mathrm{Ri}+\mathrm{Rd}) / 3$

Lack of Information (Lp+Ls+Lo+La)/4 
Inconsistent Information ( $\mathrm{Iu}+\mathrm{Ii}+\mathrm{Ie}) / 3$

\section{Total CDDQ score}

Mean of the ten scales -- $\quad(\mathrm{Rm}+\mathrm{Ri}+\mathrm{Rd}+\mathrm{Lp}+\mathrm{Ls}+\mathrm{Lo}+\mathrm{La}+\mathrm{Iu}+\mathrm{Ii}+\mathrm{Ie}) / 10$

\section{$\underline{\text { Interpretation }}$}

The simple rule of thumb is that a difficulty category with a mean response of 6.34 and above is considered a "salient" difficulty category, a mean score lower than 3.33 is considered a "negligible" difficulty category, and categories with scores between 3.33 and 6.34 are considered as "moderate" difficulty categories. A more comprehensive interpretation procedure, based on the relative salience of the individual's difficulties, validated by career-counseling experts' judgments, was also developed (see Amir, Gati, \& Kleiman, 2007). The Internet version of the CDDQ automatically scores the questionnaire and the clients' profiles are interpreted according to this method; and the interpretive feedback highlights the focuses of the clients' career decision-making difficulties.

\section{Psychometric properties of the CDDQ}

Reliabilities of the CDDQ (Cronbach $\alpha$ Internal-Consistency Estimates):

\begin{tabular}{|l|l|l|l|l|l|l|l|}
\hline \multirow{2}{*}{ Study } & \multicolumn{3}{|c|}{ Sample } & \multicolumn{3}{c|}{ Cronbach Alpha Reliabilities } \\
\cline { 2 - 9 } & Group & Age & \multicolumn{1}{|c|}{$\mathrm{n}$} & $\begin{array}{l}\text { Lack of } \\
\text { Readiness }\end{array}$ & $\begin{array}{l}\text { Lack of } \\
\text { Information }\end{array}$ & $\begin{array}{l}\text { Inconsistent } \\
\text { Information }\end{array}$ & $\begin{array}{l}\text { Total } \\
\text { CDDQ }\end{array}$ \\
\hline $\begin{array}{l}\text { G,K\&O } \\
\mathbf{( 1 9 9 6 )}\end{array}$ & $\begin{array}{l}\text { Israeli } \\
\text { Young } \\
\text { Adults }\end{array}$ & $\begin{array}{l}19- \\
23\end{array}$ & 259 & .70 & .93 & .91 & .95 \\
\hline $\begin{array}{l}\text { G,K\&O } \\
\mathbf{( 1 9 9 6 )}\end{array}$ & $\begin{array}{l}\text { American } \\
\text { Students }\end{array}$ & $\begin{array}{l}17- \\
23\end{array}$ & 304 & .63 & .95 & .89 & .95 \\
\hline $\begin{array}{l}\text { O\&G } \\
\mathbf{( 1 9 9 8 )}\end{array}$ & $\begin{array}{l}\text { American } \\
\text { Students }\end{array}$ & $16-$ & 43 & .62 & .94 & .86 & .94 \\
\hline $\begin{array}{l}\text { G,O,K\&S } \\
\mathbf{( 2 0 0 0 )}\end{array}$ & $\begin{array}{l}\text { Israeli } \\
\text { Career } \\
\text { Counselees }\end{array}$ & $\begin{array}{l}18- \\
42\end{array}$ & 95 & .68 & .86 & .85 & .90 \\
\hline G\&S & Israeli & $14-$ & 1772 & .58 & .88 & .87 & .91 \\
\hline
\end{tabular}




\begin{tabular}{|l|l|l|l|l|l|l|l|}
\hline $\mathbf{2 0 0 1 a )}$ & $\begin{array}{l}\text { High- } \\
\text { School } \\
\text { Students }\end{array}$ & 17 & & & & & \\
\hline $\begin{array}{l}\text { G\&S } \\
\mathbf{2 0 0 1 b})\end{array}$ & $\begin{array}{l}\text { Israeli } \\
\text { Young } \\
\text { Adults }\end{array}$ & $\begin{array}{l}19- \\
23\end{array}$ & 417 & .61 & .87 & .77 & .88 \\
\hline $\begin{array}{l}\text { Mau } \\
\mathbf{2 0 0 1 )}\end{array}$ & American & $18-$ & 514 & .66 & .96 & .92 & .96 \\
\hline & Students & $23^{*}$ & & & & & \\
\hline
\end{tabular}

* Inter-quartile range

Test-Retest Estimates

\begin{tabular}{|c|c|c|c|c|c|c|c|}
\hline \multirow{2}{*}{ Study } & \multicolumn{2}{|c|}{ Sample } & \multicolumn{5}{c|}{ Test-Retest Reliabilities } \\
\cline { 2 - 8 } & Group & Age & $\mathrm{n}$ & $\begin{array}{c}\text { Lack of } \\
\text { Readiness }\end{array}$ & $\begin{array}{c}\text { Lack of } \\
\text { Information }\end{array}$ & $\begin{array}{c}\text { Inconsistent } \\
\text { Information }\end{array}$ & $\begin{array}{c}\text { Total } \\
\text { Questionnaire }\end{array}$ \\
\hline $\begin{array}{c}\text { G,K\&O } \\
\mathbf{( 1 9 9 6 )}\end{array}$ & $\begin{array}{c}\text { Israeli } \\
\text { Young } \\
\text { Adults }\end{array}$ & $\begin{array}{c}19- \\
23\end{array}$ & 259 & .67 & .74 & .72 & .80 \\
\hline $\begin{array}{c}\text { G\&S } \\
\mathbf{( 2 0 0 1 b )}\end{array}$ & $\begin{array}{c}\text { Israeli } \\
\text { Young } \\
\text { Adults }\end{array}$ & $19-$ & 417 & .81 & .69 & .75 & .79 \\
\hline $\begin{array}{c}\text { Mau } \\
\mathbf{( 2 0 0 1 )}\end{array}$ & Taiwanese & -- & 93 & .56 & .85 & & .78 \\
\hline
\end{tabular}




\title{
VITA
}

\author{
Erin Mills \\ Darden College of Education, Old Dominion University, Norfolk VA
}

\section{Work Experience \\ Lord Fairfax Community College, Middletown VA - August 2017- Present Education Support Specialist III, Career Counselor}

- Identify student and school needs in consulting with high school and college administration and counselors

- Develop and implement services to address those needs in person or online

- Serve as a career pathway specialist in the high school, and increase interest in colleges by using coaching to help insure student's transition success into post-secondary education

- Make connections with business and industry pathways, integrate work based learning experiences into the high school and design and delivery content in courses focused on employability skills and soft skills training

\section{Regent University, Virginia Beach VA - November 2016-October 2017} Instructional Designer for Leadership Development and Education

- Served as the primary instructional designer for content creation, maintenance and revision of orientation, onboarding, and ongoing leadership development course material

- Created measurable learning objectives, designed and developed high-level design documents, reports and programs in order to provide educational offerings for a broad range of audiences

- Demonstrated exceptional ability to transform complex content into simple forms of communication enabling others to effectively understand and contribute within various types of learning opportunities and outcomes

- Researched and implemented current trends and best practices to align, assess and evaluate programs, faculty and staff on operational metrics, problem solving, quality and performance improvement processes and technology use

\section{Regent University, Virginia Beach VA - August 2015-October 2016}

\section{Associate Director for Training and Quality Assurance}

- Oversaw a cross-functional team of 16 including: Training Coordinators (on campus) and Quality Assurance Specialists (distance employees), held employees accountable to performance metrics and created collaboration

- Assessed training needs and developed materials to administer at orientation and during onboarding

- Designed and facilitated learning through a variety of delivery methods including programs, classroom instruction, virtual training and on-the-job coaching in order to provide new and existing employees information on academic programs, technology use, sales techniques, and rapport building

- Demonstrated strong presentation skills, ability to build relationships, and motivated large groups of people toward a common goal while assessing training outcomes and ensuring quality standards 
Old Dominion University, Norfolk VA - May 2007-August 2015 Assistant Director, Career Center

- Supported university enrollment and retention goals by providing comprehensive career and job readiness services to students from first point of entry through graduation and alumni status

- Collaborated with internal faculty and staff as well as external contacts to identify and develop new and existing partnerships to promote and advertise employment opportunities, and co-curricular activities

- Oversaw the International Career Advantage Program, workshops and orientations, consulted students on the international internship process, and advised on career planning, job search strategies and student involvement, provided professional development and ensured compliance with university policies

\section{Old Dominion University, Norfolk VA - July 2005-May 2007 Program Manager, College of Engineering and Technology}

- Served as Liaison for the Commonwealth Graduate Engineering Program (CGEP)

- Monitored and ensured compliance of the program admission and registration procedures including the planning, advertising, and attendance of recruitment sessions, development of promotional material, managing communication with current and prospective distance students, and preparing enrollment and financial reports

- Created communication programs to effectively describe and promote the college and its accomplishments through websites, brochures, newspaper ads, magazine inserts, and other promotional products, oversaw yearly college events

\section{Shenandoah University, Winchester, VA - August 2004-June 2005 Conservatory Office Assistant}

- Updated and maintained student records, processed and analyzed transfer credit evaluations, processed changes in major and curriculum, and completed degree audits to ensure students had met graduation requirements

- Prepared billing related to contract costs for services to high schools and tutorial clients

- Served as the Graphic Designer for the Performing Arts Summer Festival

\section{RBI, Media Associates, Winchester, VA - April 2004-August 2004 Graphic Designer}

- Produced and designed advertisements and published materials as print and online sources

- Maintained strong working knowledge of multiple design programs and software, skilled in desktop publishing including determining layout, size of illustrative material, copy, and typeface

- Completed projects requiring the creation of new designs and logos, updating web pages, and producing ads for mass media while working directly with clients to meet design goals and objectives

\section{Presentations and Publications}

- Stefaniak, J., \& Mills, E., (2016, October) Aligning multiple perspectives; Career needs of international students. Presented at: Association for Educational Communication and Technology annual conference, Las Vegas, NV.

- Stefaniak, J., Mills, E., Young, S., \& Yi, B. (2015, November) Career needs of international students. Poster presented at: Association for Educational Communication and Technology annual conference, Indianapolis, IN. 
- CMC Adopts Telepresence Technology to Enhance Student-Employer Communication, (2013) Inside ODU

- ODU's Practice Room Offers Support at Career Fairs, (2010) NACE Spotlight

- Forbes, B., Mills, E., Wunderlich, T., (2010) Trip to the Virtual Career World, Multi-User Virtual Environments for the Classroom, IGI Global, www.igi.global.com

\section{Education}

Doctor of Philosophy in Education; Instructional Design and Technology Emphasis in Human Performance, December 2017, Old Dominion University

- Dissertation: A Comparative Analysis Between the Career Needs of Domestic and International Instructional Design Students

Master of Science in Education

Emphasis in International Higher Education, 2008, Old Dominion University

Bachelor of Arts in Communication

Emphasis in Graphic Design, 2003, Longwood University

\section{Technical Skills}

- Design: Microsoft Office Suite, SharePoint, Publisher, Adobe Photoshop, Articulate, Camtasia, Prezi, Voice Thread, Qualtrics

- Administration: NaceLink, Leo Online, SCT BANNER, Blackboard, Hobsons, eRecruiting, InsideSales, Recruiter, Discover, Pipeline, Contact Center and Avaya Quality Monitoring, SPSS, VA Wizard

\section{Experiential Education}

Student Engagement Research Project (2015-16): Conducted an environmental needs assessment in order to identify opportunities to improve career services provided to international students with the goal of developing better leadership development programming and training sessions, while implementing quality assurance measures for continuous improvement

Internship (2014): Worked with faculty to conduct a needs and learning analysis on how to gain internship credit as a College of Science student, developed objectives for content, wrote and created electronic content, and recorded and implemented videos for students to be included as part of the distance learning series on the Career Center's website

Study Abroad in Italy (2013): Interviewed Italian career counselors who were involved with employment training initiatives, helped facilitate cultural exchange discussions and wrote a paper comparing Italian and American training and instructional design approaches

\section{Teaching Experience}

UNIV 100: University Orientation, UNIV 200: Career Implementation, UNIV 400: Career Engagement, STEM 110: Technology and Your World, STEM 251: Microsoft Office,

\section{Membership and Awards}

Member, Association for Educational Communication and Technology, Fall 2011 to Present

John R. Broderick Diversity Champion Award, Spring 2015

Old Dominion University Administrator of the Year Award, Spring 2015

\section{Language and Travel}

Significant experience living and traveling abroad, fluent in Spanish

\section{Volunteer Work and Certifications}

Certified Career Development Facilitator, Spring 2013

Virginia Tidewater Consortium for Higher Education Certificate of College Teaching, Fall 2008 